\title{
The effects of endophytic fungi of NZ terrestrial orchids: developing methods for conservation
}

\author{
By
}

Jonathan Frericks

A thesis submitted to the Victoria University of Wellington in fulfilment of the requirement for the degree of Masters in Ecology and Biodiversity

Te Whare Wānanga o te Ūpoko o te Ika a Māui

November 2014 



\section{Abstract}

Nearly $40 \%$ of New Zealand (NZ) orchid species are of conservation concern, some critically endangered, largely due to habitat loss. In NZ, there are currently no propagation programs for terrestrial orchids all of which rely on symbiotic fungi to provide the nutrients required for germination, and little is known about the specific fungal species that might make this possible.

To develop an understanding of the fungal interactions affecting recruitment in the field, a survey of endophytic fungal diversity from the roots of Chiloglottis valida, Microtis unifolia, Pterostylis banksii, Spiranthes novae-zelandiae and Thelymitra longifolia was carried out. The identification of fungi was assisted by obtaining sequences of the ITS rDNA gene marker. Seeds of $M$. unifolia, P. banksii, S. novae-zelandiae and T. longifolia were inoculated with cultured endophytes that were recovered from the roots of conspecific orchids, and their effect on seed germination evaluated. Seed viability using fluorescein diacetate was assayed on all species prior to all experiments and showed moderate to high viability scores for all species. Recovered endophytes belonged to the phyla Ascomycota, Basidiomycota, and Zygomycota. The effect of the different endophytes on seed germination was variable, with five inoculants exhibiting a positive response. Three inoculants had a consistent negative effect on seed germination.

The distribution of orchid symbiotic mycorrhizae in situ was investigated at OtariWilton's Bush, Wellington, NZ. Mesh seed packets containing seed of M. unifolia and T. longifolia were interred for 150 days, along transects ( $\leq 1$ metre) that originated at adult orchids at three sites, and an additional site with no adult orchids was used as a control. No small-scale patterns were detected; however, germination rates were higher at undisturbed sites. Seed viability was considerably reduced to $<2 \%$ after five months under the soil suggesting M. unifolia and T. longifolia seeds do not persist in the seed bank beyond one growing season. Sequences of ITS rDNA indicate Tulasnella calospora assists in the germination of $M$. unifolia at this site.

Similarly, Tulasnella calospora promoted germination of the Nationally Vulnerable wetland species S. novae-zelandiae. Pelotons were isolated from the roots of $S$. novaezelandiae plants from a wild population from the lower north island and cultured in Petri dishes. Germination of this orchid began after 30 days from inoculation when the pelotons are already observed inside the embryo. Chlorophyllus tissue was observed after c. 80 days of inoculation. The phylogenetic relationship of Asian-Pacific Spiranthes species with New Zealand Spiranthes was also investigated using nuclear (ITS) and chloroplast (trnLtrnF) DNA sequences. Phylogenetic analyses supported the recognition of Spiranthes novae-zelandiae 'Motutangi' as a distinct taxonomic unit. It was also found that the AsianPacific Spiranthes species are in need of taxonomic revision.

Methods used and developed in this thesis study could be used to identify potential orchid symbionts and pathogens, assess suitable potential relocation sites, and propagation of NZ orchids using symbiotic fungi for restoration and conservation purposes. 


\section{Acknowledgements}

I would like to thank Carlos Lehnebach for his incredible support, time, and enthusiasm for this project. I have really appreciated your supervision and look forward to further collaborations. Thanks to Andrew Munkacsi for sharing his lab and his knowledge. I would also like to thank Peter Ritchie who was always helpful and supportive. Thank you to Aaron Hart for pushing me on, even when things were not going well.

Thank you to Kevin Matthews, Yangna Sun and Yibo Luo (Chinese Academy of Sciences), Kuga Yukari, Mike Lusk (New Zealand Native Orchid Group), and Jeremy Rolfe (Department of Conservation), without whom I would not have had so many samples.

I am thankful for the support of the Otari-Wilton's Bush Trust and Phil Parnell. Thanks to Finn Michalak and Rewi Elliot for allowing me to put my experiment in the middle of their garden beds.

Thanks to Joe Zuccarello for answering my random questions and Lawrence Zettler for answering the less-random ones. I would also like to thank Shirley Pledger whose skilful statistics took me on a magical journey.

I am extremely grateful to the Australian Orchid Foundation for enabling me to learn techniques first-hand from the kind people at Kings Park and Botanic Garden: Belinda Davis, Wei Han, and Kingsley Dixon.

Thank you to: the Museum of New Zealand Te Papa Tongarewa for the Te Papa MSc Scholarship in Plant Molecular Systematics; the Wellington Botanical Society for the Student Grant and the Arnold and Ruth Dench Botanical Award; and the San Diego Orchid Society for helping fund this project.

Thank you to the Royal Society of New Zealand Marsden Fund and the Victoria University Centre for Biodiscovery for enabling me to present my work, meet my orchid heroes, and gain global context for my work during the $5^{\text {th }}$ International Orchid Conservation Congress (IOCC) at La Réunion.

Finally, thank you to my family and friends for all you do in the other half of my life - now you get to see where l've been all this time! 


\section{Table of Contents}

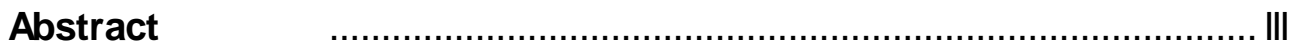

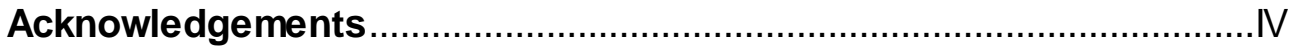

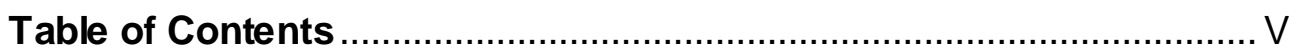

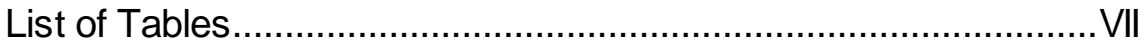

List of Figures ...................................................................

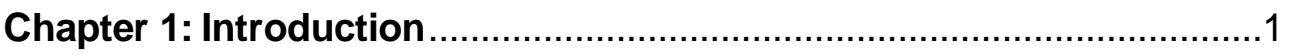

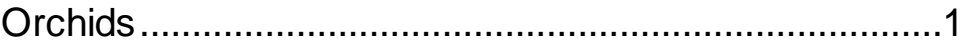

New Zealand orchids ..............................................

Fungal interaction..........................................................

Specificity ........................................................... 4

Orchid mycorrhizae..................................................... 5

Mycorrhizae isolation and seed germination ..................6

Conservation issues of terrestrial orchids.......................8

The aims of this thesis research....................................

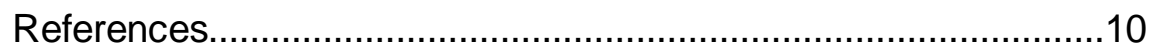

Chapter 2: Diversity of fungal endophytes in New Zealand orchids and their effect on seed germination....................................15

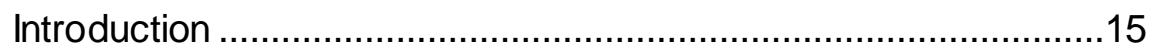

Methods ......................................................................... 18

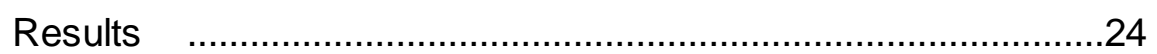

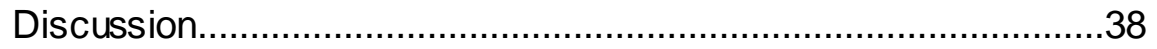

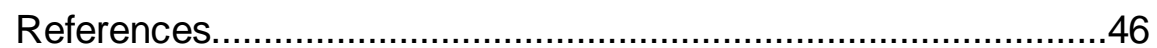

Chapter 3: In situ germination of two terrestrial orchids:

Microtis unifolia and Thelymitra longifolia, within an urban bush reserve in Wellington ........................................................52

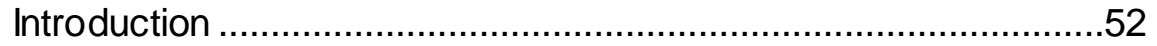

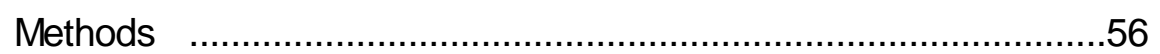

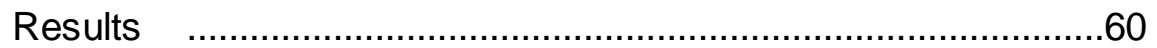

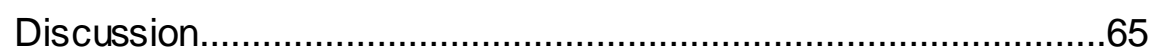

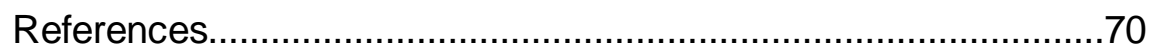

Chapter 4: Phylogenetic affinities and symbiotic germination of Spiranthes novae-zelandiae Hook.f., a

nationally vulnerable wetland orchid....................................................73

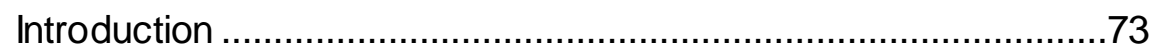

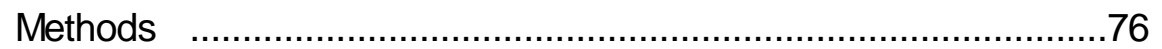

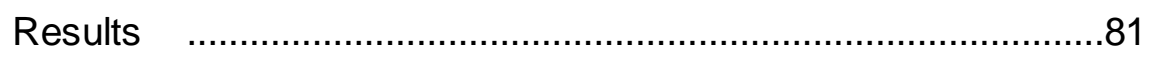

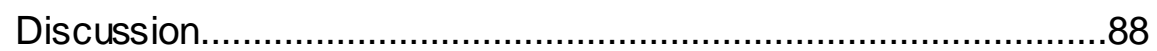

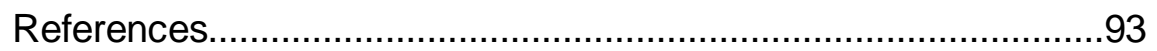


Table of Contents continued...

Chapter 5: General discussion and recommendations ........................98

Endophyte diversity ................................................ 98

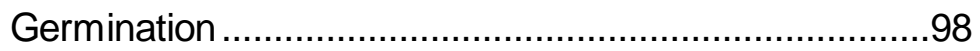

Seed baiting ............................................................ 100

Ex situ orchid ............................................................101

Conservation considerations.....................................101

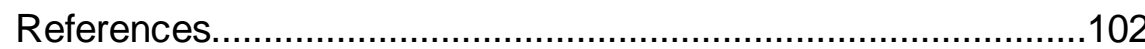




\section{List of Tables}

Table 1.1 Number of orchid species grouped by altitude zone and habitat in the Lower North Island (NZ) .................................

Table 1.2 Description of stages of ochid protocorm development .............7

Table 2.1 Primers used to Amplify ITS1-5.8-ITS2 nrDNA .........................20

Table 2.2 Results of TukeyHSD test and pairwise vector

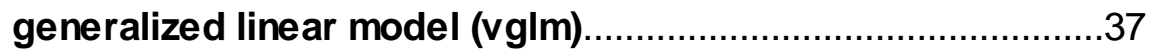

Table 3.1 Locations of In Situ Sites .........................................................58

Table 4.1 Primers used to amplify ITS1-5.8-ITS2 nrDNA and trnL-trnF cpDNA. .78

\section{List of Figures}

Figure 2.1 Location of the orchid population sites sampled for this study in the southern half of the North Island, NZ...........18

Figure 2.2 Roots of $\boldsymbol{M}$. unifolia to be dissected......................................19

Figure 2.3 Section of lateral root of $M$. unifolia. .......................................19

Figure 2.4 Culture plate of S. novae-zelandiae seed inoculated with 'Epacrid' (A24) inoculant ..............................................23

Figure 2.5 Development of $S$. novae-zelandiae seed inoculated with 'Epacrid' (A24) inoculant at day 54. .23

Figure 2.6 UPGMA tree of Basidiomycota isolates based on ITS1-

$5.8 \mathrm{~s}-$ ITS2 sequences and modelled by $\mathrm{p}$-distance .25

Figure 2.7 UPGMA tree of Ascomycota isolates based on ITS1-

5.8s-ITS2 sequences and modelled by $\mathrm{p}$-distance. .26

Figure 2.8 UPGMA tree of Zygomycota isolates based on ITS1-

$5.8 \mathrm{~s}$-ITS2 sequences and modelled by $\mathrm{p}$-distance.

Figure 2.9 Diversity of fungal endophytes (OTUs) recovered from each orchid species and sites.

Figure 2.10 Expected number of OTUs for each sampling unit (plant).

Figure 2.11 Seed viability assessment using FDA assay with seed of $T$. longifolia.

Figure 2.12 Seed Viability from FDA assay compared with

progression of negative controls

Figure 2.13 Cumulative proportions of seed in each stage of germination. .35

Figure 3.1 Microtis unifolia and Thelymitra longifolia .54 
Figure 3.2 Sample seed packet

Figure 3.3 Map of Study Sites in Otari-Wilton's Bush. .............................58

Figure 3.4 Orchid seed viability prior and post in situ experiment...........60

Figure 3.5 Total seeds of $M$. unifolia and $T$. longifolia at stage 2 or beyond that germinated at each site.

Figure 3.6 Germination of seed along all transects .62

Figure 3.7 Six seedlings of $M$. unifolia removed froma seed packet from Site B (control)

Figure 3.8 Maximum Likelihood tree of Tulasnella calospora using nuclear marker ITS1-5.8s-ITS2.

Figure 4.1 Collection sites of $S$. novae-zelandiae $(A, B)$ and $S$. novae-zelandiae 'Motutangi'.

Figure 4.2 Maximum likelihood cladogram of Al Spiranthes ITS

GenBank accessions

Figure 4.3 Maximum Likelihood tree of Spiranthes spp. using nuclear marker ITS1-5.8s-ITS2 .83

Figure 4.4 Maximum likelihood tree of Spiranthes spp. based on chloroplast marker trnL-trnF. .84

Figure 4.5 Maximum Likelihood tree of Spiranthes using

concatenated ITS and trnL-trnF markers. .85

Figure 4.6 Maximum Likelihood tree of $T$. calospora using nuclear marker ITS1-5.8s-ITS2 .86

Figure 4.7 Stages of development of S. novae-zelandiae. .87 


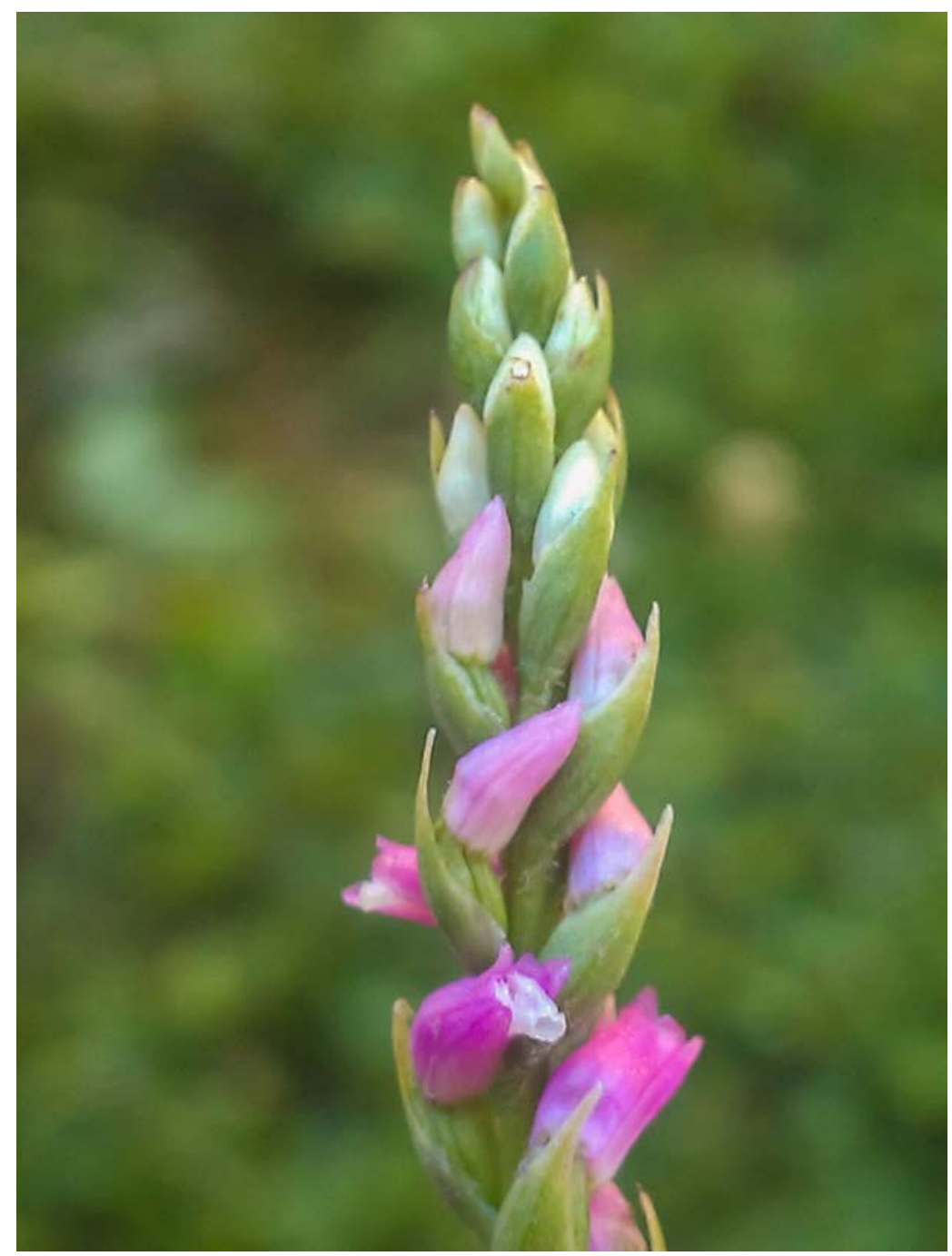

Spiranthes novae-zelandiae 


\section{Chapter 1: Introduction}

\section{Orchids}

Orchidaceae is a one of the most diverse families of plants, perhaps second only to Asteraceae. The Orchidaceae family is comprised of five subfamilies (Freudenstein et al., 2004) with 870 genera (Swarts \& Dixon, 2009b) and approximately 25,000 species (Wingham \& Willems, 2003). This level of diversity equates to approximately $6-11 \%$ of the known seed plant species (Pillon \& Chase, 2007). Orchids have a global distribution and they are cosmopolitan (Singh \& Duggal, 2009), found in almost every kind of land habitat (Weston, Perkins, \& Entwisle, 2005). Greatest species richness exists around the tropics of America and Asia, and follows global patterns of species richness in other flora (Swarts \& Dixon, 2009b). However, orchids also exist in extremely cold climates such as above the Arctic circle (Blinova, 2011) and on isolated islands in the sub-Antarctic region (Clements \& Jones, 2007). Approximately two thirds of all orchid species grow on trees (epiphytically) or on rocks (lithophytically), and the remainder grow terrestrially (Swarts \& Dixon, 2009b).

Global distribution studies of terrestrial orchids estimate that 400 species of terrestrial orchid occur in North Asia and over 300 in the Europe-North African-Near East region. There is a high level of endemism among Australia's 300, or more, species. New Zealand has more than 100 species (Wingham \& Willems, 2003) and about 84\% of them are endemic (Lehnebach, 2002).

Orchids are economically important and feature prominently in horticultural markets (Dearnaley, 2007), but also for natural medicines (Singh \& Duggal, 2009). The most economically and culturally significant orchid is Vanilla (Fouché \& Jouve, 1999). Historically, the medicinal use of orchid tubers dates back to at least $4^{\text {th }}$ Century BC Greece (Kumbaric, Savo, \& Caneva, 2013).

Orchid flowers are typically bilaterally symmetrical with three petals and 3 sepals. One of the petals is often modified and is called the labellum and is often the lowest petal (De Lange, Rolfe, St George, \& Sawyer, 2007). Their reproductive organ is called the column and it consists of a fused stamen and carpels (Bradshaw et al., 2010). Orchid flowers produce thousands of tiny seeds that develop within the ovary and are released from capsules and are wind dispersed (Cooper, 1989). 
The most striking feature about this family is the prevalence of a condition in which internal fungi are a source of nutrition (Cameron, Leake, \& Read, 2006). There is variability among orchids' dependence on these fungi, which are termed endophytes or endosymbionts depending on their contribution to host nutrition. For example, some orchid species lack chlorophyll and are considered fully myco-heterotrophic due to their reliance on endosymbiont fungi for all their energetic needs (Rasmussen, 1995). Most orchids, however, utilise fungi as part of their feeding strategy and are considered partially myco-heterotrophic.

\section{New Zealand orchids}

There are approximately 160 species of orchid in New Zealand (NZ) and there may be many more undescribed species (De Lange et al., 2007). Most NZ orchids are terrestrial and their above-ground parts senesce after flowering, emerging again from underground pseudobulbs the following season (Cooper, 1989). NZ Orchids occur in a variety of habitats at all altitudes: coastal, lowland, montane, subalpine, and alpine (Table 1.1).

Table 1.1. Number of orchid species grouped by altitude zone and habitat in the Lower North Island (NZ). Some species may occur in multiple locations. (De Lange et al., 2007)

\begin{tabular}{llllll} 
& $\begin{array}{l}\text { Coastal } \\
\text { - }\end{array}$ & Lowland & Montane & Subalpine & Alpine \\
& $10-300 \mathrm{~m}$ & $300-800 \mathrm{~m}$ & $800-1100 \mathrm{~m}$ & $>1100 \mathrm{~m}$ \\
\hline Open ground & 9 & 1 & 12 & 7 & - \\
Grassland & 9 & 1 & 17 & 11 & - \\
Wetland & 1 & 2 & 21 & 13 & - \\
Shrubland & 2 & 4 & 46 & 19 & - \\
Beech forest & - & 3 & 41 & 23 & - \\
Other indigenous forest & 2 & 4 & 44 & 21 & - \\
Plantation forest & 1 & 2 & 25 & 13 & - \\
\hline Other & - & - & - & - & 4 \\
\hline
\end{tabular}

In NZ, the Orchidaceae family contains 12 threatened species, seven of which are nationally critical, one is nationally endangered, and four are nationally vulnerable. There are also 32 species that are at risk (De Lange et al., 2012). The nationally critical, Calochilus herbaceous, is thought to be highly dependent on a mycorrhiza for germination (Forester \& Townsend, 2004). Spiranthes novae-zelandiae, a NZ endemic wetland orchid 
is nationally vulnerable, with population decline mainly due to habitat loss (De Lange et al., 2007; De Lange et al., 2012).

There is some controversy about whether several NZ species are identical to some Australian species (St George, Irwin, Hatch, \& Scanlen, 2001). This may have conservation implications for at least one orchid species, Sullivania minor, which is considered nationally critical in NZ but is abundant in Australia (De Lange et al., 2009). Australian populations might provide a good experiment group for development of species-appropriate conservations practises.

There are four orchid species that are thought to have a vagrant distribution in NZ having dispersed to NZ, probably from Australia. There are four other species are regarded as non-native colonisers, which have also dispersed to NZ but have established breeding populations. A single site containing Chiloglottis valida occurs in NZ, but further recruitment has not been seen due to the absence of the pollinator (De Lange et al., 2007). This species occurs in Australia (Dawson, Molloy, \& Beuzenberg, 2007), which may be the source of the NZ population. There are also 63 orchids have been listed as 'not threatened' in the most recent assessment of the conservation status of NZ plants (De Lange et al., 2012).

\section{Fungal interaction}

Symbiotic fungi are able to provide the major nutrients such as carbon and nitrogen to orchids (Cameron et al., 2006). Orchid mycorrhizae are also essential for seed germination (Brundrett, 2007) and early development because their tiny seeds lack the necessary energy reserves (Shan, Liew, Weatherhead, \& Hodgkiss, 2002). The symbiotic interaction enables the exchange nutrients between plants and fungi (Brundrett, 2007) resulting in a mutualistic association.

In mature plants endosymbiont fungi are often found in the cortical cells of the roots and protocorms and sometimes in stems (Brundrett, 2007). Simple hyphal penetration of the cell is the initial mode of infection, and chemotaxis has not been observed (Rasmussen, 1995). The infection of neighbouring cells occurs by a single hypha spreading from one cell into another (Zettler, Sharma, \& Rasmussen, 2003). Most orchids form an association with the fungal endophyte that is typified by intracellular coils of hyphae called pelotons, which lyse inside hyphal membranes and are separated from orchid cell cytoplasm by a membrane of orchid origin. Nutrient exchange occurs across these membranes. The peloton is eventually digested by the plant cell. (Zettler et al., 2003). 
During germination, all orchids are considered fully mycoheterotrophic (Barrett, Freudenstein, Taylor, \& Kõljalg, 2010). It is also during this time that the mycorrhizal during which orchid fungal association is more species-specific (Bidartondo \& Read, 2008), however, the mode of infection is the same as in adults. The mycorrhizal hyphae enters the seed though rhizoids or suspensor cells (Rasmussen \& Rasmussen, 2009). Orchid endosymbionts form pelotons in parenchyma cells, and this type of cell makes up a large portion of the protocorm (Peterson, Massicotte, \& Melville, 2004). Orchid growth begins only once the fungus is established and pelotons are digested (Arditti, 1992). In some cases fungal infections may overwhelm orchid root function and cause cell death. However, some orchid species have mechanisms to control this by producing toxins that limit the rigour of the infection (Zettler et al., 2003).

For a long time there was uncertainty about whether the relationship between the orchid and the fungi was mutualism because the mycorrhizal fungi are able to subsist saprophytically in the soil (Brundrett, 2007) independently of orchids (Arditti, 1992). Though no negative effect on the endosymbiont fungi had been demonstrated, there was a dearth of information about the transfer of any products to the fungi from the plant (Zettler et al., 2003). Recently it has been demonstrated that products of photosynthesis can pass from a green-leaved terrestrial orchid to the endophytic fungus (Cameron et al., 2006) and there is now support for an exploitative symbiosis with mutualistic phases (Brundrett, 2007).

\section{Specificity of symbiosis}

Specificity of the orchid for fungal partners varies across orchid genera and species. For instance most Northern Hemisphere and Australian orchids have highly specific fungal associations but some species are able to associate with a number of different fungi (Brundrett, 2007).

Two sister species of non-photosynthetic orchids, Corallorhiza maculata and Corallorhiza mertenina demonstrated varying degrees of specificity in California, USA (Taylor \& Bruns, 1999). In C. mertenina, three fungal species were found across seven populations and in C. maculata 20 fungal species were found in 21 populations. Individuals of $C$. maculata growing under oaks shared no endophyte species with those growing under conifers, and those above $2 \mathrm{~km}$ altitude shared no endophyte species with those living below that height. Taylor and Bruns (1999) found that associations in $C$. maculata were so specific that even colour-morphs living together shared no endophyte species (Fay \& Krauss, 2003). This example highlights both the orchid specificity for a fungi species, and the tolerance of a species to a range of endosymbiont species. What is 
evident is that there may be genetic and geographic influences determining the associations formed between orchids and symbiotic fungi (Fay \& Krauss, 2003).

In some orchids 'switching' occurs when a new endosymbiont is present and replaces the previous one (Otero, Thrall, Clements, Burdon, \& Miller, 2011). This may occur due to external factors, or at different life stages of the orchid (Dearnaley, 2007). This switching means that a mycorrhiza that is found in an adult plant may not be the same that facilitates germination (Phillips, Barrett, Dixon, \& Hopper, 2011).

\section{Orchid mycorrhizae}

Most symbiotic fungi of photosynthetic orchids belong to the polyphyletic Rhizoctonia (Basidiomycota) genus (Brundrett, 2007) or other Rhizoctonia-like genera (Arditti, 1992). An association with Rhizoctonia-like fungi is thought to be ancestral for all orchids and associations with other endophytes developing later (Arditti, 1992). Fully mycotrophic orchids too, are thought to have developed from the ancestral condition of myco-heterotrophy (Arditti, 1992). Currently little is understood about the ecology and phylogeny of the Rhizoctonia group (Brundrett, 2007) which also contains pathogens of commercial horticultural crops such as Rhizoctonia solani (Swarts \& Dixon, 2009b).

Historically, species have been included in the Rhizoctonia group merely because they are associated with the roots of living plants (García, Onco, \& Susan, 2006). Members of this group vary greatly and include anamorph (asexual) and teleomorph (sexual) states (Shan et al., 2002). Most orchid endosymbionts are found, and reproduce in the asexual anamorphic state (Taylor \& McCormick, 2008) but some have been known to enter teleomorphic sexual states (Zettler et al., 2003). Teleomorphs are easier to identify and have led to the assignment of some fungi to other new genera (Andersen \& Stalpers, 1994) which are synonymous with their anamorphic classification in Rhizoctonia (Brundrett, 2007). The following Basidiomycota genera are found to contain orchid mycorrhizae: Epulorhiza, Monoliopsis, Rhizoctonia, Tulasnella, Sebacina, Ceratobasidium and Thanatephorus (García et al., 2006; Rasmussen, 1995). A small number of Ascomycota, such as those of the order Pezizales, have been found to form associations with orchids too (Těšitelová, Těšitel, Jersáková, RÍhová, \& Selosse, 2012).

There are very few diagnostic features that assist with the identification of Rhizoctonia. The typical morphology is a filamentous assemblage of hyphae. They do not produce spores but have uniform multicellular sclerotia (García et al., 2006), that are able to remain dormant in the soil for extended periods. Species definitions in this genus have been characterised by colour and colony morphology when grown on specific media 
(Shan et al., 2002). There are approximately 119 epithets of Rhizoctonia at the species or subspecies level of nomenclature (Andersen \& Stalpers, 1994).

Until recently, the tendency for similar fungi to grow into each other was used to group members of the Rhizoctonia complex to understand their genetic diversity (García et al., 2006). More recent DNA analysis has shown that although this method demonstrated evolutionary similarity, there are better ways to elucidated the evolutionary relationships (Shan et al., 2002). The advent of modern molecular methods first saw the use of restriction fragment length polymorphism (RFLP) for identifying and defining species (Taylor \& McCormick, 2008), but this has now largely being superseded by DNA sequencing methods. A 'DNA barcoding' approach using a standardised gene sequence is often used to resolve the phylogeny and determine species boundaries, irrespective of their sexual morphology (Tedersoo et al., 2008).

\section{Mycorrhizae isolation and seed germination}

Many of the methods of isolation and culture of fungi from the roots of orchids involve the cleaning or sterilization (Zettler et al., 2003) of roots prior to dissection or removal of epidermis. Pelotons are manipulated and removed from orchid cells before being cleaned and rinsed in sterile $\mathrm{H}_{2} \mathrm{O}$. Pelotons are used as initiators of cultures and are placed on antibiotic growth media plates. If needed, growing tips are sub-cultured onto new media plates. The cultures remain viable when stored at ambient temperature if they are sub-cultured at 3-month intervals. Other methods have been developed that enable them to be stored at $6^{\circ} \mathrm{C}$ for up to a year.

To germinate seed symbiotically, surface-sterilised orchid seeds are placed on oatmeal agar medium and a small cube of agar infused with a compatible mycorrhizal inoculum is also placed on the medium. The plates are then incubated at in the dark and within 4-6 weeks protocorms should form (Batty, Brundrett, Dixon, \& Sivasithamparam, 2006). Often, a mycorrhiza is considered compatible once chlorophyllous tissue is produced (Ramsay \& Dixon, 2003). However, this may take longer, be sporadic or synchronous depending on the species. Protocorms develop through 5 stages before they are regarded as a seedling (Table 1.2). 
Table 1.2. Description of stages of ochid protocorm development. Descriptions adapted from McKendrick, Leake, Taylor, \& Read (2000) and Zettler, Stewart, Bowles, Jacobs, \& Jacobs (2001).

\begin{tabular}{|c|c|c|}
\hline Stage 0 & No swelling & $=0$ \\
\hline Stage 1 & $\begin{array}{l}\text { Characterised by the swelling of the embryo in } \\
\text { the testa (indicated by arrow). May be } \\
\text { accompanied by one or more rhizoids. } \\
\text { Production of } 1 \text { or more rhizoids. Some studies } \\
\text { regard this as the onset of germination (Tan et } \\
\text { al., 2014). }\end{array}$ & \\
\hline Stage 2 & $\begin{array}{l}\text { The embryo enlarges further, rupturing the testa } \\
\text { and further production of rhizoids (indicated by } \\
\text { arrows) occurs. }\end{array}$ & \\
\hline Stage 3 & $\begin{array}{l}\text { Formation and appearance of the proto- } \\
\text { meristem (Zettler et al., 2001) from which the } \\
\text { first leaf develops (indicated by arrow). This } \\
\text { stage is often regarded as the commencement } \\
\text { of symbiotic development. }\end{array}$ & \\
\hline Stage 4 & $\begin{array}{l}\text { Marked by the appearance of appearance of } \\
\text { first leaf (indicated by arrow). Chlorophyllous } \\
\text { tissues begin to develop. }\end{array}$ & \\
\hline Stage 5 & Elongation of leaf (indicated by arrow). & \\
\hline
\end{tabular}




\section{Conservation issues of terrestrial orchids}

Terrestrial orchids are more threatened globally than epiphytic orchids (Lehnebach, Robertson, \& Hedderley, 2005) possibly because they have a greater dependence on soil-borne mycorrhizae. This is evidenced by over half of orchid extinctions have been terrestrial species (Swarts \& Dixon, 2009b). There is a significant level of orchid diversity resulting from the complex ecological specialisation of orchids (Beltrán-nambo et al., 2012) but this means there is an intrinsic risk to some species because of their dependence on changeable ecological factors such as mycorrhizae (Swarts, Sinclair, Francis, \& Dixon, 2010) and species-specific pollinators (Brundrett, 2007).

Some terrestrial orchids reproduce clonally via a wide range of subterranean organ types. While these organs can be used for nutrient storage and growth, persisting rhizomes with bulb-like tubers, bulbils, underground runners, and asexual corms may be used for vegetative reproduction (Wingham \& Willems, 2003). These organs enable populations to persist in the absence of recruitment through sexual reproduction

Seeds of terrestrial species are more difficult germinate asymbiotically than epiphytic species, so it is important to understand their interaction with the fungal endosymbiont for conservation efforts (Zettler et al., 2003). Studies into orchid and mycorrhizal distribution patterns may also help to understand biogeographical limiting factors of orchid species (De Lange et al., 2007) and could provide essential information for orchid conservation programmes (Brundrett, 2007).

Over-collection and illegal export are problematic for endangered terrestrial orchids in North Asia, but loss of habitat and habitat degradation are major threats to orchid survival in North America, Australasia and Europe (Wingham \& Willems, 2003). Habitat loss is one of the main threats for terrestrial orchids in NZ, along with amateur collectors and herbivory (De Lange et al., 2007). Collectors have been implicated in the demise or reduction in at least two lower North Island orchid species (De Lange et al., 2007). Animals such as possums and birds feeding on endangered species may add further pressures to populations, though evidence for this is scant (De Lange et al., 2007). The causes of habitat loss are numerous and include processes such as competition, and human activity. Loss of habitat is largely due to farmland and urban sprawl, drained wetlands, and disturbance associated with roads (De Lange et al., 2007).

The goal of propagation programs, such as those at Kings Park and Botanic Garden in Perth, Australia, is work to mitigate threats and conserve critically endangered orchids by propagating them ex situ for release into the field (Swarts \& Dixon, 2009a). 
Research of orchid mycorrhizae in NZ has not progressed in parity with international research. The earliest published article with a focus on NZ orchid mycorrhizae was published 1962. Ella Campbell demonstrated the morphology and the mode of infection by the fungus Armillaria mellea (Basidiomycota) in a mycotrophic orchid Gastrodia cunninghamii (Campbell, 1962). Campbell also described a tripartite association between the achlorophyllous orchid Danhatchia australis parasitizing Lycoperdon perlatum (Basidiomycota) that lives in association with Beilschmiedia tarairi (Campbell, 1970). All of these studies have been based on morphological and histological observations and only recently have molecular studies on NZ orchid mycorrhizae been conducted. In 2012, Tulasnella calospora was recovered from the NZ spider orchid Nematoceras iridescens (Watkins, 2012).

\section{The aims of this thesis research}

The overall goal of this thesis research was to develop tools for the conservation of NZ native orchids by assessing the effect of endophytic fungi on the germination of NZ orchids and to identify mycorrhizal symbionts that facilitate germination. This study was set up in three main parts and each component has been written as a discrete study to be easily adapted for publication.

In chapter two, the fungal endophytes of a number of NZ orchids were isolated, cultured and identified using molecular methods. The effect each fungal isolate on seed germination in the same species it was isolated from, was assessed in vitro. In chapter three, a seed germination experiment was conducted in situ at a urban reserve (OtariWilton's Bush, Wellington). The aim of this chapter was to identify mycorrhizal fungi that promoted the germination of two orchid species that occur in the reserve. An investigation into the distribution of suitable germination sites proximate to established plants was also conducted by placing samples of orchid seed along transects originating from the established plants and scoring the germination after six months. Chapter four investigated the successful symbiotic germination of a nationally vulnerable orchid (Spiranthes novaezelandiae) with a Basidiomycete fungi (Tulasnella calospora) are presented. The phylogenetic affinities of the orchid and the fungi are investigated using DNA sequence data. In chapter five the research findings are discussed and summarised before recommendations are made for future propagation programs and further orchid mycorrhizal research. This research has increased our understanding of the endophyte communities that may limit distribution and recruitment in orchids, which is important knowledge to help improve restoration, relocation and population reinforcement programmes for the conservation of orchid populations in NZ. 


\section{References}

Aewsakul, N., Maneesorn, D., Serivichyaswat, P., Taluengjit, A., \& Nontachaiyapoom, S. (2013). Ex vitro symbiotic seed germination of Spathoglottis plicata Blume on common orchid cultivation substrates. Scientia Horticulturae, 160, 238-242. doi:10.1016/j.scienta.2013.05.034

Aggarwal, S., \& Zettler, L. W. (2010). Reintroduction of an endangered terrestrial orchid, Dactylorhiza hatagirea (D. Don) Soo, assisted by symbiotic seed germination: First report from the Indian subcontinent. Nature and Science, 8(10), 139-145.

Andersen, T. F., \& Stalpers, J. A. (1994). A checklist of Rhizoctonia epithets. Mycotaxon, 51, 437467. Retrieved from http://www.cbs.knaw.nl/Research/Stalpers/Stalpers1994-Mycotaxon 51,437-457.pdf

Arditti, J. (1992). Mycorrhiza. In Fundamentals of Orchid Biology (pp. 419-451).

Barrett, C. F., Freudenstein, J. V, Taylor, D. L., \& Kõljalg, U. (2010). Rangewide analysis of fungal associations in the fully mycoheterotrophic Corallorhiza striata complex (Orchidaceae) reveals extreme specificity on ectomycorrhizal Tomentella (Thelephoraceae) across North America. American Journal of Botany, 97(4), 628-43. doi:10.3732/ajb.0900230

Batty, A. L., Brundrett, M. C., Dixon, K. W., \& Sivasithamparam, K. (2006). New methods to improve symbiotic propagation of temperate terrestrial orchid seedlings from axenic culture to soil. Australian Journal of Botany, 54(4), 367-374. doi:10.1071/BT04023

Beltrán-nambo, M. D. L. Á., Larrocea, P. O., Garciglia, R. S., Ospina, T. O., Trujillo, M. M., \& Carreón-abud, Y. (2012). Distribution and abundance of terrestrial orchids of the genus Bletia in sites with different degrees of disturbance, in the Cupatitzio Natural Reserve, México. International Journal of Biodiversity and Conservation, 4(8), 316-325. doi:10.5897/IJBC11.225

Bidartondo, M. I., \& Read, D. J. (2008). Fungal specificity bottlenecks during orchid germination and development. Molecular Ecology, 17(16), 3707-16. doi:10.1111/j.1365294X.2008.03848.x

Blinova, I. V. (2011). Populations of orchids at the northern limit of their distribution (Murmansk Oblast): Effect of climate. Russian Journal of Ecology, 39(1), 26-33. doi:10.1134/S1067413608010050

Bradshaw, E., Rudall, P. J., Devey, D. S., Thomas, M. M., Glover, B. J., \& Bateman, R. M. (2010). Comparative labellum micromorphology of the sexually deceptive temperate orchid genus Ophrys: diverse epidermal cell types and multiple origins of structural colour. Botanical Journal of the Linnean Society, 162(3), 504-540. doi:10.1111/j.1095-8339.2010.01033.x

Brundrett, M. C. (2007). Scientific approaches to Australian temperate terrestrial orchid conservation. Australian Journal of Botany, 55(3), 293. doi:10.1071/BT06131 
Cameron, D. D., Leake, J. R., \& Read, D. J. (2006). Mutualistic mycorrhiza in orchids: evidence from plant-fungus carbon and nitrogen transfers in the green-leaved terrestrial orchid Goodyera repens. The New Phytologist, 171(2), 405-16. doi:10.1111/j.1469-8137.2006.01767.x

Campbell, E. O. (1962). The Mycorrhiza of Gastrodia cunninghamii Hook f. Transactions of the Royal Society of New Zealand, 1(24), 289-296.

Campbell, E. O. (1970). The fungal association of Yoania australis. Transactions of the Royal Society of New Zealand, 12(2), 5-12.

Clements, M. A., \& Jones, D. L. (2007). A new species of Nematoceras and characterisation of $N$. dienemum (Orchidaceae), both from subantarctic Macquarie Island. Telopea, 11(4), 405411. doi:ISSN0312-9764

Cooper, D. (1989). New Zealand native orchids. A field guide. (p. 103). Wellington: Wellington Orchid Society Inc.

Dawson, M. I., Molloy, B. P. J., \& Beuzenberg, E. J. (2007). Contributions to a chromosome atlas of the New Zealand flora-39. Orchidaceae. New Zealand Journal of Botany, 45(4), 611-684. doi:10.1080/00288250709509743

De Lange, P. J., Norton, D. A., Courtney, S. P., Heenan, P. B., Barkla, J. W., Cameron, E. K., ... Townsend, A. J. (2009). Threatened and uncommon plants of New Zealand (2008 revision). New Zealand Journal of Botany, 47(1), 61-96. doi:10.1080/00288250909509794

De Lange, P. J., Rolfe, J. R., Champion, P. D., Courtney, S. P., Heenan, P. B., Barkla, J. W., ... Hitchmough, R. A. (2012). Conservation status of New Zealand indigenous vascular plants, 2012 (p. 70). Wellington: Department of Conservation, Te Papa Atawhai. Retrieved from http://www.nzpen.org.nz/publications/NZTCS-Vascular Plants - 2013.pdf

De Lange, P. J., Rolfe, J. R., St George, I., \& Sawyer, J. (2007). Wild orchids of the lower North Island. Wellington: New Zealand Department of Conservation.

Dearnaley, J. D. W. (2007). Further advances in orchid mycorrhizal research. Mycorrhiza, 17(6), 475-86. doi:10.1007/s00572-007-0138-1

Fay, M. F., \& Krauss, S. L. (2003). Orchid conservation genetics in the molecular age. In K. W. Dixon, S. P. Kell, R. L. Barret, \& P. J. Cribb (Eds.), Orchid Conservation (pp. 91-112). Kota Kinabalu: Natural History Publications (Borneo).

Forester, L., \& Townsend, A. (2004). Threatened plants of Northland Conservancy Threatened plants of Northland Conservancy (p. 80). Wel: Department of Conservation, Te Papa Atawhai. Retrieved from http://www.doc.govt.nz/Documents/science-andtechnical/ThrplantsNorthland01.pdf

Fouché, J. G., \& Jouve, L. (1999). Vanilla planifolia: history, botany and culture in Reunion island. Agronomie, 19(8), 689-703. doi:10.1051/agro:19990804

Freudenstein, J. V., Van Den Berg, C., Goldman, D. H., Kores, P. J., Molvray, M., \& Chase, M. W. (2004). An Expanded Plastid DNA Phylogeny Of Orchidaceae And Analysis Of Jackknife 
Branch Support Strategy. American Journal of Botany, 91(1), 149-157. Retrieved from http://www.amjbot.org/content/91/1/149.short

García, V. G., Onco, M. A. P., \& Susan, V. R. (2006). Review. Biology and Systematics of the form genus Rhizoctonia. Spanish Journal of Agricultural Research, 4(1), 55-79. Retrieved from http://revistas.inia.es/index.php/sjar/article/download/178/175

Kumbaric, A., Savo, V., \& Caneva, G. (2013). Orchids in the Roman culture and iconography: Evidence for the first representations in antiquity. Journal of Cultural Heritage, 14(4), 311316. doi:10.1016/j.culher.2012.09.002

Lehnebach, C. A. (2002). Pollination ecology of New Zealand orchids. Massey University.

Lehnebach, C. A., Robertson, A. W., \& Hedderley, D. (2005). Pollination studies of four New Zealand terrestrial orchids and the implication for their conservation. New Zealand Journal of Botany, 43, 467-477.

McKendrick, S. L., Leake, J. R., Taylor, D. L., \& Read, D. J. (2000). Symbiotic germination and development of myco-heterotrophic plants in nature: ontogeny of Corallorhiza trifida and characterization of its mycorrhizal fungi. New Phytologist, 145, 523-537.

Otero, J. T., Thrall, P. H., Clements, M., Burdon, J. J., \& Miller, J. T. (2011). Codiversification of orchids (Pterostylidinae) and their associated mycorrhizal fungi. Australian Journal of Botany, 59(5), 480. doi:10.1071/BT11053

Peterson, R. L., Massicotte, H. B., \& Melville, L. H. (2004). Mycorrhizas: Anatomy and Cell Biology. Wallingford: $C A B$ International.

Phillips, R. D., Barrett, M. D., Dixon, K. W., \& Hopper, S. D. (2011). Do mycorrhizal symbioses cause rarity in orchids? Journal of Ecology, 99(3), 858-869. doi:10.1111/j.1365-2745.2011.01797.x

Pillon, Y., \& Chase, M. W. (2007). Taxonomic exaggeration and its effects on orchid conservation. Conservation Biology: The Journal of the Society for Conservation Biology, 21(1), 263-5. doi:10.1111/j.1523-1739.2006.00573.x

Ramsay, M. M., \& Dixon, K. W. (2003). Propagation Science, Recovery and Translocation of Terrestrial Orchids. In K. W. Dixon, S. P. Kell, R. L. Barret, \& P. J. Cribb (Eds.), Orchid Conservation (pp. 259-288). Kota Kinabalu: Natural History Publications (Borneo).

Rasmussen, H. N. (1995). Terrestrial orchids from seed to mycotrophic plant. Melbourne: Cambridge University Press.

Rasmussen, H. N., \& Rasmussen, F. N. (2009). Orchid mycorrhiza: implications of a mycophagous life style. Oikos, 118(3), 334-345. doi:10.1111/j.1600-0706.2008.17116.x

Shan, X. C., Liew, E. C. Y., Weatherhead, M. a, \& Hodgkiss, I. J. (2002). Characterization and taxonomic placement of Rhizoctonia-like endophytes from orchid roots. Mycologia, 94(2), 230-9. Retrieved from http://www.ncbi.nlm.nih.gov/pubmed/21156492

Singh, A., \& Duggal, S. (2009). Medicinal Orchids-An Overview. Ethnobotanical Leaflets, 13, 399412. Retrieved from http://opensiuc.lib.siu.edu/ebl/vol2009/iss3/3/ 
St George, I., Irwin, B., Hatch, D., \& Scanlen, E. (2001). Field guide to the New Zealand orchids (Second Ed.). Wellington: The New Zealand Native Orchid Group.

Swangmaneecharern, P., Serivichyaswat, P., \& Nontachaiyapoom, S. (2012). Promoting effect of orchid mycorrhizal fungi Epulorhiza isolates on seed germination of Dendrobium orchids. Scientia Horticulturae, 148, 55-58. doi:10.1016/j.scienta.2012.09.013

Swarts, N. D., \& Dixon, K. W. (2009a). Perspectives on orchid conservation in botanicgardens. Trends in Plant Science, 14(11), 590-8. doi:10.1016/j.tplants.2009.07.008

Swarts, N. D., \& Dixon, K. W. (2009b). Terrestrial orchid conservation in the age of extinction. Annals of Botany, 104(3), 543-56. doi:10.1093/aob/mcp025

Swarts, N. D., Sinclair, E. a, Francis, A., \& Dixon, K. W. (2010). Ecological specialization in mycorrhizal symbiosis leads to rarity in an endangered orchid. Molecular Ecology, 19(15), 3226-42. doi:10.1111/j.1365-294X.2010.04736.x

Tan, X. M., Wang, C. L., Chen, X. M., Zhou, Y. Q., Wang, Y. Q., Luo, A. X., ... Guo, S. X. (2014). In vitro seed germination and seedling growth of an endangered epiphytic orchid, Dendrobium officinale, endemic to China using mycorrhizal fungi (Tulasnella sp.). Scientia Horticulturae, 165, 62-68. doi:10.1016/j.scienta.2013.10.031

Taylor, D. L., \& Bruns, T. D. (1999). Population, habitat and genetic correlates of mycorrhizal specialization in the "cheating" orchids Corallorhiza maculata and C. mertensiana. Molecular Ecology, 8(10), 1719-32. Retrieved from http://www.ncbi.nlm.nih.gov/pubmed/10583834

Taylor, D. L., \& McCormick, M. K. (2008). Internal transcribed spacer primers and sequences for improved characterization of basidiomycetous orchid mycorrhizas. The New Phytologist, 177(4), 1020-33. doi:10.1111/j.1469-8137.2007.02320.x

Tedersoo, L., Jairus, T., Horton, B. M., Abarenkov, K., Suvi, T., Saar, I., \& Kõljalg, U. (2008). Strong host preference of ectomycorrhizal fungi in a Tasmanian wet sclerophyll forest as revealed by DNA barcoding and taxon-specific primers. The New Phytologist, 180(2), 479-90. doi:10.1111/j.1469-8137.2008.02561.x

Těšitelová, T., Těšitel, J., Jersáková, J., Ríhová, G., \& Selosse, M.-A. (2012). Symbiotic germination capability of four Epipactis species (Orchidaceae) is broader than expected from adult ecology. American Journal of Botany, 99(6), 1020-32. doi:10.3732/ajb.1100503

Watkins, R. L. S. (2012). The biogeography, ecology and endophyte mycorrhiza of the New Zealand Corybas alliance (Orchidaceae) : specifically, Nematoceras iridescens (Irwin et Molloy) Molloy, D.L.Jones \& M.A.Clem. (species). Massey University. Retrieved from http://hdl.handle.net/10179/4063

Weston, P. H., Perkins, A. J., \& Entwisle, T. J. (2005). More than symbioses: orchid ecology, with examples from the Sydney Region. Cunninghamia , 9(1), 1-15. Retrieved from https://www.rbgsyd.nsw.gov.au/_data/assets/pdf_file/0020/72524/Cun9Wes001.pdf

Wingham, D. F., \& Willems, J. H. (2003). Demographic studies and life-history strategies of temperate terrestrial orchids as a basis for conservation. In K. W. Dixon, S. P. Kell, R. L. 
Barret, \& P. J. Cribb (Eds.), Orchid Conservation (pp. 137-158). Kota Kinabalu: Natural History Publications (Borneo).

Zettler, L. W., Sharma, J., \& Rasmussen, F. N. (2003). Mycorrhizal diversity. In Orchid Conservation (pp. 205-226). Kota Kinabalu: Natural History Publications (Borneo).

Zettler, L. W., Stewart, S. L., Bowles, M. L., Jacobs, K. A., \& Jacobs, A. (2001). Mycorrhizal Fungi and Cold-Assisted Symbiotic Germination of the Federally Threatened Eastern Prairie Fringed Orchid, Platanthera Leucophaea (Nuttall) Lindley. American Midland Naturalist, 145(1), 168175. 


\section{Chapter 2: Diversity of fungal endophytes in New Zealand orchids and their effect on seed germination}

\section{Introduction}

Orchids are among the most diverse plant families (Swarts \& Dixon, 2009), however, many orchids around the world are threatened and are listed in the International Union for Conservation of Nature (IUCN) Red List. In New Zealand (NZ) approximately one third of terrestrial orchid flora are at risk (De Lange et al., 2012).

Propagation techniques for endangered orchids are being developed worldwide in order to conserve species of particular cultural importance (Aggarwal \& Zettler, 2010) or in cases of extreme threat. However, propagation of orchids from seed is complicated because many orchids rely on fungi to facilitate germination of their seeds (Arditti \& Ghani, 2000) and may benefit from this relationship beyond the early stages of development (Rasmussen, 1995). The tiny dust-like seeds of orchids do not contain large energy reserves and are reliant on external sources of energy via the fungal interaction (Eriksson \& Kainulainen, 2011). Further limiting conservation efforts, there is evidence that some orchids undergo 'host switching' by selecting different fungal partners during their lifetime (Taylor, 2004) so that a symbiotic fungi present an adult orchid may not be the fungi that facilitated germination. This orchid-fungus symbiosis has consistently been reported as a mutualistic association (Cameron, Leake, \& Read, 2006) with the exception of the fully myco-heterotrophic orchids parasitizing its fungal partner (Ogura-Tsujita, Gebauer, Hashimoto, Umata, \& Yukawa, 2009).

In adult orchids, the interaction is typically characterised by the formation of hyphal clumps, commonly known as pelotons, in the space between the cell wall and cell membrane (Dearnaley, Martos, \& Selosse, 2012). The location of the fungal colonisation is often in the cortical parenchyma of living roots (Látr, Čuříková, Baláž, \& Jurčák, 2008) or in the collar (Huynh, Thomson, McLean, \& Lawrie, 2009). To obtain nutrients from the fungi, hyphal cells are lysed and their contents are digested in a process actuated by the orchid host (Rasmussen, 2002). However, the mechanisms which allow hyphae to remain in cells undigested are unknown (Rasmussen, 2002). 
The identification of symbiotic fungi is an integral step to understanding the functional ecology and evolution patterns of the orchid-fungus symbiosis. The fungal phylum Basidiomycota contains most of commonly found endosymbionts. These belong to the following anamorphic (asexual) genera: Epulorhiza, Monoliopsis, Rhizoctonia, or the following teleomorph (sexual) genera: Tulasnella, Sebacina, Ceratobasidium and Thanatephorus (García, Onco, \& Susan, 2006; Rasmussen, 1995). A small number of Ascomycota, such as those of the order Pezizales, have been found to form associations with orchids too (Těšitelová, Těšitel, Jersáková, Ríhová, \& Selosse, 2012).

Identification of orchid fungi is a complicated task. Historically, higher fungi have been identified by microscopic observations, and dual naming of fungi has resulted from studies focusing on morphological differences in their teleomorph (sexual) or anamorph (asexual) states. For example, Rhizoctonia solani is the anamorph of the teleomorph Thanatephorus cucumeris (García et al., 2006). Some members of a fungal species may exhibit hyphal compatibility and are able to undergo hyphal fusion. This enables the grouping of fungal taxa into anastomosis groups, complicating classification further by forming groups within taxa that share diagnostic morphological features (Ogoshi, 1987). Since the advent of molecular biology and the use of DNA markers for species identification and phylogenetic reconstruction, many of the uncertainties of fungi nomenclature are being resolved (Guarro, Gené, \& Stchigel, 1999). Also, dual-naming of newly described fungi no longer occurs (Hawksworth, 2011) and this has simplified matters considerably.

Many studies aim to identify symbiotic orchid mycorrhizae by adopting methodologies that target specific fungal groups, particularly basidiomycetes (Gardes \& Bruns, 1993; Jacquemyn, Brys, Cammue, Honnay, \& Lievens, 2011) and Tulasnellaceae (Taylor \& McCormick, 2008). Many of these studies have assessed fungal-orchid specificity (Hollick, 2004) and its role in orchid distribution patterns (Phillips, Barrett, Dixon, \& Hopper, 2011) or searched for an effective inoculant for orchid propagation (Sathiyadash, Muthukumar, Murugan, Sathishkumar, \& Pandey, 2014) (also see Chapter 4). The latter is particularly important for temperate terrestrial orchid species for which a germination protocol using high-nutrient asymbiotic media has not been successful. Additionally, symbiotically germinated orchids exhibit higher growth vigour and survivorship when being reintroduced to the field (Dixon \& Ramsay, 2003).

The identification of endophytes in NZ orchids has been limited. Dame Ella Campbell was very active in fully-mycotrophic orchid research the middle of the $20^{\text {th }}$ century. She described the histology of the association between the achlorophyllous 
orchid Gastrodia cunninghamii and its endophyte Armillaria mellea (Campbell, 1962). Some of her work included describing tripartite interactions between orchids and fungi, and associated angiosperms. For example, the orchid Danhatchia australis is parasitic on the fungus Lycoperdon perlatum, which grows in association with Beilschmiedia tarairi (Campbell, 1970).

The only prior molecular work in NZ orchid endophytes was undertaken by Watkins (2012). A number of Tulasnella calospora strains isolated from Nematoceras iridescens were reported here but their efficacy in germinating seeds of this species was not demonstrated. Other fungi isolated from $N$. iridescens included species from Ascomycota genera such as Trichoderma, Penicillium, Leptodontidium, Neonectria, and Cryptosporiopsis; Basidiomycota genus Rhodotorula; and the Zygomycota genus Mucor (Watkins, 2012).

Five species of terrestrial orchids were selected for this study based on their distribution patterns, taxonomic diversity, and habitat preferences. Microtis unifolia has a broad ecological range throughout NZ, occurring in forests, wetlands, and grasslands, and is common in cultivated areas. This is sharply contrasted with Spiranthes novae-zelandiae which is a nationally threatened, range-restricted, endemic wetland species. Thelymitra longifolia and Pterostylis banksii are moderately widespread, occurring in forests and shrublands, and represent the two most taxonomically diverse genera of orchids in NZ. Chiloglottis valida is considered as a 'vagrant' species in NZ (De Lange et al., 2012), present at a single NZ site, and is believed to have dispersed from Australia in recent years.

This study aimed to isolate, culture, and identify the fungal diversity inhabiting the roots of the aforementioned NZ orchids and compared the diversity of endophytes among sites, species, habitats, and distributions. Further, this study investigated the functional component of this biodiversity by investigating the effect of the fungal endophyte cultures on in vitro seed development. 


\section{Methods}

\section{Study species and collection of plant material}

Plant material, including roots, of C. valida was collected in December 2012 from a single site in pine forest $28 \mathrm{~km}$ from Taupō, NZ. Plant, root, and seed material of $M$. unifolia from one site, of $P$. banksii from two sites and of $T$. longifolia from three sites was collected in January 2013 from the hills above Eastbourne, Wellington, NZ. Multiple sites of $T$. longifolia and $P$. banksii were sampled to investigate intra-specific variation of endophyte diversity. This would also reveal the intra-specific variation in the response to endophyte inoculants during germination and protocorm development. Plant, root, and seed material of S. novae-zelandiae was collected from a single site in January 2013 located in Tararua Forest Park, Wellington, NZ.

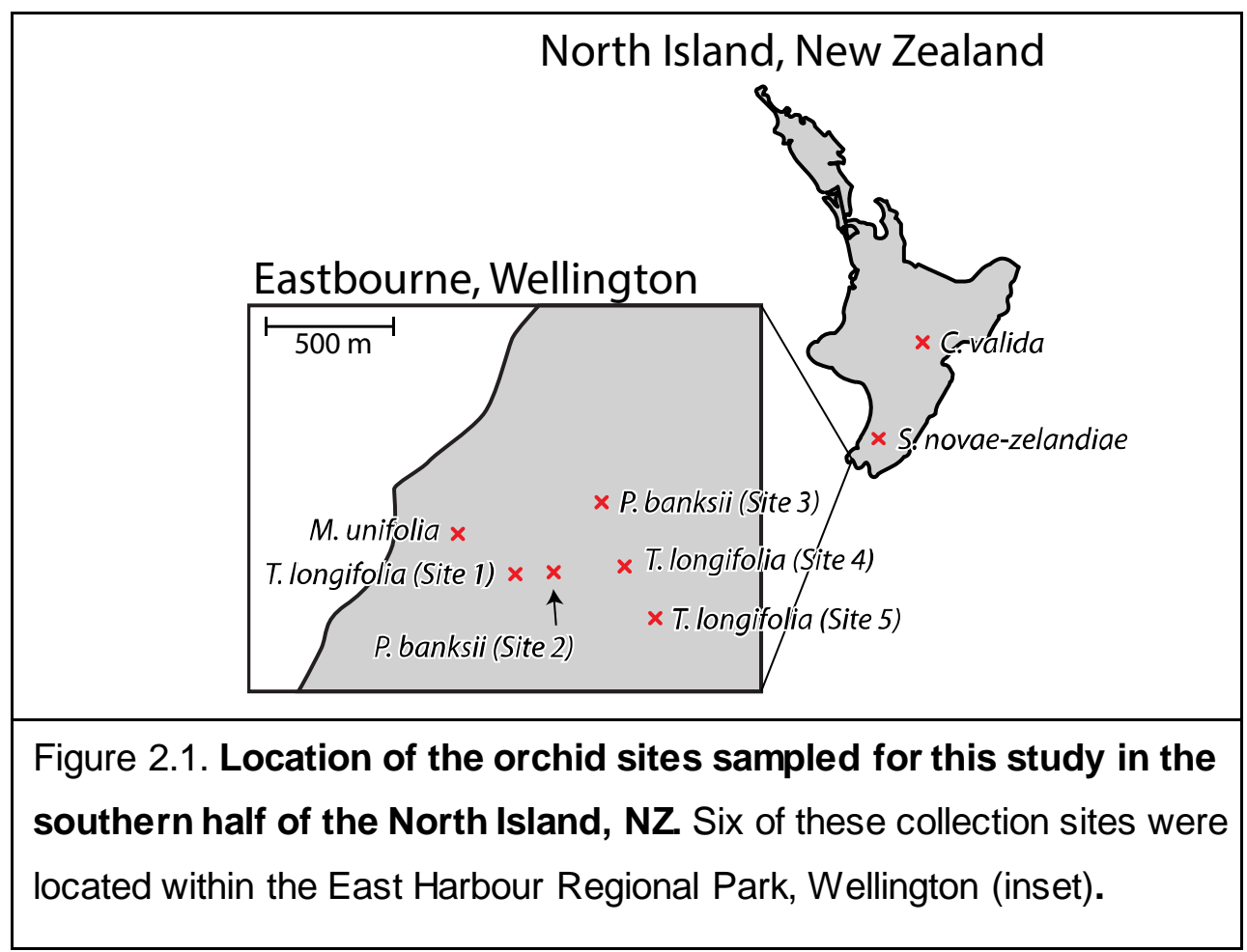

\section{Fungal isolation}

A fungal isolation media (FIM) was prepared, modified from Clements and Ellyard (1979), as a low nutrient, antibacterial media so that initial fungal colonies developed more slowly (reducing the rate of rapid-growing fungi inundating other colonies) and bacterial contamination was minimised. First, $0.143 \mathrm{~g}$ of streptomycin sulphate was combined with $10 \mathrm{ml}$ of sterile double distilled water $\left(\mathrm{ddH}_{2} \mathrm{O}\right)$ and shaken until dissolved. This solution was filter-sterilised in a $2 \mu \mathrm{m}$ sterilising filter and put to one side. A volume of $990 \mathrm{ml}$ of 
$\mathrm{dd}_{2} \mathrm{O}$ was placed on a stirring platform to which the following reagents were added: $0.3 \mathrm{~g}$ of sodium nitrate, $0.2 \mathrm{~g}$ of potassium dihydrogen orthophosphate, $0.1 \mathrm{~g}$ magnesium sulphate, $0.1 \mathrm{~g}$ potassium chloride, $0.1 \mathrm{~g}$ yeast extract and $2.5 \mathrm{~g}$ of sucrose. The solution was then brought to $\mathrm{pH} 6.8$ before adding $8 \mathrm{~g}$ of agar. The solution was then autoclaved for 20 minutes at $120^{\circ} \mathrm{C}$ and returned to the stirring platform to cool to approximately $60^{\circ} \mathrm{C}$ before adding the streptomycin sulphate solution. The media was then poured into $60 \mathrm{~mm}$ Petri dishes under a laminar flow and allowed to cool and set. Plates were stored in the dark at $4{ }^{\circ} \mathrm{C}$ and used within 5 days.

Fresh orchid material from the root collar and lateral root was serially washed in $\mathrm{ddH}_{2} \mathrm{O}$. Epidermis cells were scraped and removed. Pelotons were manually removed from cortical cells and serially washed in sterile $\mathrm{dd}_{2} \mathrm{O}$ before placing on to Petri dishes containing FIM. Six $10 \mu \mathrm{l}$ aliquots of pelotons suspended in $\mathrm{dd}_{2} \mathrm{O}$ were placed around the circumference of three FIM plates per plant. Growing tips of resulting fungal colonies were sub-cultured onto FIM plates to obtain pure strains.

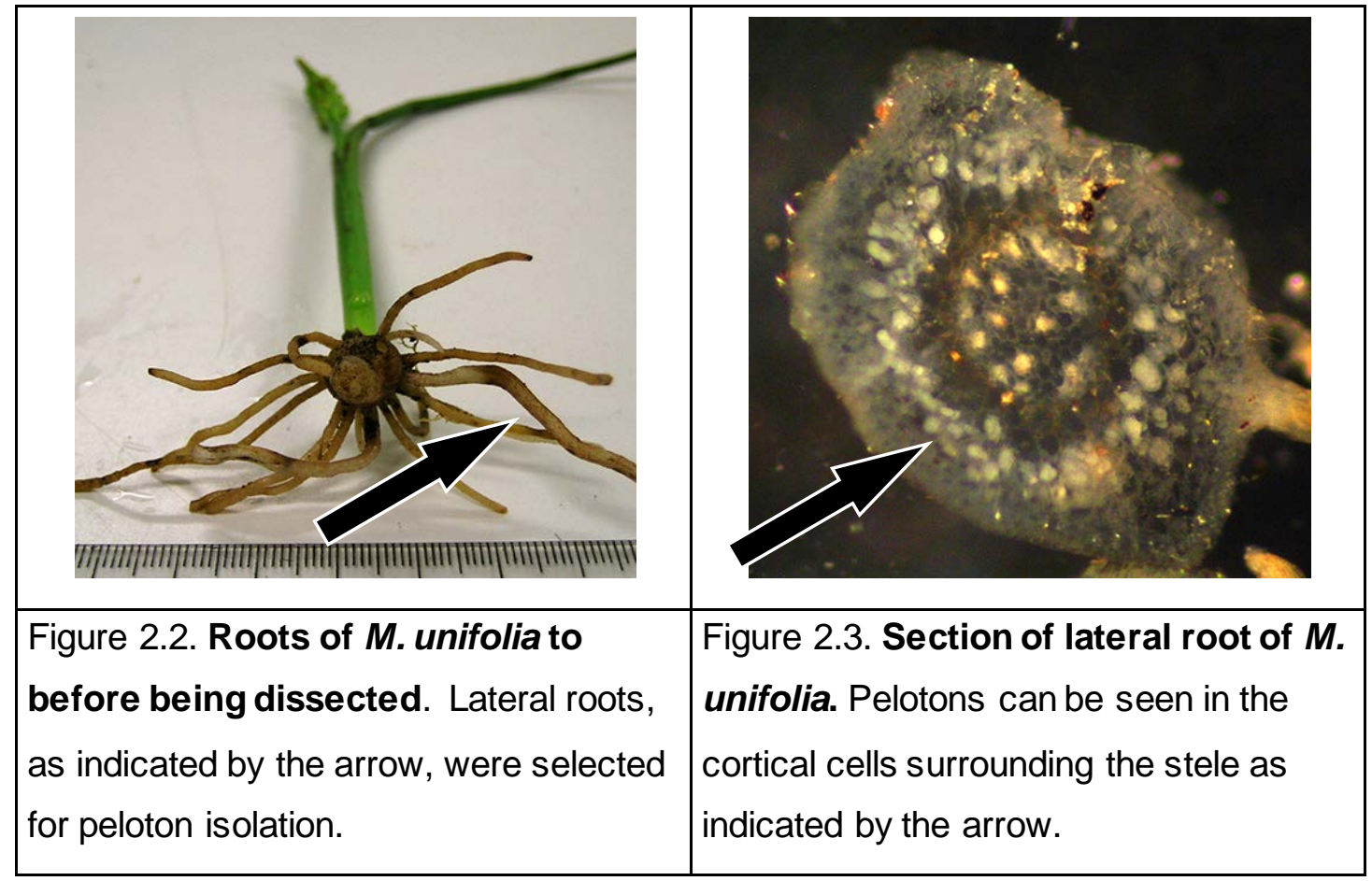

Nutrient-rich media, potato dextrose agar (PDA), was used to grow thick hyphal mats for DNA extraction and as inoculants for orchid seed germination experiments. A volume of $1 \mathrm{~L}$ was placed on a stirring platform and $24 \mathrm{~g}$ of PDA powder was dissolved into it. The solution was brought to $\mathrm{pH} 6.8$ before adding $8 \mathrm{~g}$ of Agar. The solution was then autoclaved at $120^{\circ} \mathrm{C}$ for 20 minutes, and poured upon cooling into $60 \mathrm{~mm}$ Petri dishes under a laminar flow. 


\section{DNA extraction}

Genomic DNA was extracted from fungi using the protocol described by (Beach, Piper, \& Nurse, 1982) with some modifications. Each fungal isolate culture was scraped from the PDA plates with a sterile blade to obtain between $0.1 \mathrm{~g}$ and $0.5 \mathrm{~g}$ of hyphal material that was placed into $1.7 \mathrm{ml}$ microcentrifuge tubes with $300 \mu \mathrm{l}$ of $0.5 \mathrm{~mm}$ glass beads. A $300 \mu \mathrm{l}$ aliquot of $5 \%$ SDS was added to each tube and the mixture was macerated with a sterile pestle. A $300 \mu$ aliquot of 25:24:1 phenol-chloroform-isoamyl alcohol was added to each tube and vortexed for 6 minutes. The tubes were centrifuged at 14,000 rpm for 5 minutes before the upper, aqueous phase of each was transferred into new $1.7 \mathrm{ml}$ microcentrifuge tubes containing $1 \mathrm{ml}$ of $90 \%$ Ethanol. Tubes were inverted gently five times and centrifuged at 14,000 rpm for 5 minutes. The supernatant was poured off from each tube and the pellets were allowed to dry before being resuspended in $40 \mu \mathrm{l} \mathrm{TE} \mathrm{pH8.} \mathrm{The} \mathrm{concentration} \mathrm{and} \mathrm{size} \mathrm{of} \mathrm{the} \mathrm{extracted} \mathrm{DNA} \mathrm{was} \mathrm{estimated} \mathrm{by}$ electrophoresis running each sample on a $1 \%$ agarose gel and followed by staining with ethidium bromide.

\section{Amplification and sequencing}

For molecular identification, the internal transcribed spacer (ITS) region was selected for its ability to identify fungi to the species level (Nilsson, Kristiansson, Ryberg, Hallenberg, \& Larsson, 2008). Three primer pairs were used to assess the diversity of fungi (ITS1F-ITS4, ITS1OF-ITS4OF, ITS1a-ITS4-Tul; Table 2.).

Table 2.1. Primers used to Amplify ITS1-5.8-ITS2 nrDNA.

\begin{tabular}{llll}
\hline Primer & Direction & Sequence $\left(5^{\prime}-3^{\prime}\right)$ & Source \\
\hline ITS1a & $F$ & CCTTGTACACACCGCCCGT & (Sharpe, Harbach, \& Butlin, 2000) \\
ITS1F & $F$ & CTTGGTCATTAGAGGAAGTAA & (Gardes \& Bruns, 1993) \\
ITS10F1 & $F$ & AACTCGGCCATTAGAGGAAGT & (Taylor \& McCormick, 2008) \\
ITS10F2 & $F$ & AACTTGGTCATTAGAGGAAGT & (Taylor \& McCormick, 2008) \\
ITS4 & $R$ & TCCTCCGCTTATTGATATGC & (White, Bruns, Lee, \& Taylor, 1990) \\
ITS4OF & $R$ & GTTACTAGGGGATCCTTGTT & (Taylor \& McCormick, 2008) \\
ITS4-Tul & $R$ & CCGCCAGATTCACACATTGA & (Taylor \& McCormick, 2008) \\
\hline
\end{tabular}

Each $20 \mu \mathrm{l} \mathrm{PCR}$ contained $1 \mathrm{M}$ betaine, $75 \mathrm{mM}$ Tris- $\mathrm{HCl}(\mathrm{pH} 8.8), 20 \mathrm{mM}$ ammonium sulphate, $2.5 \mathrm{mM} \mathrm{MgCl}$, $0.5 \mu \mathrm{M}$ forward primer, $0.5 \mu \mathrm{M}$ reverse primer, 0.25 $\mathrm{mM}$ of each deoxynucleotide (dATP, dCTP, dGTP and dTTP), $1 \cup(0.2 \mu l)$ Thermo Fisher Scientific Red Hot Taq DNA polymerase, 0.01\% (v/v) Tween 20, and $1 \mu$ of template 
DNA. In cases where PCR yields were low, $2 \mathrm{mg} / \mathrm{mlBSA}$ was added to preferentially bind to inhibiting factors (Farell \& Alexandre, 2012).

The reaction mix was thermally cycled with an initial denaturing stage of $95^{\circ} \mathrm{C}$ for 2 minutes followed by 35 cycles of $95^{\circ} \mathrm{C}$ for 1 minute, $55^{\circ} \mathrm{C}$ for 1 min and $72{ }^{\circ} \mathrm{C}$ for 1 minute 30 seconds, culminating with an additional extension stage of $72{ }^{\circ} \mathrm{C}$ for 5 minutes. To clean up PCR products for DNA sequencing, Exonuclease I and Shrimp Alkaline Phosphatase were used to digest single stranded oligonucleotides and remove phosphate groups from excess dNTPs, respectively.

Sequencing reactions of $2.5 \mu \mathrm{M}$ forward or reverse primer and approximately 200 ng of DNA were made up to a final volume of $10 \mu \mathrm{l}$ with $\mathrm{ddH}_{2} \mathrm{O}$ and run on the Applied Biosystems 3730xI DNA Analyzer by Macrogen Inc. (Seoul, South Korea). Sequences were edited with Geneious 4.8 and BLAST database queries of GENBANK (Benson, Karsch-Mizrachi, Lipman, Ostell, \& Wheeler, 2005) were conducted to identify the closest matching sequence/organism for each culture.

\section{Determining operational taxonomic units (OTUs)}

Taxonomic units were determined using an 'unweighted pair group method with arithmetic mean' (UPGMA) (Sneath \& Sokal, 1973) phylogram with 1000 bootstrap replicates (Felsenstein, 1985) generated in MEGA6 (Tamura, Stecher, Peterson, Filipski, \& Kumar, 2013) using p-distances (Nei \& Kumar, 2000). The UPGMA method was selected as the most basic analysis which does not account for variation in the function and biology of the sequences. Entities forming polytomies with a strongly supported (> $62 \%$ ) recent common ancestor (RCA) or clades with little or no divergence were designated as different OTUs. In some cases weaker clades were designated as OTU's because sister clades satisfied the above OTU determinants. Rarefaction curves with 95\% confidence intervals were generated in Estimates (Colwell et al., 2012) and plotted to demonstrate sampling saturation.

\section{$\underline{\text { In vitro orchid seed germination }}$}

Seeds of M. unifolia, P. banksii, S. novae-zelandiae and T. longifolia (from three sites) were removed from plants collected for endophyte isolation and stored in dark and dry conditions at room temperature for 3-6 months. The $C$. valida was not included in the germination experiment due to lack of seed. Seed was prepared for inoculation and viability assay by soaking in $\mathrm{dd}_{2} \mathrm{O}$ for 20 hours. Seeds were then sterilised in a $2 \%$ calcium hypochlorite solution with $2 \mathrm{ml}$ of tween80 on a stirring platform for 10 minutes and then washed 3 times in sterile $\mathrm{dd}_{2} \mathrm{O}$. Seed viability for each species was scored from random samples of seeds after being soaked in a solution of $0.5 \%$ fluorescein 
diacetate (FDA) in acetone for 10 minutes and then photographed under fluorescence microscope using a FITC filter. Seed viability scores were calculated for each site and species except for $S$. novae-zelandiae due to limited seed availability.

Germination was assayed in oatmeal agar (OMA) media prepared with $2.5 \mathrm{~g}$ finely cut oats in $1 \mathrm{~L} \mathrm{ddH_{2 }} \mathrm{O}$. The solution was brought to $\mathrm{pH} 5.5$ and $8 \mathrm{~g}$ of agar was added. The media was autoclaved for 20 minutes at $120^{\circ} \mathrm{C}$, before placing it on a stirring platform to combine. The solution was poured into $60 \mathrm{~mm}$ Petri dishes and allowed to set in the laminar flow. Sterile seeds were spread on the OMA plates and set aside for four days to ensure no contamination was present.

At the onset of the germination experiment, 36 OTUs had been cultured and identified from all of the orchid species included in the study. One culture from each OTU was selected and used as inoculant (Figure 2.6, Figure 2.7 and Figure 2.8; Inoculants are indicated by black spot). To determine the effect of each of these OTUs on seed germination, 3-5 $\mathrm{mm}^{2}$ cubes of the fungal culture, was placed on OMA-seed plates. Seeds of each orchid species were inoculated with a strain of fungi isolated from the adult of that same orchid species. In the case of the widespread M. unifolia, seed plates were inoculated with all the OTUs isolated from all other orchid plants. Additionally, because most known orchid mycorrhizae belong to the phylum Basidiomycota, the cultures that were identified as such were used to inoculate seeds of all species of orchids. Each combination of seed and inoculant was replicated three times. Negative controls consisting of seed placed on OMA with no inoculants were replicated three times for each seed source. In total there were 369 plates including negative controls: 111 plates of $M$. unifolia; 60 plates for each of the three collection sites of $T$. longifolia; 48 plates for $P$. banksii; and 30 plates for S. novae-zelandiae. Inoculated plates were sealed with plastic paraffin film and placed in a dark incubator set to $17^{\circ} \mathrm{C}$. Progress was monitored weekly, and seeds that proceeded into stage 4 of germination were moved to an incubator at $20^{\circ} \mathrm{C}$ and a diurnal cycle of 12 hours light and 12 hours dark. After 150 days plates were removed and scored by counting the number of seeds at each stage, at three random locations on each plate. Descriptions of seed germination stages follow those of Stewart \& Zettler (2002). 


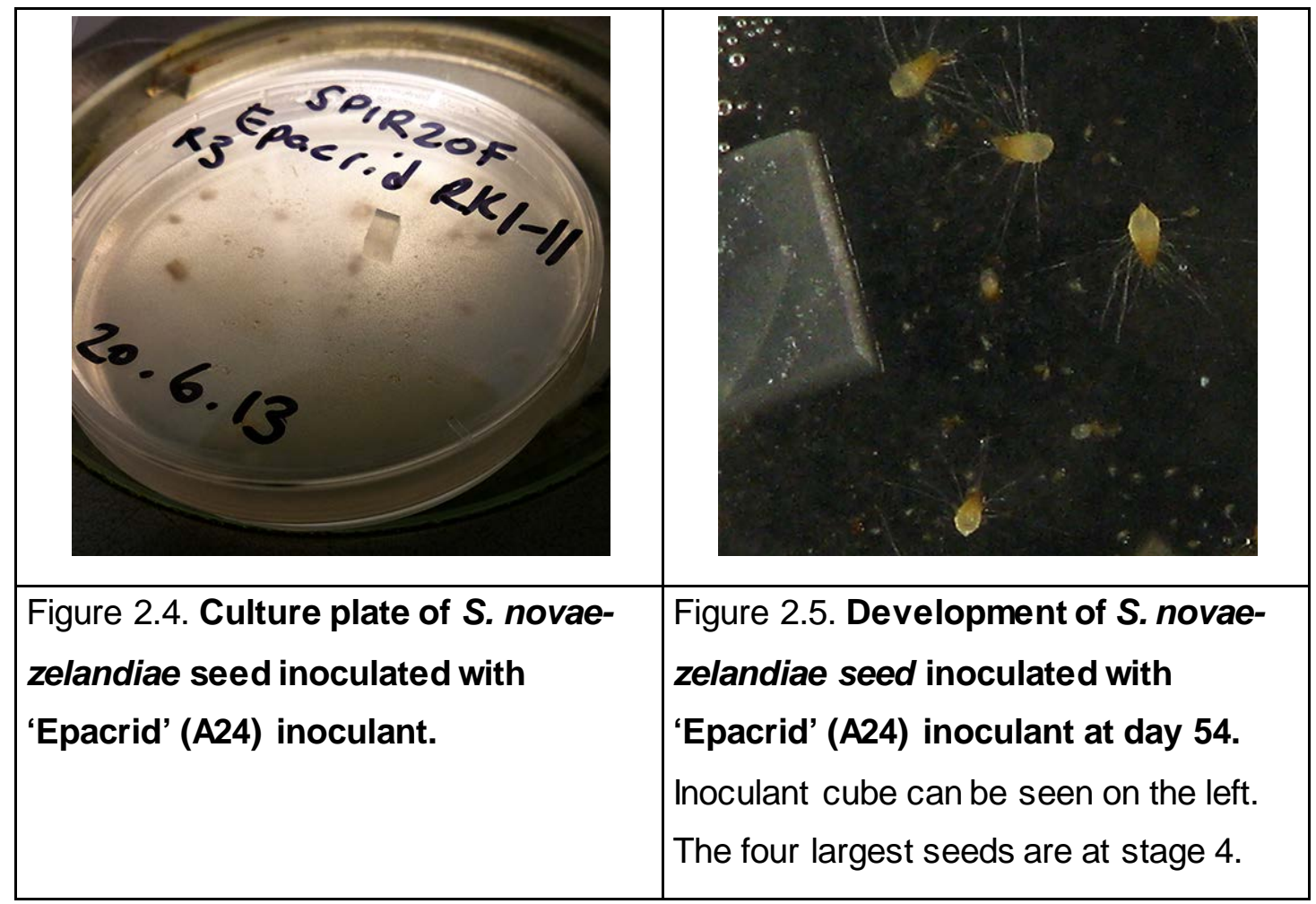

\section{Statistical analyses}

To assess the relative strength the effect of the inoculant and whether the effect they had on germination was significant, raw counts were used in a pairwise vector generalized linear model (vglm) using VGAM libraries in R (Yee, 2010) after a sequential Holm-Bonferroni correction (Holm, 1979). Proportional data was transformed into cumulative proportions by summing the proportions that had achieved each stage with the proportions that had achieved higher stages. This was done because seed that had progressed further, had inherently achieved stages that it had passed through. For example, to understand the proportion of seed that achieved stage 2, the proportions that had achieved stage 3 and stage 4 must be added because they had also achieved this stage prior to progressing. Cumulative proportions were plotted in R. The cumulative proportions were arc-sine transformed in $\mathrm{R}$ to normalise them before conducting an analysis of variance (ANOVA) (Pandey, Sharma, Taylor, \& Yadon, 2013). A post-hoc Tukey honestly significant difference (TukeyHSD) test was done in R (De Long, Swarts, Dixon, \& Egerton-Warburton, 2013) to discover at which stage inoculated seed plates differed from the negative controls with $5 \%$ significance $(p>0.05)$. 


\section{Results}

\section{Three major fungal groups represented in orchid endophytes}

A total of 46 OTUs were recovered from 123 fungal cultures obtained from 21 plants. The ITS sequences obtained were compared to GenBank accessions and used to identify the isolates to the genus or species level using the closest matches with a similarity of $97 \%$ or greater. Cultured organisms belonged to one of three phyla: Ascomycota, Basidiomycota, and Zygomycota. The UPGMA trees for each group suggested the presence of 4 basidiomycete OTUs (11\% of total OTUs, Figure 2.6), 25 ascomycete OTUs (47\% of total OTUs, Figure 2.7 ) and 17 zygomycete OTUs (42\% of total OTUs, Figure 2.8).

The final alignment of Basidiomycota isolates contained 16 sequences that were 637 base pairs long. The sum of the branch lengths on the UPGMA tree was 0.49077638 (Figure 2.6). Two Basidiomycota were identified as Rhizoctonia and two as Tulasnella calospora (99\% Identity). The two Rhizoctonia sequences matched Rhizoctonia solani $\leq 93 \%$. The two weakly supported $T$. calospora clades (B03, B04, Figure 2.6) were considered as different OTUs and their effect on germination was assessed separately.

The alignment of Ascomycota isolates contained 47 sequences that were 688 base pairs long. The sum of the branch lengths on the UPGMA tree was 1.56894520 (Figure 2.7). Most of the 25 ascomycete OTUs were strongly supported (Figure 2.7). There is strong support (100\%) for the relatively diverse Trichoderma (teleomorph Hypocrea) clade (A01-A08, Figure 2.7), which were recovered from all species and sites except $M$. unifolia and T. longifolia (Site 1). Three clades with $100 \%$ bootstrap support contained sequences from $\geq 3$ cultures. These genera were llyonectria (A15, A16), Pochonia (A03, A18, A19)and Articulostpora (A23). Six sequences were sole representatives of divergent genera, such as Clonostachys (A09), Lecanicillium (A11), Metarhizium (A17), Diaprorthe (A21), Penicillium (A22), and Beauveria (A25). Sequences from two genera were grouped in separate clades suggesting genera that are not monopyletic. The genera Paeceilomyces and Verticillium seem to be paraphyletic as sequences were group in different clades with high bootstrap support (i.e. A13, A14 and A10, A12 in Figure 2.3, respectively) Only one sequence could not be identified to the genus level with GenBank (A24, Figure 2.7). It closely matched sequences on GeneBank that had not been formally identified to genus or species level and was only designated as "Epacrid". The 'Epacrid' clade is sister to sequences identified as Articulospora (A23). 


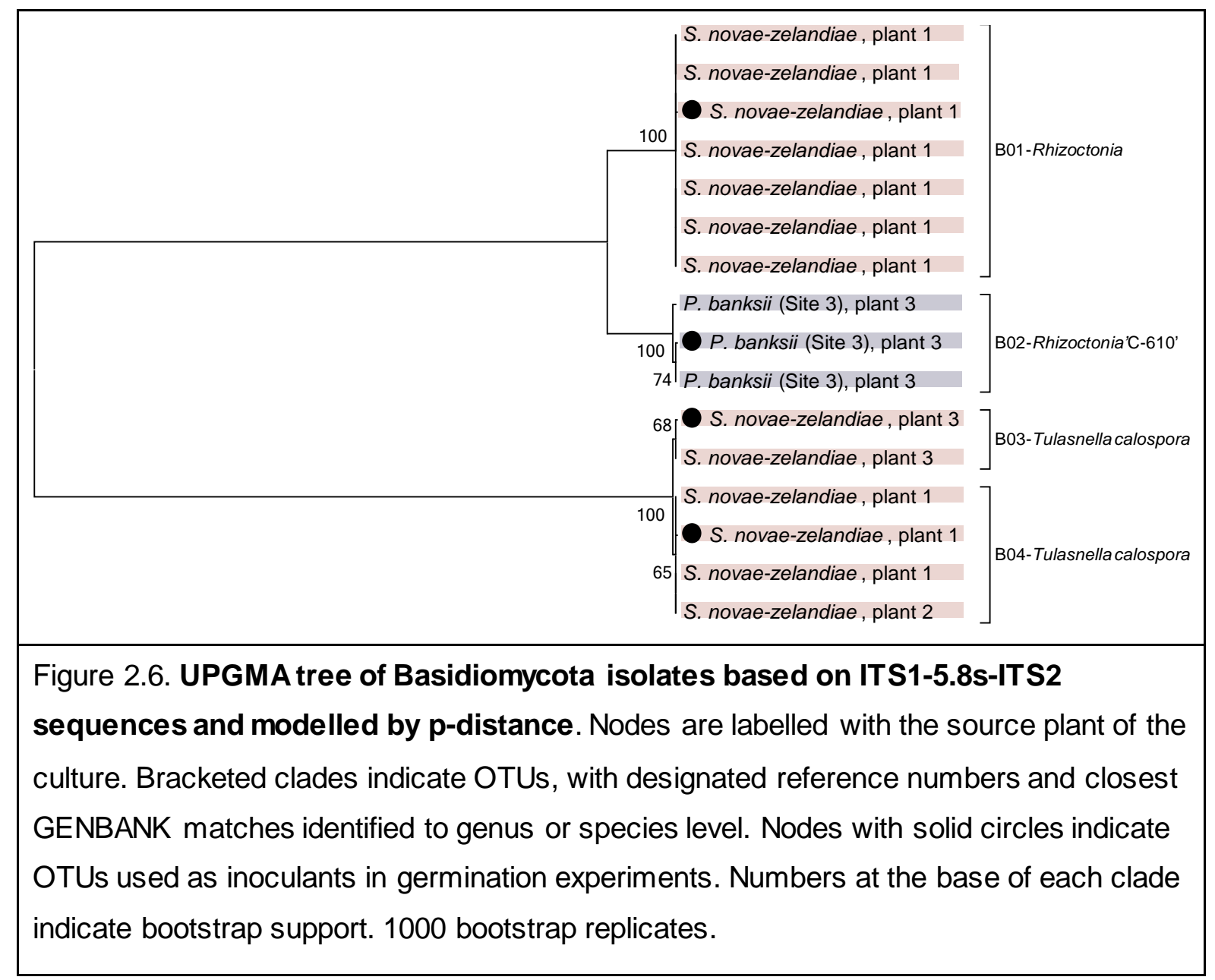

The alignment of Zygomycota isolates contained 60 sequences and 677 positions. The sum of the branch lengths on the UPGMA tree was 1.16401549 (Figure 2.8). The phylum Zygomycota had a relatively high number of OTUs and most of the Zygomycota OTUs were strongly supported (Figure 2.8). An overwhelming majority of the sequences (97\%) belonging to the genus Mortierella. Only two Zygomycota sequences were not from the genus Mortierella and were matched to Mucor (Z16) and Umbelopsis (Z17) respectively. Within the Mortierella clade there were two deeply divergent clades. The first contained OTUs Z01-Z05 (100\% bootstrap support), and the second Z06-Z15 (93\% bootstrap support). 


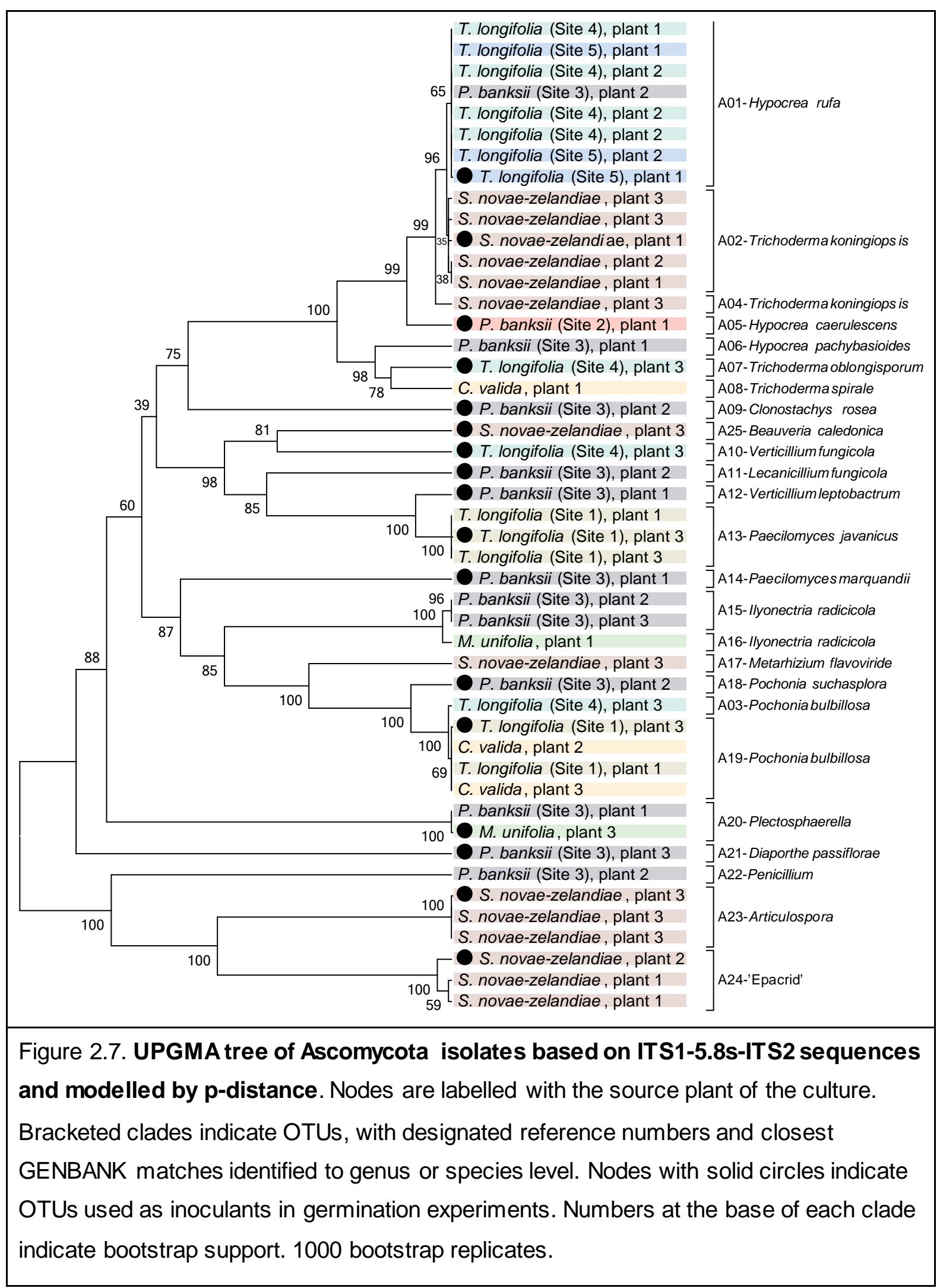




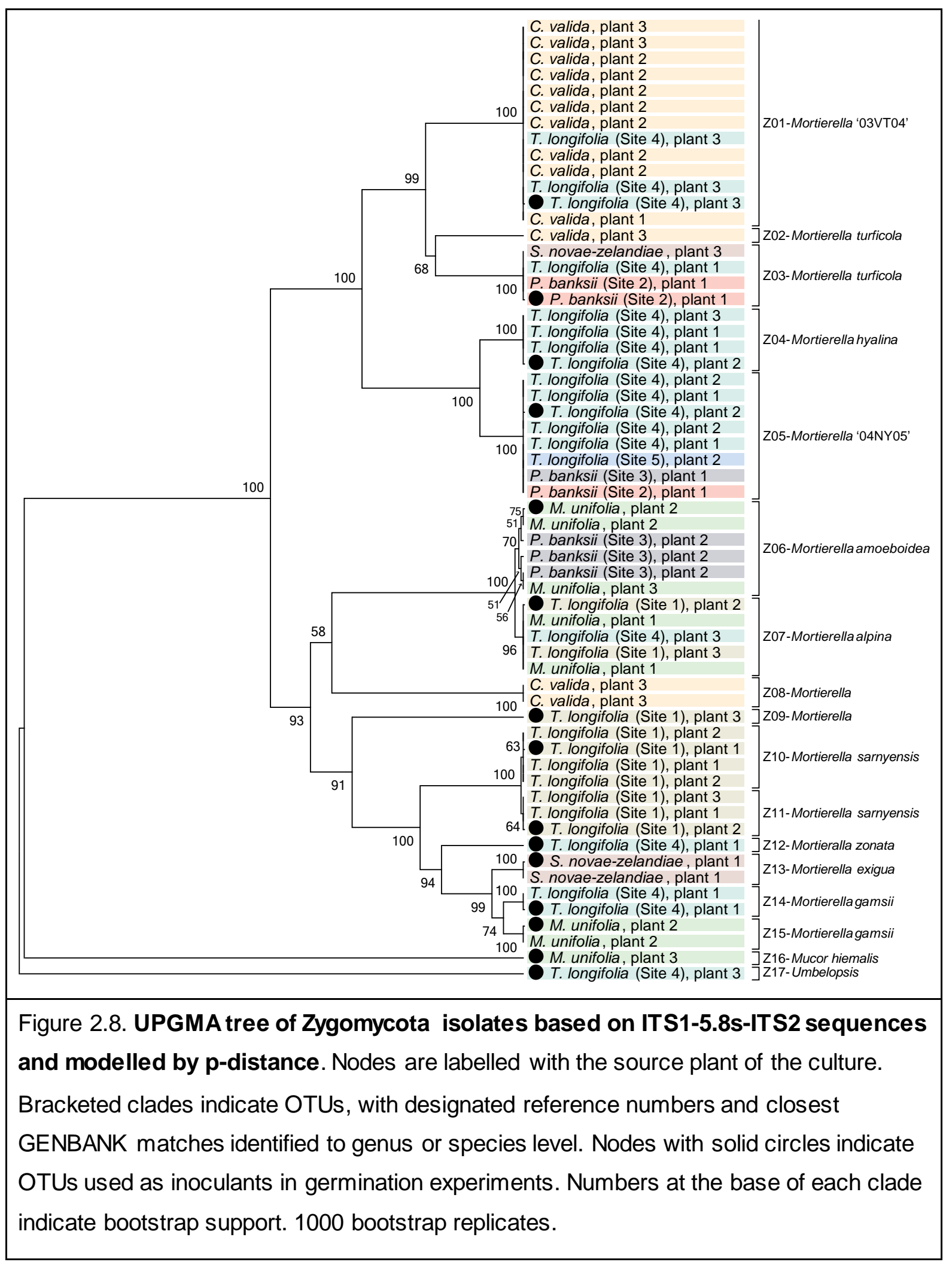




\section{Fungal diversity in orchids is variable between species and between sites}

Every orchid species sampled at each site contained at least one Ascomycota and one Zygomycota, however, Basidiomycota were only recovered from P. banksii (Site 3) and $S$. novae-zelandiae. The number of OTUs recovered from each site ranged from two - in T. longifolia, to 14 - in P. banksii (Site 3).

The following is a description of the fungal endophyte diversity found at each site. Five OTUs were recovered from C. valida: two Ascomycota (Trichoderma and Pochonia) and three Zygomycota (Mortierella). The endophyte diversity within M. unifolia was moderately diverse, with six OTUs recovered: two Ascomycota (Ilyonectria and Plectosphaerella) and four Zygomycota (Mortierella and Mucor). Both sites of $P$. banksii had a different OTU diversity. Three OTUs were recovered from $P$. banksii from Site 2: one Ascomycota (Hypocrea) and two Zygomycota (Mortierella). Meanwhile, 13 OTUs were found in P. banksii from Site 3: one Basidiomycota (Rhizoctonia), 11 Ascomycota (Hypocrea, Clonostachys, Lecanicillium, Verticillium, Penicillium, Paecilomyces, Ilyonectra, Pochonia, Plectosphaerella, and Diaporthe), and two Zygomycota (Mortierella). The endophyte community within $S$. novae-zelandiae was highly diverse with 11 OTUs recovered: three Basidiomycota (Rhizoctonia and Tulasnella), six Ascomycota (Trichoderma, Metarhizium, Beauveria, Articulospora, and 'Epacrid') and two Zygomycota (Mortierella). The lowest and the highest diversity was recovered from within the three sites of T. longifolia. From Site 1, six OTUs were recovered: two Ascomycota (Paecilomyces and Pochonia) and four Zygomycota (Mortierella). The endophyte community at Site 4 was highly diverse, with 12 OTUs recovered: four Ascomycota (Hypocrea, Trichoderma, Verticillium, and Pochonia) and eight Zygomycota (Mortierella and Umbelopsis). The endophyte community from Site 5 had the lowest diversity with only two OTUs recovered: one Ascomycota (Hypocrea) and one Zygomycota (Mortierella). 


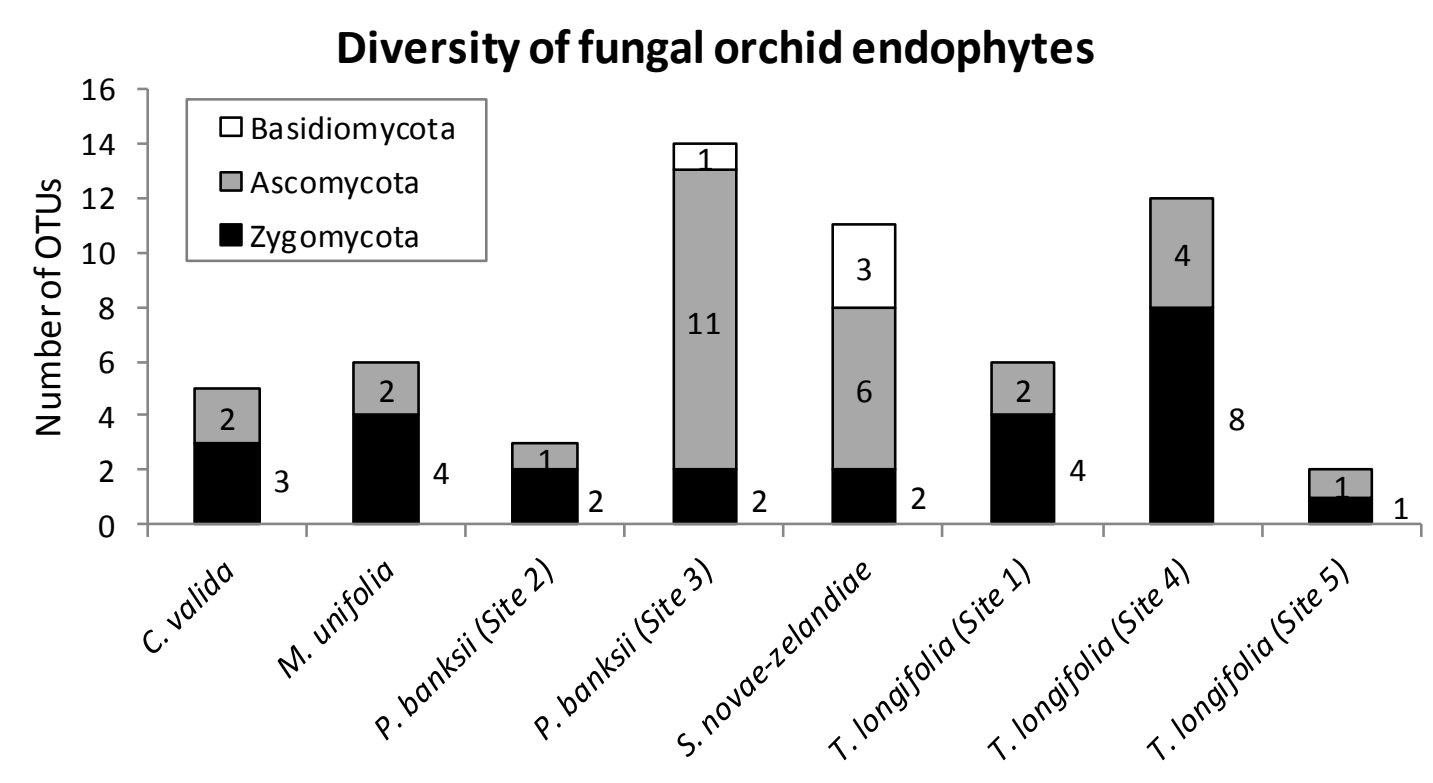

Figure 2.9. Diversity of fungal endophytes (OTUs) recovered from each orchid species and sites. Numbers indicate the number of OTUs recovered from each orchid species belonging to the corresponding phylum. Each stack represents the diversity recovered from three plants.

\section{Sampling saturation predicts more OTUs for most sites}

Sampling saturation methodology adapted from ecological studies (Gotelli \& Colwell, 2001) show that, at most sites, further sampling is necessary in order to ensure that all possible OTUs are recovered from the roots of the orchids, using the same methods. This methodology includes abundance and species richness to make predictions about the number of OTUs (Gotelli \& Colwell, 2001). In the case of S. novaezelandiae, a total of five plants should be sampled, and based on current data there are approximately 14 OTUs predicted in this species (Figure 6). The saturation curve for $T$. longifolia (Site 5) appears to asymptote at four samples so that there are a total of two OTUs predicted. The prediction for $C$. valida is that sampling four other plants will demonstrate the predicted diversity of five OTUs (Figure 6). For T. longifolia (Site 1) the entire diversity of endophytes appears to be captured at three plants, with a total of approximately six OTUs predicted (Figure 6). The asymptote for $T$. longifolia (Site 4) appears to require more than five plants to be sampled and will reveal approximately 15 OTUs (Figure 6). For M. unifolia, much greater than five plants are required to discover the predicted diversity of fungal OTUs (Figure 6). The curves for $P$. banksii (Site 2 ) and $P$. banksii (Site 3) appear linear, so the method cannot predict how many samples are required to capture the diversity in these orchids, or the number is very large (Figure 6). 


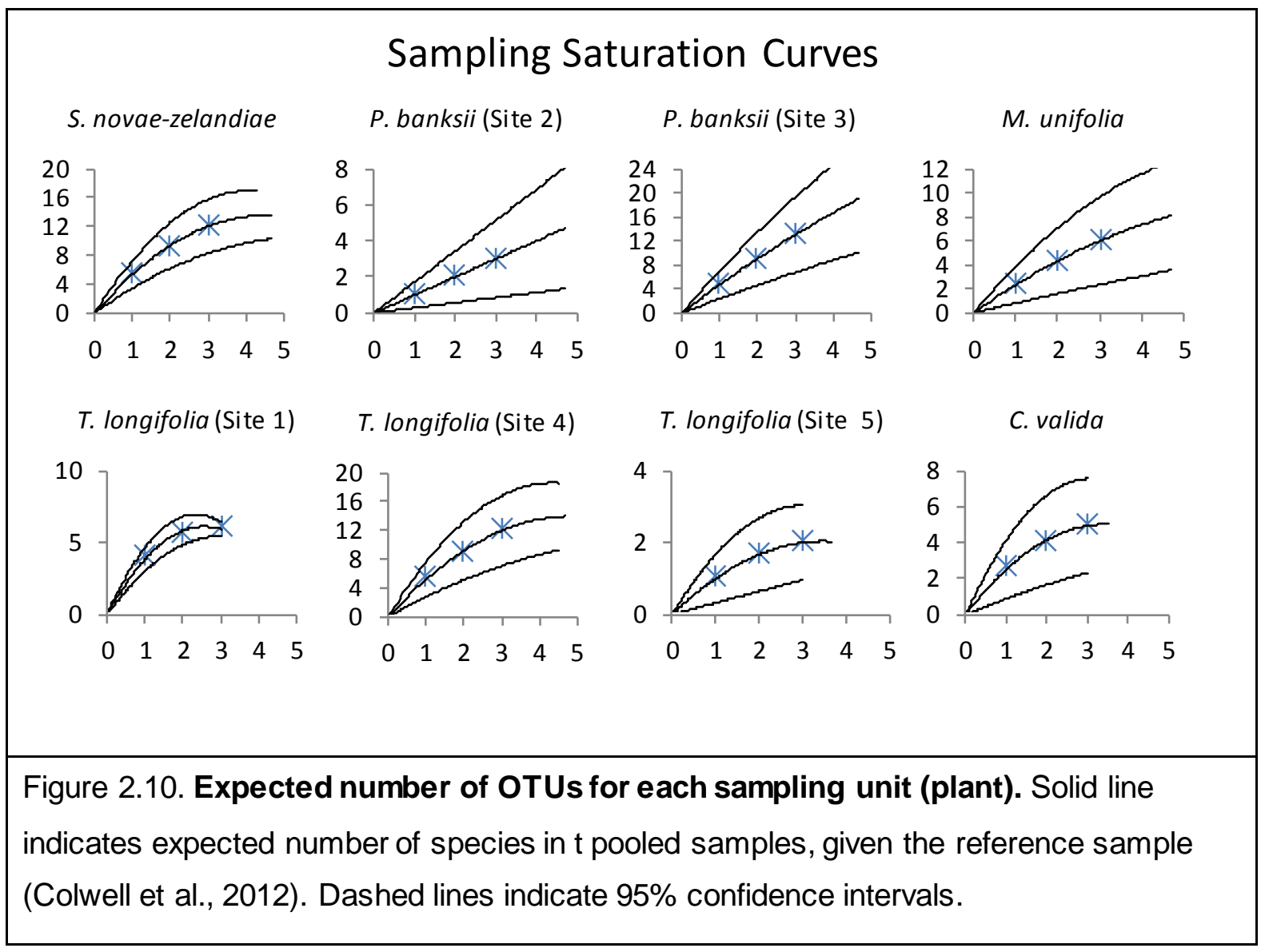

\section{Seed viability}

FDA was used to assess the viability of the orchid seeds to be used for the inoculation experiment (Figure 2.11). Seed viability in M. unifolia was 67\%. The seed viability of $P$. banksii ranged from $67 \%$ (Site 2) to $91 \%$ (Site 3), showing a $24 \%$ difference in viability between sites. The viability of $T$. Iongifolia seeds was $64 \%$ (Site 1), $90 \%$ (Site 5 ) and $94 \%$ (Site 4), revealing a 29\% variation in viability between sites with the lowest and highest viability scores. Viability of $S$. novae-zelandiae seeds was not carried out due to limited seed availability. 


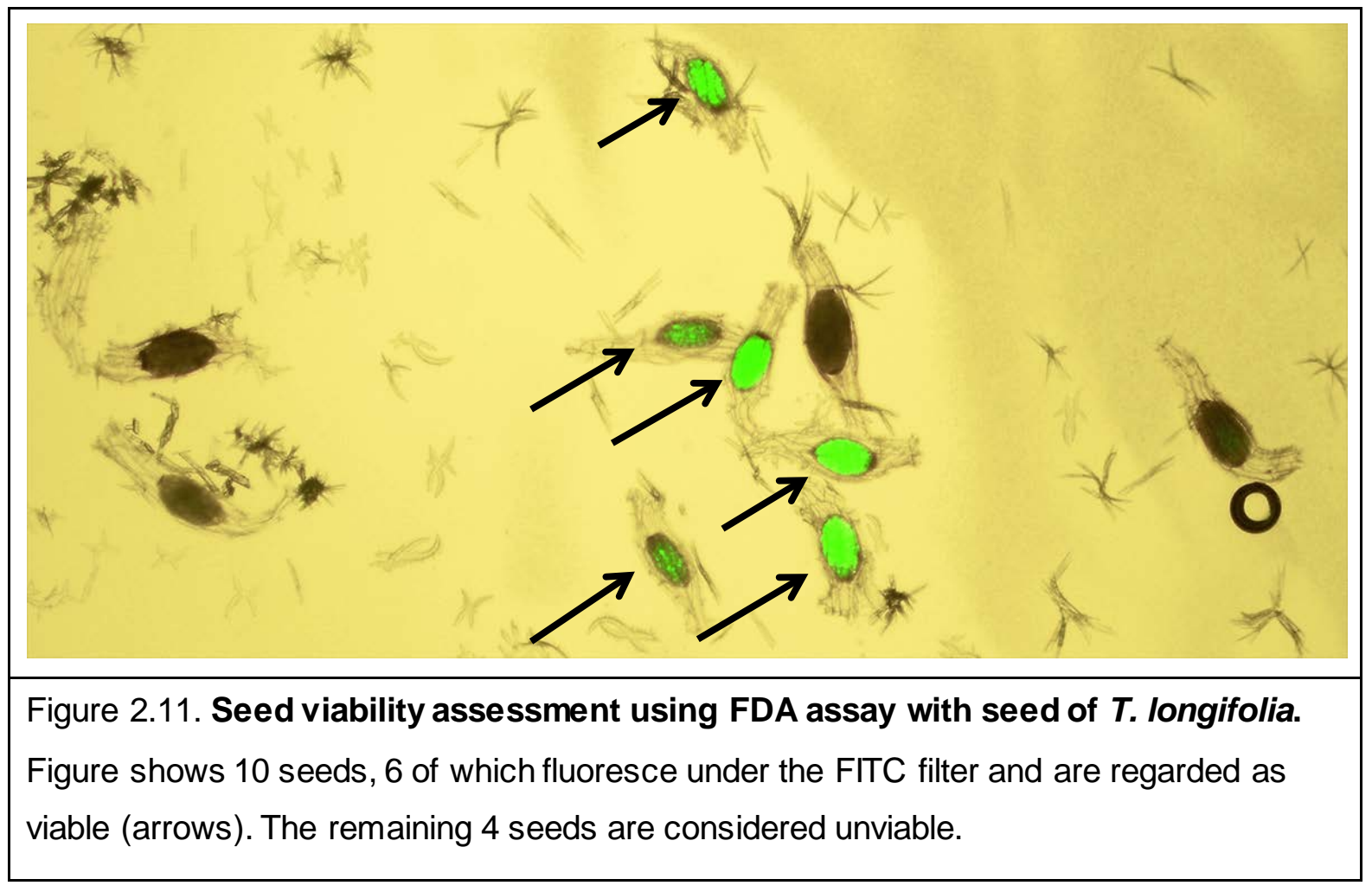

Overall FDA viability scores for each orchid tested followed the same trend as the results of the negative control, i.e. seeds placed on inoculants-free plates and progressing out of stage 0 . For T. Iongifolia, from all three sites the deviation between the both methods was $\leq 4 \%$ (Figure 2.12). However, this was not always the case and the FDA scores for $P$. banksii from Site 3 were $77 \%$ higher than what was shown by the negative control. Viability scores of $M$. unifolia seed were also higher than the percentage of seed in the negative controls moving out of stage 0 , but the sample sizes varied. Pterostylis banksii from Site 2 was not included in germination trials due to lack of seed availability, therefore values for the negative controls are not available. 


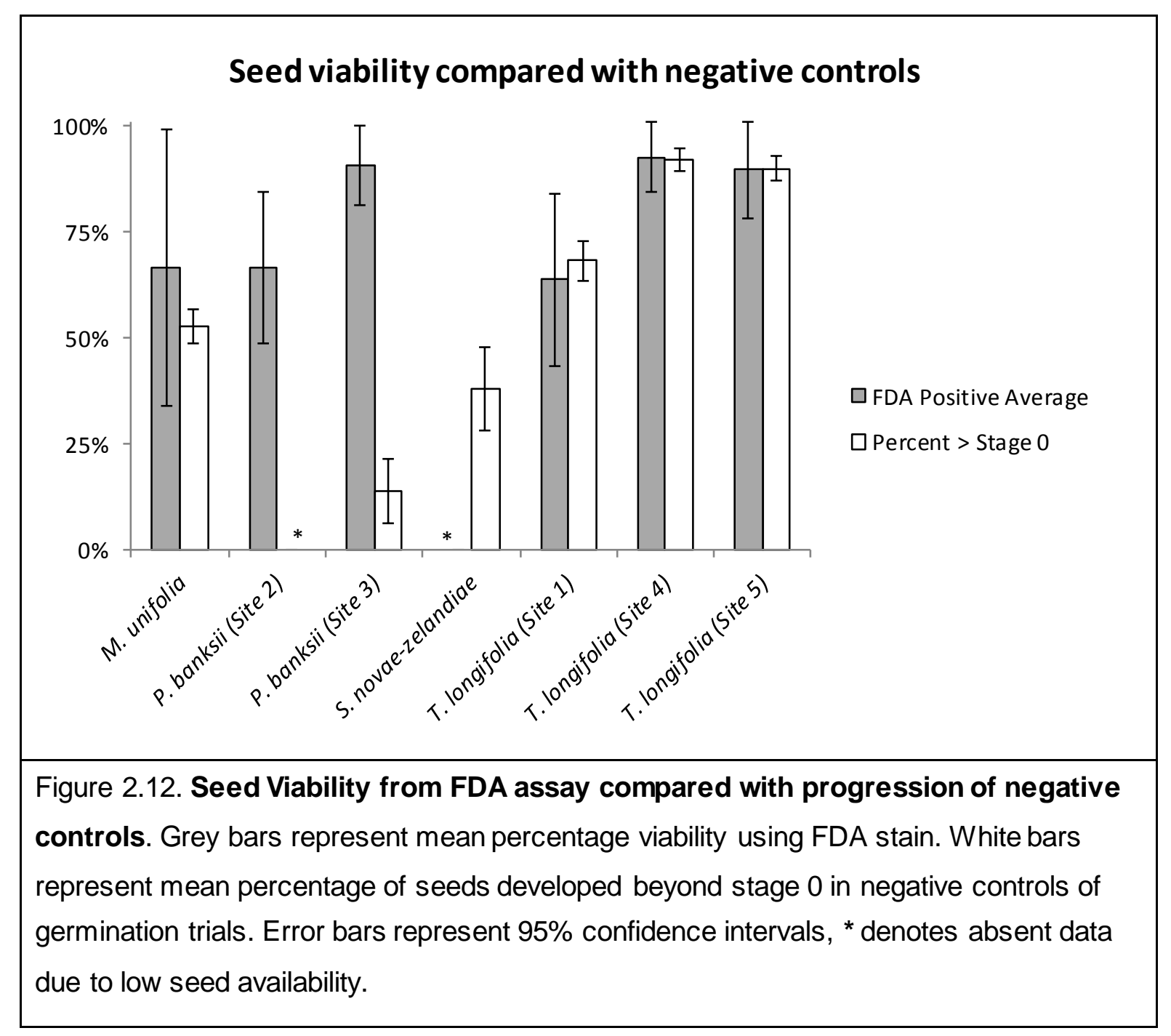




\section{Negative controls did not progress beyond stage 2}

High proportions of seeds of $M$. unifolia and T. longifolia achieved stage 2 in the absence of inoculants. For M. unifolia, 51\% of seeds progressed to stage 2 . Similarly, for T. longifolia from Site 1, 55\% achieved stage 2. For T. longifolia from Site 4 and Site 5, the proportions of seed developing to stage 2 were $83 \%$ and $84 \%$, respectively. Only $5 \%$ of $P$. banksii seeds achieved stage 2 without inoculants. No seeds from S. novae-zelandiae achieved stage 2 , and only $38 \%$ achieved stage 1 without inoculants.

\section{Cumulative proportions}

The cumulative proportion figures demonstrate a variety of responses to the diversity of endophytes isolated from each site (Figure 2.13). Each line connects the cumulative proportion of seeds which developed to protocorm stage, so that when the cumulative proportion reached 1 (equivalent to 100\%), all of the seeds in that treatment did not develop beyond the corresponding stage.

Cumulative proportions of development of S. novae-zelandiae (A, Figure 2.13) suggest that most of the nine inoculants had a positive effect on germination through stages S0 to S3. Two inoculants facilitated seeds to develop beyond stage 2 with statistical significance $(p<0.05)$. Both of these are Ascomycota: 'Epacrid' (A24) and Beauveria (A25),

Cumulative proportions of development of $M$. unifolia (B, Figure 2.13) suggest that most of the 36 inoculants had a negative or non-significant effect on protocorm development. Two inoculants facilitated seeds to develop beyond stage 2 with statistical significance $(p<0.5)$. One of these was Tulasnella (B03) and the other was 'Epacrid' (A24).

Cumulative proportions of development of $P$. banksii (Site 3) (C, Figure 2.13) show that all of the 15 inoculants had a negative or non-significant effect on germination. Nearly with $100 \%$ of seeds only achieved stage 1 irrespective of the inoculant. The negative controls, however, progressed to stage 2.

Seed from the three sites of $T$. longifolia were inoculated with the same 19 inoculants and showed variation, but also congruence in their response to the fungi. Cumulative proportions of development of $T$. longifolia (Site 1) (D, Figure 2.13) showed positive, negative, and non-significant effects dependent on the inoculant. A species of Mortierella (Z14) had a positive effect on seeds developing into stage 3, but none developed further. Four inoculants had a significant negative effect and can be seen in the cumulative proportions figure. These cultures were Rhizoctonia (B02), Tulasnella (B04), Hypocrea (A01), and Mortierella (Z07). Cumulative proportions of development of 
T. longifolia (Site 4) (E, Figure 2.13) show that all of the inoculants had a negative or nonsignificant effect on germination. Three inoculants that had a significant negative effect were Rhizoctonia (B02), Hypocrea (A01), and Mortierella (Z07). Cumulative proportions of development of $T$. longifolia (Site 5) (F, Figure 2.13) show that all of the inoculants had a negative or non-significant effect on germination. Seven inoculants that had a significant negative effect were Rhizoctonia (B01), Rhizoctonia (B02), Hypocrea (A01), Trichoderma (A07), Verticillium (A100, Mortierella (Z07), and Mortierella (Z14).

A comparison between development of the seed from three $T$. longifolia sites shows that three inoculants that had a consistently significant negative effect were Rhizoctonia (B02), Hypocrea (A01) and Mortierella (Z07). Additionally, the response to Mortierella (Z14) was positive, negative or non-significant depending on the site.

\section{Detailed statistical comparison with negative controls}

The table of the effect of inoculants at each stage of germination (Table 2.2) shows a wide range of responses. Seeds in most of the negative controls achieved stage 2 , so seeds developing beyond this threshold were considered as germinated. The $p$ values for the strength of the interactions are found in the column groups for each species, and the strength of the interaction can only be compared within species trials i.e. the $p$-value for an inoculants effect on seed of one species cannot be compared to the $p$ value for the effect of the same inoculant on seed of another species. The inoculants are arranged in descending order of their average p-value from the vglm, so that the inoculants with the strongest effect are at the top.

Four inoculants were able to facilitate germination into stage 3 or beyond. The Tulasnella (B03) inoculant enabled the germination of $M$. unifolia but had no effect on $S$. novae-zelandiae. The 'Epacrid' (A24) enabled the germination of M. unifolia and S. novaezelandiae seeds. The Beauveria (A25) inoculant enabled the germination of S. novaezelandiae but had no effect on M. unifolia. The Mortierella (Z14) inoculant enabled the germination of $T$. longifolia (Site 1 ) but had a negative effect on $M$. unifolia and $T$. longifolia from Site 5, but had not effect on $T$. longifolia from Site 4.

Fourteen inoculants had no effect on germination consistently across species and site. These were predominantly Mortierella (Z01, Z04, Z09, Z10, Z11, Z12, Z15), and also Umbelopsis (Z17), Trichoderma (A02), Verticillium (A12), Paecilomyces (A13), Metarhizium (A17) and Pochonia (Z19), Articulospora (A23). 


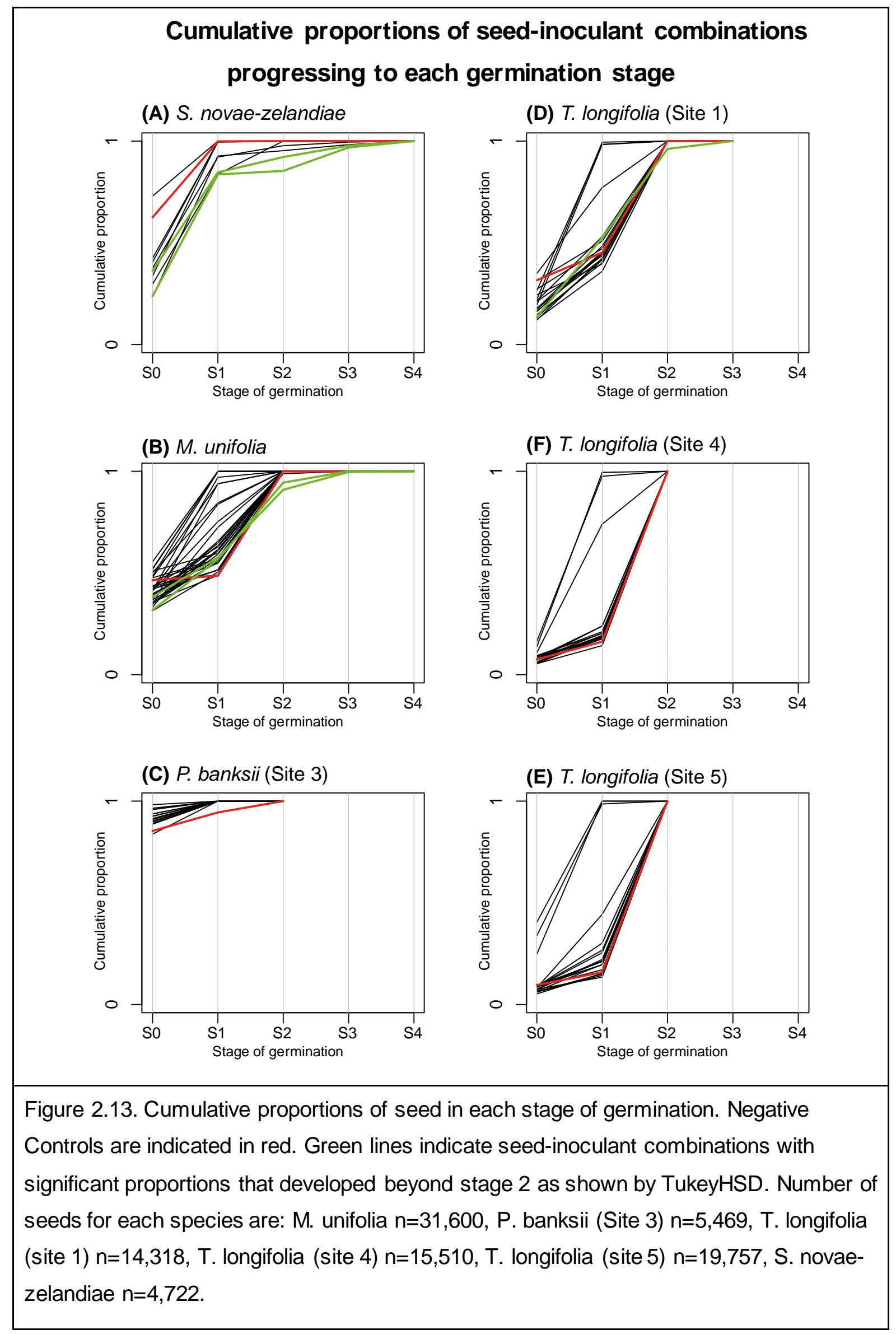


Ten inoculants had a negative effect on germination consistently across species and site. These were predominantly Ascomycota: Hypocrea (A01), Trichoderma (A02), Clonostachys (A09), Paecilomyces (A14), Pochonia (A18), Plectosphaerella (A20), Diaporthe (A21) and also three Zygomycota which are species of Mortierella (Z06, Z07) and Mucor (Z16).

The remaining ten inoculants did not facilitate germination and had mixed effects between seed species and site. Rhizoctonia (B01) enabled a greater proportion seed of $S$. novae-zelandiae to achieve stage 2 than the negative control but had the opposite effect on P. banksii and T. longifolia (Site 5), and had no effect on seeds of M. unifolia, $T$. longifolia (Site 1) and T. longifolia (Site 4). Rhizoctonia (B02) had a consistently negative effect on seed development across all species and site except $S$. novae-zelandiae, on which it had no effect. Tulasnella (B04) had a negative effect on seed development of $M$. unifolia, P. banksii and T. longifolia (Site 1), but no effect on T. longifolia (Site 4), T. longifolia (Site 5) or S. novae-zelandiae. The Hypocrea (A05) and Lecanicillium (A11) inoculants had no effect on seed development of $M$. unifolia but had a negative effect on $P$. banksii. The Verticillium (A10) inoculant had no effect on seed development of $M$. unifolia, T. longifolia (Site 1) and T. longifolia (Site 4) but had a negative effect on $P$. banksii and T. Iongifolia (Site 5). Two Mortierella (Z03, Z05) inoculants had a negative effect on seed development of $P$. banksii, but no effect on $M$. unifolia or seed from any of the $T$. longifolia sites. The Mortierella (Z13) had a negative effect on seed development of M. unifolia. 


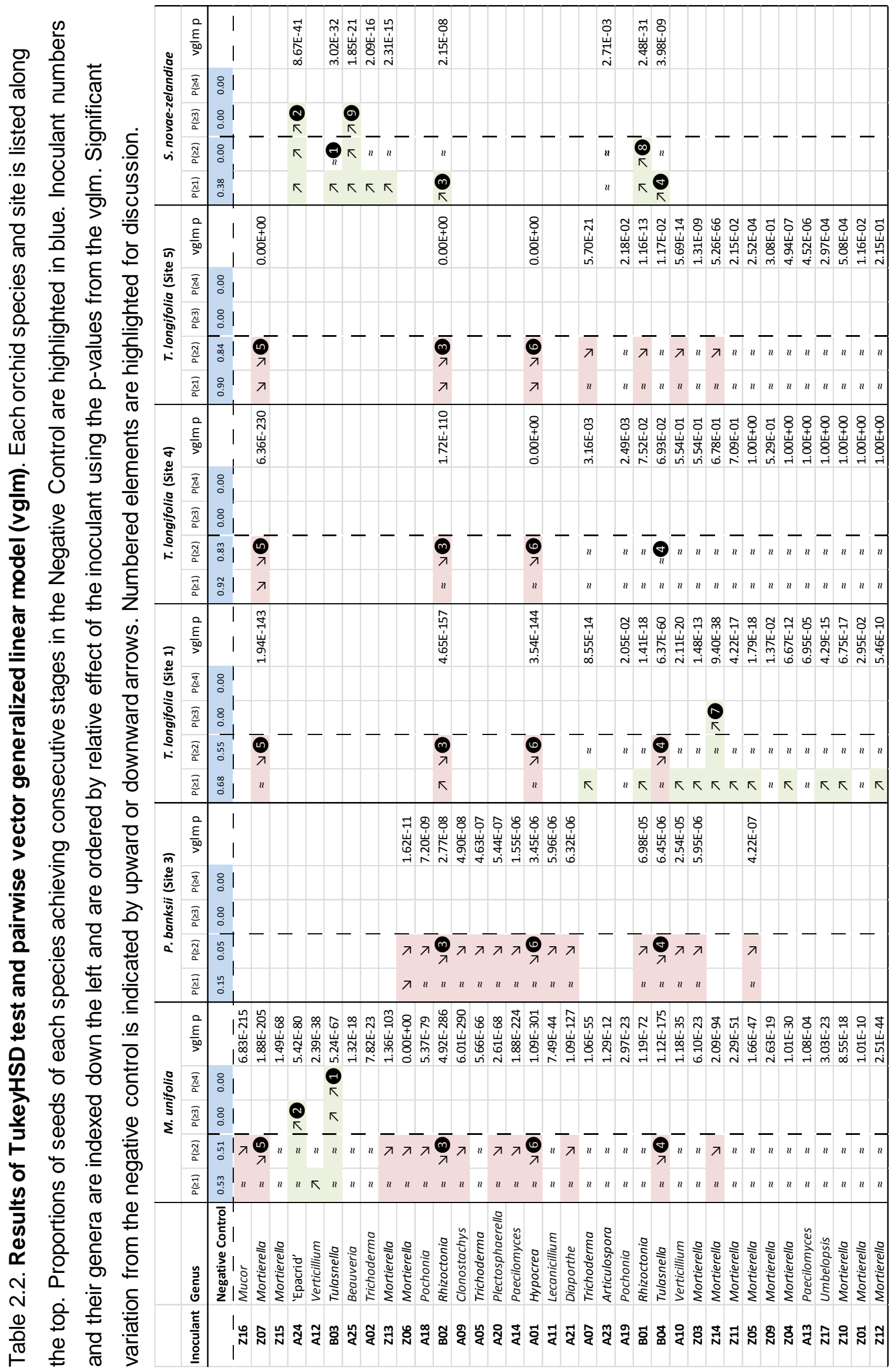




\section{Discussion}

It was the aim of this chapter to isolate, culture, and identify the fungal diversity inhabiting the roots of a range of NZ orchids and compare the diversity of endophytes among orchid site, species, habitats, and distributions. The functional component of the biodiversity was also investigated, which was achieved by studying the effect of the fungal endophyte cultures on in vitro seed development.

\section{Endophyte diversity}

Considerable diversity of endophytes was uncovered in the five orchid species studied here and 46 OTUs were isolated and genetically identified. These belonged to Basidiomycota (4 OTU), Ascomycota (25 OTU) and Zygomycota (17).

The number of OTUs recovered from comparable studies have a broad range and these values are highly dependent on sampling methods and OTU criteria. An assessment of endophyte diversity in the Czech Republic, Central Europe, found 66 OTUs in six Pseudorchis aldiba plants using a 97\% similarity threshold for Basidiomycota but a 99\% similarity threshold for Ascomycota (Kohout, Těšitelová, Roy, Vohník, \& Jersáková, 2013). In contrast, only six fungal taxa were found in four Dipodium hamiltonianum plants in Australia (Dearnaley \& Le Brocque, 2006).

Basidiomycota were recovered only from $P$. banksii (1 OTU) and S. novaezelandiae (2 OTUs) (Figure 2.9). This is surprising because in Australia and Japan, members of this phylum have been recovered from some species included in this study, such as M. unifolia (Milligan \& Williams, 1988), T. longifolia (Warcup, 1981), C. valida (Roche et al., 2010), and also from other species within Spiranthes (Masuhara, Katsuya, \& Yamaguchi, 1993) and Pterostylis (Irwin, Bougoure, \& Dearnaley, 2007). Perhaps the Basidiomycota in these orchids did not respond favourably to the culture conditions. It may be that the culturing methodology favoured mycotrophic taxa or fast-growing fungi, which were able to consume or competitively exclude slower growing and saprophytic fungi such as Basidiomycota. A similar finding was reported in China by Jiang, Yang, Zhang, \& Fu (2011), who found only one Basidiomycota in the roots of one Changnienia amoena (Orchidaceae) among root samples from four locations included in their study.

Members of two divergent lineages of Basidiomycota were recovered: Two Rhizoctonia, and two Tulasnella (Figure 2.6). The two similar Tulasnella OTUs both match T. calospora closely and are likely strains of this 'universal' endosymbiont of a range of orchids (Hadley, 1970). The two Rhizoctonia OTUs (B01 and B02, Figure 2.6) are probably have a wide distribution range as they were isolated here from different orchid 
species and that had different provenance. Tulasnella calospora has been found in a range of orchid genera from a range of geographic locations. Such as: Prasophyllum giganteum and Diuris magnifica in Australia (Bonnardeaux et al., 2007); Changnienia amoena in China (Jiang et al., 2011); Bipinnula fimbriata in Chile (Steinfort, Verdugo, Besoain, \& Cisternas, 2010); Orchis purpurea and Serapias vomeracea in Italy (Girlanda et al., 2011); Dactylorhiza majalis in Denmark (Kristiansen, Taylor, Kjøller, Rasmussen, \& Rosendahl, 2001) and also in NZ Nematoceras iridescens (Watkins, 2012).

The diversity of Ascomycota and Zygomycota recovered here was high, species of these phyla are likely to be common endophytes in orchids because all orchid species studied here are from different sites had members of these phyla in their roots (Figure 2.9). It is interesting to note that the 25 Ascomycota OTUs isolated in this study represent lineages from a range of trophic strategies: saprophytic, parasitic on plants, fungi, insects, and animals. Some Ascomycota recovered in this study, such as Verticillium and Trichoderma have previously been recorded in the roots of orchids (Salifah, Muskhazli, Rusea, \& Nithiyaa, 2011). Their presence alone does not describe their effect on the host orchid and their effects on developing protocorms are discussed later.

Despite the high diversity of Zygomycota (17 OTUs) recovered in this study, most cultures were identified as belonging to the genus Mortierella. Members of this genus have been found in orchids such as: $R$. streptopetala var. stenophyla in Africa (Ochora, Stock, Linder, \& Newton, 2001) Pseudorchis albida in Europe (Kohout et al., 2013) and Grammatophyllum scriptum in Asia (Salifah et al., 2011). The two other Zygomycota recovered matched and Umbelopsis species and Mucor hiemalis (Z16, Z17; Figure 2.8) on GenBank. Zygomycota are predominantly saprophytes or parasites and cultures grow rapidly (Raven, Evert, \& Eichhorn, 2005). This rapid growth was seen on culture plates in the present study. Umbelopsis is an genus of early diverging Zygomycota often isolated from forest soils and tree roots (Wang, Liu, \& Zheng, 2013)

\section{Designation of OTUs disconnected from diagnostic characters}

Nuclear ribosomal subunits such as ITS (5.8S), 18S, and $28 \mathrm{~S}$ are routinely used to assist in resolving fungal taxonomy and delimiting species (Guarro et al., 1999). Some studies consider a $97 \%$ or $95 \%$ sequence divergence threshold for the ITS marker to be acceptable for delimiting species in a range of biota, including fungi (Bailarote, Lievens, \& Jacquemyn, 2012). However, others suggest that even a $2 \%$ difference in the guaninecytosine content of fungal sequences may indicate species-level demarcation threshold (Guarro et al., 1999). The application of thresholds for species delimitation depends on 
the variation of the marker within taxonomic groups, and understanding this variation relies on broad taxon sampling.

The phylogenetic approach for defining OTUs in this study did not include diagnostic features that define species, therefore the proposed taxonomy cannot be strictly applied. Most of the ITS1-5.8s-ITS2 sequences generated in this study matched GenBank accessions which had been identified to the species level and some only to the genus level. A great number of sequences generated in this study were greater than $97 \%$ similar to each other, but matched different GenBank accessions more closely. Therefore the $97 \%$ threshold was not sensitive enough to describe the diversity adequately. The phylogenetic approach used in this study was more sensitive to multiple levels of variation within a single alignment irrespective of threshold values.

\section{Endophyte diversity did not follow host distribution or habitat trends.}

There was no pattern of endophyte diversity following the distribution range of orchids. For example, $M$. unifolia is a very widespread species, and showed moderate diversity (6 OTUs), while S. novae-zelandiae which has a limited distribution, showed high endophyte diversity (11 OTUs).

Seeds of $P$. banksii responded negatively to all inoculants relative to negative controls, suggesting that it may require specific fungi or it may require additional treatment such as stratification, to enable further development. The FDA assay demonstrated high viability (Figure 2.12) for this species which further supporting the idea that conditions were not optimal. Conversely, S. novae-zelandiae responded positively to most inoculants in the early development stages, and all inoculants enabled equal or better seed development relative to negative controls. For the most part, the seeds from all three sites of $T$. longifolia responded alike to each inoculant, except in the cases of B01, B04, A07, A10, and Z14 (Table 2.2). The only species exposed to all the inoculants was M. unifolia and therefore it provides a framework by which inoculants can be compared with each other.

It was expected that a basidiomycete fungus would be recovered from $M$ unifolia because a similarly widespread Australian orchid, Microtis media, forms associations with a number of basidiomycete fungi that inhabit a range of habitats, such as Tulasnella calospora, Piriformospora indica, Sebacina vermifera, and species of Ceratobasidium (De Long et al., 2013). However, none of the 6 OTUs recovered from M. unifolia in this study are known to form a symbiotic association with any Microtis species. The limitations to the culturing methodology mentioned earlier may also apply here. 
The number of OTUs recovered from within each species and from orchids at different sites did not follow any discernible pattern. There was low diversity of endophytes in $P$. banksii from Site 2, and high diversity in $P$ banksii from Site 3. These two sites are less than 500 metres apart and are along the same ridgeline, surrounded by similar shrub and tree species composition and light levels. Similarly, T. longifolia from Site 4 contained high diversity of fungi, and T. longifolia from Site 5 contained few OTUs. Both of these sites are less than 400 metres apart within the same valley, and similar habitats. Comparing the endophyte diversity from sites of $T$. longifolia and $P$. banksii that yielded high diversity shows that $T$. longifolia was dominated by Zygomycota, whereas $P$. banksii was dominated by Ascomycota (Figure 2.9). Both of these sites were less than 400 meters apart. A moderate level of diversity was recovered from T. longifolia (Site 1) and M. unifolia. The T. longifolia (Site 1) sample was collected from the forest margin, and the M. unifolia site was in an open, grassy area.

Another species with moderate endophyte diversity (5 OTUs) was $C$. valida from a location dominated by pine trees. This species is present in eastern Australia, where it is known to form associations with a narrow group of Tulasnella fungi (Roche et al., 2010). None of the endophytes recovered from $C$. valida in the present study are known to form associations with it.

High endophyte diversity (11 OTUs) was recovered from S. novae-zelandiae, which is from a wetland habitat, and shares a similar composition of phyla as P. banksii (Site 3). Overall these observations suggest that these broadly defined habitat types are probably not useful for predicting endophyte community composition within orchids. Comprehensive studies of how habitat types affect orchid endophyte diversity are scarce possibly due to the many other factors that are difficult to control for in field studies.

Based on the orchid sample size and number of sites included in this project it appears that neither region (Eastbourne/ Tararua /Taupō), habitat (native forest/wetland/pine forest), site (sites in hills above Eastbourne), species, nor species abundance (weedy/endangered/vagrant) are related to diversity of recovered endophytes. This was a small scale study featuring a low number of samples from range of taxa. It is recommended that further studies aim to be of a greater scale, comparing the diversity of endophytes among more individuals and between more sites of each species to identify patterns of endophyte communities between sites. For commonly occurring orchids, studies along biogeographic gradients such as elevation or substrate type, may provide valuable insights into orchid-fungal associations. Analysing soil properties adjacent to orchids may also provide useful predictors of endophyte diversity and surveys of soil and 
roots undertaken over a season may reveal how successional endophyte communities change. For instance, this has been shown in Quercus robur (English oak) where adjacent fungi and succession play a role in shaping endophyte communities (Marta, 2012) and it may be that this also occurs in terrestrial orchids.

\section{Inoculants affected seed germination differentially}

The seed response of all orchid species to the four Basidiomycota isolates was variable, some of them facilitate germination for some orchid species while in others no effect was detected or had a negative effect. For instance, the Tulasnella (B03) inoculant was successful in facilitating germination of $M$. unifolia into stage $4(1$, Table 2.2$)$ but this was not statistically significant for S. novae-zelandiae. Despite this, germination beyond protocorm stages was achieved using this inoculant (see Chapter 4) suggesting that tests were not sensitive enough to register the low germination rates. A closely related Tulasnella inoculant (B04) was unable to facilitate germination into stage 3 in $M$ unifolia, P. banksii, T. longifolia or S. novae-zelandiae (4, Table 2.2) and no seeds progressed beyond stage 2 with this inoculant. It is unlikely that this is due to specificity because $M$. unifolia, S. novae-zelandiae and T. longifolia are known to germinate with a range of Tulasnella strains. This is an example of the difficulties faced with in vitro germination trials. There are a number of potential causes for failure of germination, including loss of efficacy of inoculant (Hollick, 2004), failure of symbiotic balance (Clements, 1988), or contamination by pathogenic fungi. Similarly, the Rhizoctonia (B02) inoculant had a negative effect compared to negative controls at stage 2 for all seed except for $S$. novaezelandiae (3, Table 2.2). Rhizoctonia (B02) is represented in the cumulative proportions graph (Figure 2.13) by one of the cumulative proportion lines demonstrating almost $100 \%$ of seeds only achieving stage 1 in all graphs. A similar pattern might be expected if the inoculant was a plant pathogen, such as Rhizoctonia solani. However, it is unlikely that this pathogenic culture is $R$. solani because of the low identity match $(\leq 93 \%)$ with the GenBank accession for a voucher of $R$. solani (GenBank: JQ311915.1).

The role of Ascomycata isolates on orchid seed germination is unknown but they may be beneficial parasites that can be used to control fungal and insect pathogens. For instance, members of the genus Trichoderma (teleomorph Hypocrea) are often in found the soil and in decaying wood, and they have economic implications in control of pathogenic fungi in plants (Druzhinina \& Kubicek, 2005). Some species of Trichoderma have even been found to enhance plant growth even when plant pathogens are not present (Celar \& Valic, 2005). The Trichoderma inoculants (A02, A05, A07) showed no effect on seed germination, but the Hypocrea (A01) inoculant showed a negative effect on seed development. Surprisingly, the 'Epacrid' (A24) inoculant facilitated germination into 
stage 3 for both M. unifolia and S. novae-zelandiae (2, Table 2.2). Basidiomycota-targeted PCRs confirmed the absence of Basidiomycota co-existing with the 'Epacrid' fungi. A possible explanation for this observation is the ability of $S$. novae-zelandiae to use the same fungi as some wetland Ericaceae to survive in poor soils. In NZ, some species of Ericaceae are known to occur in similar wetlands as S. novae-zelandiae (Wardle, 1991) which are typically nutrient-poor (Read, 1996). A more detailed investigation should be done to confirm that this Ascomycota does indeed facilitate germination. Further molecular and morphological characterisation of this fungus is also needed.

Fungi which are parasites of fungi and insects may unexpectedly negatively affect germination of orchid seed. Clonostachys rosea, is an effective bio-control of a number of plant crop pathogens including Botrytis cinerea (Cota, Maffia, Mizubuti, \& Macedo, 2009) and Plasmodiophora brassicae (Lahlali \& Peng, 2014). However, the inoculant that matched this taxon (A09) had negative effects on orchid seed development.

Several ascomycete isolates found in this study are known to be fungal parasites and their presence inside the orchid root may be explained by the presence of the fungi they parasitize also being in the root. This may be the case for Lecanicillium, a genus that contains insect and fungi pathogens. Specifically, Lecanicillium fungicola is a known pathogen to some fungi (Berendsen, Kalkhove, Lugones, Wösten, \& Bakker, 2012) and inoculants matching this taxon (A11) had no effect on $M$. unifolia but a negative effect on $P$. banksii. On the other hand, Beauveria caledonica is a parasite of forest Coleoptera in NZ and has been used to control invasive species (Glare, Reay, Nelson, \& Moore, 2008) and the reason for the presence of this fungi inside the orchid root is uncertain. Even more surprising is that the inoculant that was identified as Beauveria (A25) was able to facilitate germination in S. novae-zelandiae (9, Table 2.2) but had no effect on $M$. unifolia seed development. This is a new finding that requires further investigation in order to confirm and characterise the interaction. No Basidiomycota contamination was detected and development of seeds did not continue beyond stage 4 .

This study of endophytes from NZ orchids demonstrates some surprising, potentially beneficial mutualisms. One of the isolates from $P$. banksii (Site3), Verticillium leptobactrum, is a rare fungus isolated from serpentine soils (Daghino et al., 2009) which have high levels of nickel and a disproportionate ratio of magnesium to calcium (Panaccione, Sheets, Miller, \& Cumming, 2001). Fungi inside plants may mitigate the stress caused by these soil chemical properties to tolerate these environments (Panaccione et al., 2001). In the present study, orchid seeds responded variably to this inoculant (A10). Development on M. unifolia, T. longifolia (Site 1) and T. longifolia (Site 4) 
was unaffected by it, while a negative effect was seen in the development of $P$. banksii and $T$. longifolia (Site 5) seed. In no instance did it have a detectable positive effect on germination and perhaps only has positive effects on mature plants. A deeper investigation into the fungal-plant interactions may reveal more such interactions.

Orchid symbioses have been claimed with members of Zygomycota (Raven et al., 2005) but many of these may need to be reviewed due to recent taxonomic revisions placing the mutualistic order, Glomerales in a different phylum (Hibbett et al., 2007). Seven of the 15 Zygomycota inoculants isolated from this study had no effect on seed development of any orchid species. Only one Mortierella OTU (Z14) facilitated the development of seeds of $T$. longifolia from Site 1 but this finding requires further investigation as the same inoculant did not have the same effect on the seeds from the other two sites. At least one other study isolated an unidentified Mortierella species from an African orchid, Eulophia streptopetala var. streptopetala was able to facilitate germination of that orchid (Ochora et al., 2001). All DNA isolates from these cultures were screened with Basidiomycota-specific primers and so are unlikely to contain Basidiomycota contaminants.

The presence of a sole parasitic fungus may be tolerated by an orchid host but compounding factors within the endophyte community may overwhelm the host. Such is the case with $M$. hiemalis which has been known to play a role in successive fungal invasions of Cymbidium pseudobulbs causing total tissue disintegration. However, it was not able to cause as much damage in the absence of other pathogens (Sen, Acharya, Saha, \& Acharya, 2006). In the present study M. hiemalis was isolated from M. unifolia (Z16, Figure 2.8) and had a strong negative effect on development of $M$. unifolia seeds (Table 2.2) none of which developed beyond stage 2.

\section{Seed viability}

The values obtained in this study represent the first seed viability surveys in a broad range of NZ orchid species and the only other potential survey of seed viability for NZ orchids is a count of embryo presence in Nematoceras iridescens seeds suggesting $97.22 \%$ viability (Watkins, 2012). However, as shown in Figure 2.11, embryos may be present but non-viable.

There was high variation in seed viability between sites of $P$. banksii (24\% variation) and $T$. longifolia (29\%). This indicates that there may be site-specific factors which affect viability or the origin of the pollen that fertilised the seeds. Those flowers that have been cross-pollinated are likely to have a greater seed viability than those that have been self-pollinated (Kearns \& Inouye, 1993) 


\section{Conclusions}

This is the first study in NZ to assess fungal endophytes in a range of terrestrial orchids using molecular methods. Here 46 OTUs were identified within the roots of these orchids. Endophyte diversity was unable to be linked to site, species or distribution range. It is likely this is only part of the real diversity of endophytes and it should be kept in mind that each step of the isolation, subculturing and sequencing process had inherent biases that may have masked a greater diversity of endophytes. It is probable that a greater diversity will be uncovered by sampling more plants per species or site. Future studies may also benefit by surveying fungal diversity in the soil surrounding the orchids.

The symbiotic seed germination approach demonstrated endophytes produced a variable response on the seeds: from facilitative, to no effect, to pathogenic. This variability was observed across phyla but also between closely related OTUs which had contrasting effects on orchid seed development. Such as Hypocrea (A01), which had a strong negative effect on germination, and the sister clade, Trichoderma (A02) showed no effect on seed development.

Three inoculants in particular had a strong and consistent negative effect on seed development. These were Rhizoctonia (B02), Hypocrea (A01) and Mortierella (Z07). These may be considered pathogenic for orchid seed. It may be that these fungi prevent seed development in situ even in the presence of suitable symbiotic fungi. The interactions between members of the endophyte community remain to be investigated.

These findings suggest that an approach investigating trophic strategies and functional roles in assemblages may provide better insights into fungal community structure. These organisms may create a complex biotic network of parasitic and mutualistic, antagonistic and sympathetic, and physiological interactions between fungi may dictate the effect on the entire plant. Interactions with bacteria may also demonstrate a complex network of nutrient exchange (Wilkinson, Dixon, \& Sivasithamparam, 1989). While understanding these processes may be important, first step is to discover the benefit of these fungal isolates on germination of orchid seeds in isolation from each other. Understanding the effect that these fungi have on seed development will allow further inferences about their effect on recruitment and the importance for propagating species under threat of extinction. 


\section{References}

Aggarwal, S., \& Zettler, L. W. (2010). Reintroduction of an endangered terrestrial orchid, Dactylorhiza hatagirea (D. Don) Soo, assisted by symbiotic seed germination: First report from the Indian subcontinent. Nature and Science, 8(10), 139-145.

Arditti, J., \& Ghani, A. K. A. (2000). Tansley Review No. 110. Numerical and Physical Properties of Orchid Seeds and Their Biological Implications. New Phytologist, 145(3), 367-421.

Bailarote, B. C., Lievens, B., \& Jacquemyn, H. (2012). Does mycorrhizal specificity affect orchid decline and rarity? American Journal of Botany, 99(10), 1655-65. doi:10.3732/ajb.1200117

Beach, D., Piper, M., \& Nurse, P. (1982). Construction of a Schizosaccharomyces pombe gene bank in a yeast bacterial shuttle vector and its use to isolate genes by complementation. MGG Molecular \& General Genetics, 187(2), 326-329. doi:10.1007/BF00331138

Benson, D. a, Karsch-Mizrachi, I., Lipman, D. J., Ostell, J., \& Wheeler, D. L. (2005). GenBank. Nucleic Acids Research, 33(Database issue), D34-8. doi:10.1093/nar/gki063

Berendsen, R. L., Kalkhove, S. I. C., Lugones, L. G., Wösten, H. a B., \& Bakker, P. a H. M. (2012). Germination of Lecanicillium fungicola in the mycosphere of Agaricus bisporus. EnvironmentalMicrobiology Reports, 4(2), 227-33. doi:10.1111/j.1758-2229.2011.00325.x

Bonnardeaux, Y., Brundrett, M., Batty, A. L., Dixon, K. W., Koch, J., \& Sivasithamparam, K. (2007). Diversity of mycorrhizal fungi of terrestrial orchids: compatibility webs, briefencounters, lasting relationships and alien invasions. Mycological Research, 111(Pt 1), 51-61. doi:10.1016/j.mycres.2006.11.006

Cameron, D. D., Leake, J. R., \& Read, D. J. (2006). Mutualistic mycorrhiza in orchids: evidence from plant-fungus carbon and nitrogen transfers in the green-leaved terrestrial orchid Goodyera repens. The New Phytologist, 171(2), 405-16. doi:10.1111/j.1469-8137.2006.01767.x

Campbell, E. O. (1962). The Mycorrhiza of Gastrodia cunninghamii Hook f. Transactions of the Royal Society of New Zealand, 1(24), 289-296.

Campbell, E. O. (1970). The fungal association of Yoania australis. Transactions of the Royal Society of New Zealand, 12(2), 5-12.

Celar, F., \& Valic, N. (2005). Effects of Trichoderma spp. and Gliocladium roseum culture filtrates on seed germination of vegetables and maize. Journal of Plant Diseases and Protection, 112(4), 343-350.

Clements, M. A. (1988). Orchid mycorrhizal associations. Lindleyana, 3, 73-86.

Clements, M. A., \& Ellyard, R. K. (1979). The symbiotic germination of Australian terrestrial orchids. American Orchid Society Bulletin, 48, 810-816.

Colwell, R. K., Chao, A., Gotelli, N. J., Lin, S.-Y., Mao, C. X., Chazdon, R. L., \& Longino, J. T. (2012). Models and estimators linking individual-based and sample-based rarefaction, extrapolation and comparison of assemblages. Journal of Plant Ecology, 5(1), 3-21. doi:10.1093/jpe/rtr044 
Cota, L. V., Maffia, L. a., Mizubuti, E. S. G., \& Macedo, P. E. F. (2009). Biological control by Clonostachys rosea as a key component in the integrated management of strawberry gray mold. Biological Control, 50(3), 222-230. doi:10.1016/j.biocontrol.2009.04.017

Daghino, S., Turci, F., Tomatis, M., Girlanda, M., Fubini, B., \& Perotto, S. (2009). Weathering of chrysotile asbestos by the serpentine rock-inhabiting fungus Verticillium leptobactrum. FEMS Microbiology Ecology, 69(1), 132-41. doi:10.1111/j.1574-6941.2009.00695.x

De Lange, P. J., Rolfe, J. R., Champion, P. D., Courtney, S. P., Heenan, P. B., Barkla, J. W., ... Hitchmough, R. A. (2012). Conservation status of New Zealand indigenous vascular plants, 2012 (p. 70). Wellington: Department of Conservation, Te Papa Atawhai. Retrieved from http://www.nzpcn.org.nz/publications/NZTCS-Vascular Plants - 2013.pdf

De Long, J. R., Swarts, N. D., Dixon, K. W., \& Egerton-Warburton, L. M. (2013). Mycorrhizal preference promotes habitat invasion by a native Australian orchid: Microtis media. Annals of Botany, 111(3), 409-18. doi:10.1093/aob/mcs294

Dearnaley, J. D. W., \& Le Brocque, a. F. (2006). Molecularidentification of the primary root fungal endophytes of Dipodium hamiltonianum (Orchidaceae). Australian Journal of Botany, 54(5), 487. doi:10.1071/BT05149

Dearnaley, J. D. W., Martos, F., \& Selosse, M.-A. (2012). Orchid Mycorrhizas: Molecular Ecology, Physiology, Evolution and Conservation Aspects. In B. Hock (Ed.), Fungal Associations (2nd Ed., pp. 207-230). Berlin, Heidelberg:Springer. doi:10.1007/978-3-642-30826-0

Dixon, K. W., \& Ramsay, M. M. (2003). Propagation science, recovery and translocation of terrestrial orchids. In K. W. Dixon, S. P. Kell, R. L. Barrett, \& P. J. Cribb (Eds.), Orchid Conservation (1st Ed., pp. 259-288). Kota Kinabalu: Natural History Publications (Borneo).

Druzhinina, I., \& Kubicek, C. P. (2005). Species concepts and biodiversity in Trichoderma and Hypocrea: from aggregate species to species clusters? Journal of Zhejiang University. Science. B, 6(2), 100-12. doi:10.1631/jzus.2005.B0100

Eriksson, O., \& Kainulainen, K. (2011). The evolutionary ecology of dust seeds. Perspectives in Plant Ecology, Evolution and Systematics, 13(2), 73-87. doi:10.1016/j.ppees.2011.02.002

Farell, E. M., \& Alexandre, G. (2012). Bovine serum albumin further enhances the effects of organic solvents on increased yield of polymerase chain reaction of GC-rich templates. BMC Research Notes, 5(1), 257. doi:10.1186/1756-0500-5-257

Fay, M. F., \& Krauss, S. L. (2003). Orchid conservation genetics in the molecular age. In K. W. Dixon, S. P. Kell, R. L. Barret, \& P. J. Cribb (Eds.), Orchid Conservation (pp. 91-112). Kota Kinabalu: Natural History Publications (Borneo).

Felsenstein, J. (1985). Confidence Limits on Phylogenies: An Approach Using the Bootstrap. Evolution, 39(4), 783-791.

García, V. G., Onco, M. A. P., \& Susan, V. R. (2006). Review. Biology and Systematics of the form genus Rhizoctonia. Spanish Journal of Agricultural Research, 4(1), 55-79. Retrieved from http://revistas.inia.es/index.php/sjar/article/download/178/175 
Gardes, M., \& Bruns, T. D. (1993). ITS primers with enhanced specificity for basidiomycetes application to the identification of mycorrhizae and rusts. MolecularEcology, 2(2), 113-118. doi:10.1111/j.1365-294X.1993.tb00005.x

Girlanda, M., Segreto, R., Cafasso, D., Liebel, H. T., Rodda, M., Ercole, E., ... Perotto, S. (2011). Photosynthetic Mediterranean meadow orchids feature partial mycoheterotrophy and specific mycorrhizal associations. American Journal of Botany, 98(7), 1148-63. doi:10.3732/ajb.1000486

Glare, T. R., Reay, S. D., Nelson, T. L., \& Moore, R. (2008). Beauveria caledonica is a naturally occurring pathogen of forest beetles. Mycological Research, 112(Pt 3), 352-60. doi:10.1016/j.mycres.2007.10.015

Guarro, J., Gené, J., \& Stchigel, A. M. (1999). Developments in Fungal Taxonomy Developments in Fungal Taxonomy. Clinical Microbiology Reviews, 12(3), 454-500.

Hadley, G. (1970). Non-specificity of symbotic infection in orchid mycorrhiza. New Phytologist, 69(4), 1015-1023. doi:10.1111/j.1469-8137.1970.tb02481.x

Hawksworth, D. (2011). A new dawn for the naming of fungi: impacts of decisions made in Melbourne in July 2011 on the future publication and regulation of fungal names. MycoKeys, 1, 7. doi:10.3897/mycokeys.1.2062

Hibbett, D. S., Binder, M., Bischoff, J. F., Blackwell, M., Cannon, P. F., Eriksson, O. E., ... Zhang, N. (2007). A higher-level phylogenetic classification of the Fungi. Mycological Research, 111(Pt 5), 509-47. doi:10.1016/j.mycres.2007.03.004

Hollick, P. S. (2004). Mycorrhizalspecificity in endemic Western Australian terrestrialorchids (tribe Diurideae): Implications for conservation. Retrieved from http://researchrepository.murdoch.edu.au/103/

Holm, S. (1979). Board of the Foundation of the Scandinavian Journal of Statistics. Scandinavian Journal of Statistics, 6(2), 65-70.

Huynh, T. T., Thomson, R., McLean, C. B., \& Lawrie, A. C. (2009). Functional and genetic diversity of mycorrhizal fungi from single plants of Caladenia formosa (Orchidaceae). Annals of Botany, 104(4), 757-65. doi:10.1093/aob/mcp153

Irwin, M. J., Bougoure, J. J., \& Dearnaley, J. D. W. (2007). Pterostylis nutans (Orchidaceae) has a specific association with two Ceratobasidium root-associated fungi across its range in eastern Australia. Mycoscience, 48(4), 231-239. doi:10.1007/s10267-007-0360-x

Jacquemyn, H., Brys, R., Cammue, B. P. a, Honnay, O., \& Lievens, B. (2011). Mycorrhizal associations and reproductive isolation in three closely related Orchis species. Annals of Botany, 107(3), 347-56. doi:10.1093/aob/mcq248

Jiang, W., Yang, G., Zhang, C., \& Fu, C. (2011). Species composition and molecular analysis of symbiotic fungi in roots of Changnienia amoena (Orchidaceae). African Journal of Microbiology Research, 5(3), 222-228. doi:10.5897/AJMR10.479 
Kearns, C. A., \& Inouye, D. W. (1993). Techniques for Pollination Biologists. (D. W. Inouye, Ed.) (p. 586). University Press of Colorado.

Kohout, P., Těšitelová, T., Roy, M., Vohník, M., \& Jersáková, J. (2013). A diverse fungal community associated with Pseudorchis albida (Orchidaceae) roots. Fungal Ecology, 6(1), 50-64. doi:10.1016/j.funeco.2012.08.005

Kristiansen, K. a, Taylor, D. L., Kjøller, R., Rasmussen, H. N., \& Rosendahl, S. (2001). Identification of mycorrhizal fungi from single pelotons of Dactylorhiza majalis (Orchidaceae) using singlestrand conformation polymorphism and mitochondrial ribosomal large subunit DNA sequences. Molecular Ecology, 10(8), 2089-93. Retrieved from http://www.ncbi.nlm.nih.gov/pubmed/11555252

Lahlali, R., \& Peng, G. (2014). Suppression of clubroot by Clonostachys rosea via antibiosis and induced host resistance. Plant Pathology, 63(2), 447-455. doi:10.1111/ppa.12112

Látr, A., Čuříková, M., Baláž, M., \& Jurčák, J. (2008). Mycorrhizas of Cephalanthera longifolia and Dactylorhiza majalis, Two Terrestrial Orchids. Annales Botanici Fennici, 45(4), 281-289. doi:10.5735/085.045.0405

Marta, A. (2012). Variation in fungal endophyte communities of pedunculate oak (Quercus robus L.): spatial, temporaland environmentalaspects. Swedish University of Agricultural Sciences.

Masuhara, G., Katsuya, K., \& Yamaguchi, K. (1993). Potential for symbiosis of Rhizoctonia solani and binucleate Rhizoctonia with seeds of Spiranthes sinensis var. amoena in vitro. Mycological Research, 97(6), 746-752. doi:10.1016/S0953-7562(09)80156-1

Milligan, M. J., \& Williams, P. G. (1988). The Mycorrhizal Relationship of Multinucleate Rhizoctonias from Non-Orchids with Microtis (Orchidaceae). New Phytologist, 108(2), 205209.

Nei, M., \& Kumar, S. (2000). Molecular Evolution and Pylogenetics (p. 339). New York: Oxford University Press.

Nilsson, R. H., Kristiansson, E., Ryberg, M., Hallenberg, N., \& Larsson, K.-H. (2008). Intraspecific ITS Variability in the Kingdom Fungi as Expressed in the International Sequence Databases and Its Implications for Molecular Species Identification. Evolutionary Bioinformatics Online, 4(3), 193-201. Retrieved from

http://www.pubmedcentral.nih.gov/articlerender.fcgi ?artid=2614188\&tool=pmcentrez\&ren dertype=abstract

Ochora, J., Stock, W., Linder, H., \& Newton, L. (2001). Symbiotic seed germination in twelve Kenyan orchid species. Systematics and Geography of ..., 71(2), 585-596. Retrieved from http://www.jstor.org/stable/10.2307/3668703

Ogoshi, A. (1987). Ecology and Pathogenicity of Anastomosis and Intraspecific Groups of Rhizoctonia Solani Kuhn. Annual Review of Phytopathology, 25(1), 125-143.

doi:10.1146/annurev.py.25.090187.001013 
Ogura-Tsujita, Y., Gebauer, G., Hashimoto, T., Umata, H., \& Yukawa, T. (2009). Evidence for novel and specialized mycorrhizal parasitism: the orchid Gastrodia confusa gains carbon from saprotrophic Mycena. Proceedings. BiologicalSciences / The RoyalSociety, 276(1657), 7617. doi:10.1098/rspb.2008.1225

Panaccione, D. G., Sheets, N. L., Miller, S. P., \& Cumming, J. R. (2001). Diversity of Cenococcum geophilum Isolates from Serpentine and Non-Serpentine Soils. Mycologia, 93(4), 645. doi:10.2307/3761819

Pandey, M., Sharma, J., Taylor, D. L., \& Yadon, V. L. (2013). A narrowly endemic photosynthetic orchid is non-specific in its mycorrhizal associations. Molecular Ecology, 22, 2341-2354. doi:10.1111/mec.12249

Phillips, R. D., Barrett, M. D., Dixon, K. W., \& Hopper, S. D. (2011). Do mycorrhizal symbioses cause rarity in orchids? Journal of Ecology, 99(3), 858-869. doi:10.1111/j.1365-2745.2011.01797.x

Rasmussen, H. N. (1995). Terrestrial orchids from seed to mycotrophic plant. Melbourne: Cambridge University Press.

Rasmussen, H. N. (2002). Recent developments in the study of orchid mycorrhiza. Plant and Soil, 244, 169-163. doi:10.1023/A:1020246715436

Raven, P. H., Evert, R. F., \& Eichhorn, S. E. (2005). Fungi. In Biology of Plants (7th Ed., pp. 260295). New York: W. H. Freeman and Company.

Read, D. J. (1996). The Structure and Function of the Ericoid Mycorrhizal Root. Annals of Botany, 77(4), 365-374. doi:10.1006/anbo.1996.0044

Roche, S. a, Carter, R. J., Peakall, R., Smith, L. M., Whitehead, M. R., \& Linde, C. C. (2010). A narrow group of monophyletic Tulasnella (Tulasnellaceae) symbiont lineages are associated with multiple species of Chiloglottis (Orchidaceae): Implications for orchid diversity. American Journal of Botany, 97(8), 1313-27. doi:10.3732/ajb.1000049

Salifah, H. A. B., Muskhazli, M., Rusea, G., \& Nithiyaa, P. (2011). Variation in Mycorrhizal Specificity for In Vitro Symbiotic Seed Germination of Grammatophyllum speciosum Blume. Sains Malaysiana, 4O(5), 451-455.

Sathiyadash, K., Muthukumar, T., Murugan, S. B., Sathishkumar, R., \& Pandey, R. R. (2014). In vitro symbiotic seed germination of South Indian endemic orchid Coelogyne nervosa. Mycoscience, 55(3), 183-189. doi:10.1016/j.myc.2013.08.005

Sen, S., Acharya, R., Saha, A., \& Acharya, K. (2006). A New Report of Cymbidium spp. Pseudobulb Rot Orchestrated by Erwinia carotovora, Fusarium oxysporum, and Mucor hiemalis f. sp. hiemalis. Plant Disease, 90(11), 1460-1460. doi:10.1094/PD-90-1460C

Sharpe, R. G., Harbach, R. E., \& Butlin, R. K. (2000). Molecularvariation and phylogeny of members of the Minimus Group of Anopheles subgenus Cellia (Diptera: Culicidae). Systematic Entomology, 25(2), 263-272. doi:10.1046/j.1365-3113.2000.00118.x

Sneath, P. H. A., \& Sokal, R. R. (1973). Numerical Taxonomy: The Principles and Practice of NumericalClassification (p. 573). San Francisco: W. H. Freeman. 
Steinfort, U., Verdugo, G., Besoain, X., \& Cisternas, M. a. (2010). Mycorrhizal association and symbiotic germination of the terrestrial orchid Bipinnula fimbriata (Poepp.) Johnst (Orchidaceae). Flora - Morphology, Distribution, Functional Ecology of Plants, 205(12), 811817. doi:10.1016/j.flora.2010.01.005

Stewart, S. L., \& Zettler, L. W. (2002). Symbiotic germination of three semi-aquatic rein orchids (Habenaria repens, H. quinquiseta, H. macroceratitis) from Florida. Aquatic Botany, 72(1), 25-35. doi:10.1016/S0304-3770(01)00214-5

Swarts, N. D., \& Dixon, K. W. (2009). Perspectives on orchid conservation in botanic gardens. Trends in Plant Science, 14(11), 590-8. doi:10.1016/j.tplants.2009.07.008

Tamura, K., Stecher, G., Peterson, D., Filipski, A., \& Kumar, S. (2013). MEGA6: Molecular Evolutionary Genetics Analysis version 6.0. Molecular Biology and Evolution, 30(12), 2725-9. doi:10.1093/molbev/mst197

Taylor, D. L. (2004). Myco-heterotroph-fungus marriages — is fidelity over-rated? New Phytologist, 163(2), 217-221.

Taylor, D. L., \& Bruns, T. D. (1999). Population, habitat and genetic correlates of mycorrhizal specialization in the "cheating" orchids Corallorhiza maculata and C. mertensiana. Molecular Ecology, 8(10), 1719-32. Retrieved from http://www.ncbi.nlm.nih.gov/pubmed/10583834

Taylor, D. L., \& McCormick, M. K. (2008). Internal transcribed spacer primers and sequences for improved characterization of basidiomycetous orchid mycorrhizas. The New Phytologist, 177(4), 1020-33. doi:10.1111/j.1469-8137.2007.02320.x

Těšitelová, T., Těšitel, J., Jersáková, J., Ríhová, G., \& Selosse, M.-A. (2012). Symbiotic germination capability of four Epipactis species (Orchidaceae) is broader than expected from adult ecology. American Journal of Botany, 99(6), 1020-32. doi:10.3732/ajb.1100503

Wang, Y., Liu, X., \& Zheng, R. (2013). Four New Species Records of Umbelopsis ( Mucoromycotina ) from China, 2013(Figure 1), 1-2.

Warcup, J. H. (1981). The mycorrhizal relationships of Australian orchids. New Phytologist, 87(2), 371-381. doi:10.1111/j.1469-8137.1981.tb03208.x

Wardle, P. (1991). Vegetation of New Zealand (p. 679). Cambridge: University of Cambridge.

Watkins, R. L. S. (2012). The biogeography, ecology and endophyte mycorrhiza of the New Zealand Corybas alliance (Orchidaceae) : specifically, Nematoceras iridescens (Irwin et Molloy) Molloy, D.L.Jones \& M.A.Clem. (species). Massey University. Retrieved from http://hdl.handle.net/10179/4063

White, T. J., Bruns, T. D., Lee, S., \& Taylor, J. W. (1990). Amplification and Direct Sequencing of Fungal Ribosomal RNA Genes for Phylogenetics. In M. A. Innis, D. H. Gelfand, J. J. Sninsky, \& T. J. White (Eds.), PCR Protocols A guide to methods and applications (pp. 315-322). San Diego: Academic Press.

Yee, T. W. (2010). The VGAM Package for Categorical Data Analysis. Journal of Statistical Software, 32(10), 1-34. Retrieved from http://www.jstatsoft.org/v32/i10 


\section{Chapter 3: In situ germination of two terrestrial orchids: Microtis unifolia and Thelymitra longifolia, within an urban bush reserve in Wellington}

\section{Introduction}

Urban remnant forest parks are an important buffer to the loss of biodiversity in cities. They often serve as a refuge for insects (Soga, Yamaura, Koike, \& Gaston, 2014) and plants (Alvey, 2006). Conserving and expanding parks is becoming increasingly important as urban land use increases. A 'restoration ecology' approach considers population, community and ecology (Young, 2000) and is more than just revegetation of sites. Mycorrhizal fungi can play a large part in the vigour and success of plant communities in restoration sites (White, Tallaksen, \& Charvat, 2008). Orchids in particular, are reliant on mycorrhizae to enter the seed and facilitate germination in the field (Rasmussen, 1995). These fungi can live freely in the soil as saprophytes and do not rely on orchid hosts (Brundrett, 2007).

Germination of orchid seed in the field is not straightforward due to the small 'dust' seeds that can range in size from 0.25-1.2mm (Arditti, 1967). There are two distinct approaches to studying the germination of orchids: in vitro (see Chapter 4) and in situ. In vitro experiments are conducted in a laboratory and thus independent of climatic and edaphic factors (Brundrett, 2007). However, it has been long known that orchid germination should be studied in situ in the field because fungal endosymbionts determined by in vitro germination tests may not apply to field conditions (Warcup, 1975). Therefore, orchid seed baiting techniques were developed for in situ experiments by Rasmussen and Whigham (1993) to detect the presence of suitable mycorrhizae and test factors affecting orchid seed germination. In situ experiments enable the identification of suitable orchid habitats and may demonstrate the distribution of beneficial mycorrhizae (Brundrett, 2007) and detect suitable relocation sites (Brundrett, 2007), which is particularly important for restoration projects.

Otari-Wilton's Bush is an urban podocarp/broadleaf forest remnant in Wellington, New Zealand (NZ). Two relatively common orchids, Microtis unifolia (Forst. f.) Reichb. f. and Thelymitra longifolia J.R. Forst. \& G. Forst. were first recorded in Otari-Wilton's bush in 1934 (Reid, 1935). Thelymitra longifolia was not found in the 1992 survey (Marjot, 1992) but has been rediscovered in recent years. Microtis unifolia is widespread in the 
park, but $T$. longifolia occurs at just one site. Microtis unifolia (Figure 3., Left) is NZ's most common orchid (Scanlen \& St George, 2011) and it is sometimes regarded as a species aggregate (De Lange, Rolfe, St George, \& Sawyer, 2007). Microtis unifolia commonly grows in urban areas and disturbed habitats (De Lange et al., 2007). It is a robust plant that has a single tubular leaf from which the single flowering stem emerges (Cooper, 1989). It produces a dense inflorescence of small green flowers from September to December (Scanlen \& St George, 2011). Thelymitra longifolia (Figure 3., Right) is also widespread and grows in a range of habitats, from enclosed forest floors to open fields (De Lange et al., 2007). Similar to M. unifolia, T. longifolia is also sometimes regarded as a species aggregate and there are a number of taxonomically undescribed forms which have an affinity to this species (Scanlen \& St George, 2011). Thelymitra longifolia produces a single leaf and a flowering stem with few to 15 flowers during October to February (Cooper, 1989). The flowers of $T$. longifolia are 10-15 mm across and have undifferentiated sepals and petals (Cooper, 1989). Underground, both M. unifolia and T. longifolia produce tubers from which the plant will emerge the following year (Crowe, 2004). Both of these orchids are indigenous but not endemic to NZ (De Lange et al., 2007). They are well-studied in Australia and have been included in a number of in situ germination (Dowling \& Jusaitis, 2012) and ex situ germination experiments (Warcup, 1973) 


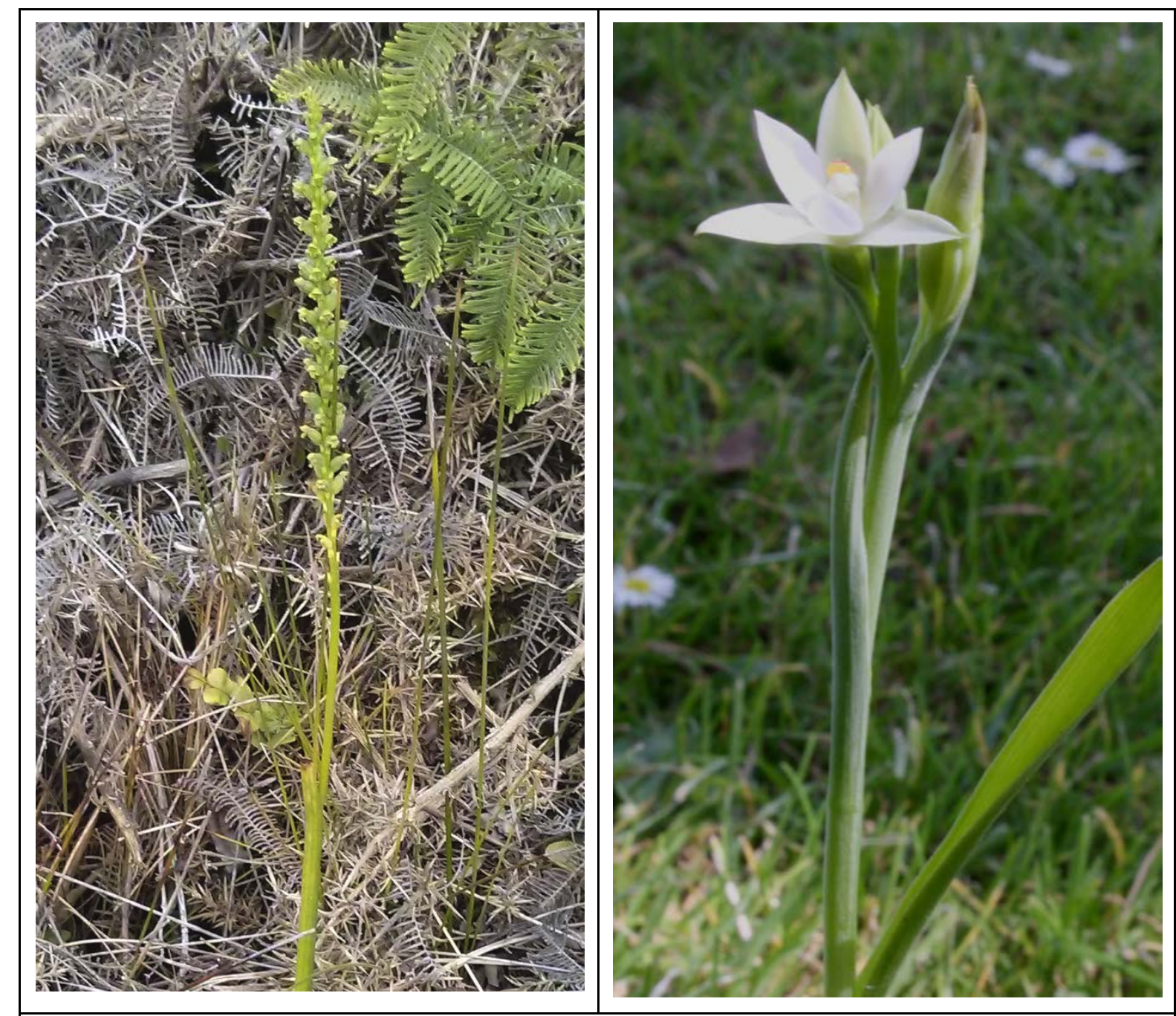

Figure 3.1. Microtis unifolia (left) and Thelymitra longifolia (right).

Identification of mycorrhizae based in morphology is difficult but molecular methods have demonstrated that orchid mycorrhizal associations are formed within a small group of fungi when compared to the mycorrhizae of all photosynthetic plants (De Long, Swarts, Dixon, \& Egerton-Warburton, 2013). In orchids, most commonly these endosymbionts belong to the genus Ceratobasium, Rhizoctonia, Sebacina or Tulasnella (Rasmussen 1995). In a comprehensive study of in vitro germination, Warcup (1981) found that $T$. longifolia could be successfully germinated in vitro with a range of Tulasnella species (T. calospora, T. asymmetrica, T. cruciate, T. irregularis, T. violea, and $T$. allantospora). Microtis unifolia was successfully germinated using Sebacina vermifera and T. calospora but no other Tulasnella species were included in the study. The T. calospora culture had been isolated from Thelymitra longifolia. It is plausible that these two orchid species share the same mycorrhizae. 
The aim of this chapter was to: 1 ) assess germination rates of $M$. unifolia and $T$. longifolia seed at four sites in Otari-Wilton's Bush, 2) to assess whether proximity to $M$. unifolia and $T$. longifolia plants enhances germination of these species at small spatial scales ( $\leq 1$ metre) distance-based pattern of suitable recruitment sites around established M. unifolia and T. longifolia, . 3) to assess seed viability before and after the experiment in order to determine whether seed retained their potential to germinate. Additionally, this study aims to identify which mycorrhiza species facilitates germination M. unifolia and $T$. longifolia within Otari-Wilton's Bush. 


\section{Methods}

\section{Study site}

The entire Otari-Wilton's Bush site covers approximately 100 hectares of NZ native forest on the floor and slopes of a valley which runs northeast-to-southwest. There are approximately 5 hectares of cultivated NZ native plant collections on the south-eastern side of the valley and a remnant broadleaf/podocarp forest of approximately 56 hectares (Marjot, 1992). The remainder is regenerating and replanted broadleaf/podocarp forest. It is surrounded on 3 sides by suburban housing, farm land, and wild scrubland and is $5 \mathrm{~km}$ from the Wellington city centre. The forest is largely made up of Dysoxylum spectabile (Kohekohe), Beilschmiedia tawa (Tawa), and Knightia excelsa (Rewarewa), but it also hosts conifers such as Dacrydium cupressinum (Rimu) and Prumnopitys taxifolia (Matai).

\section{Seed collection and viability assay}

Seeds of M. unifolia and T. longifolia were collected in December 2012 from mature seed pods collected from a single site for each species at Otari-Wilton's Bush. The collected seeds were stored in dark and dry conditions at room temperature until the start of the growing season ( 6 months).

Seeds were sterilised using $2 \%$ calcium hypochlorite with $2 \mathrm{ml}$ of Tween80 while placed on a stirring platform for 10 minutes. Seeds were then washed 3 times in sterile double distilled water $\left(\mathrm{dd}_{2} \mathrm{O}\right)$. Random seed samples of each species were soaked in $\mathrm{dd}_{2} \mathrm{O}$ for 20 hours, followed by a solution of $0.5 \%$ fluorescein diacetate (FDA) in acetone for 10 minutes before photographing under fluorescence microscope using a FITC filter. Viability scores were calculated by percentage of fluorescing seed in counts at five random locations on the slide, for both orchid species. The FDA stain assay was carried out prior to the experiment and after the experiment. A total of $178 \mathrm{M}$. unifolia seeds and $242 T$. longifolia seeds were counted prior to the experiment. For post-experiment viability rates, a total of 4,189 M. unifolia seeds were and 3,873 T. longifolia seeds were counted.

\section{Seed baiting}

The seed baiting technique used fine mesh packets that are buried in the field during the growing season and help to evaluate the presence and distribution of mycorrhizae which facilitate germination (Swarts \& Dixon, 2009). Small seed packets were assembled using Sefar 90 micron nylon mesh (Brundrett, Scade, Batty, Dixon, \& Sivasithamparam, 2003) and flagging tape so that there were two separate compartments on either side of an attachment zone for the flagging tape (Figure 3.2). The seed packets were split into compartments so that different sources of seed in each compartment may 
be used to detect variation in germination among seed sources (Brundrett et al., 2003). On one side a small amount of $M$. unifolia seeds were placed, and in the opposite side, a small amount of $T$. longifolia seed. The 40 packets were then sealed and stored in dry, dark conditions for 4 days. Each seed packet contained 2,874 \pm 675 (95\% C.I.) seeds of M. unifolia and 3,188 \pm 719 (95\% C.I.) seeds of T. longifolia.

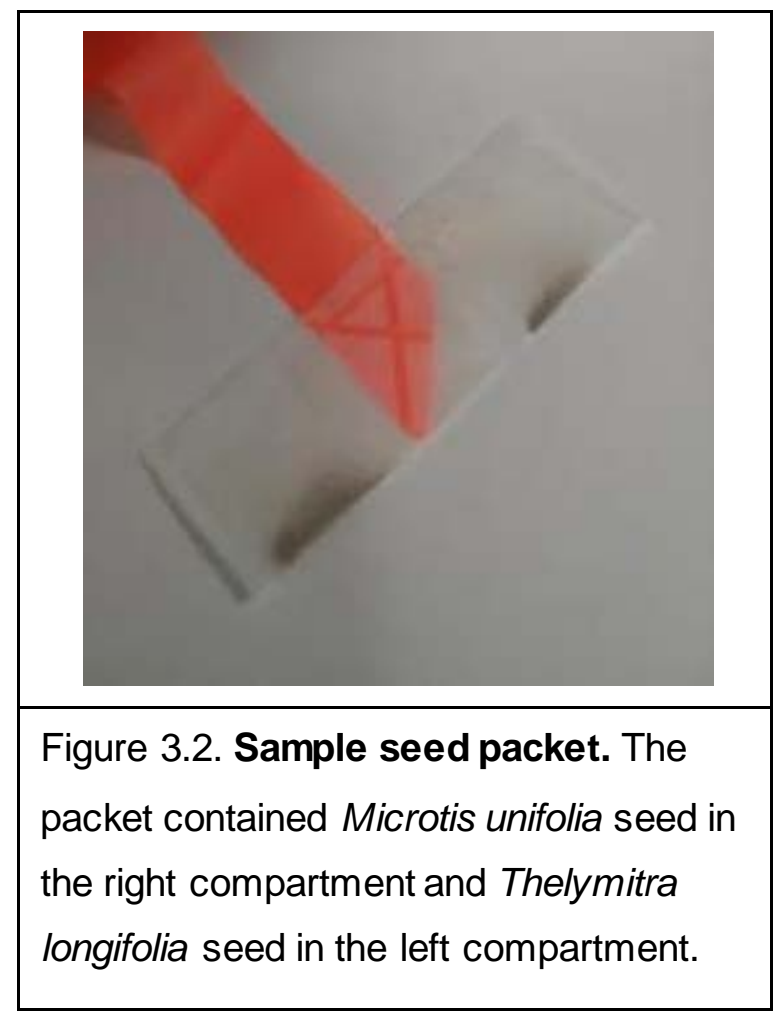

Seed packets were buried on the $7^{\text {th }}$ of June 2013, at four sites in Otari-Wilton's Bush, 14 days before the winter solstice. At sites $A, C$ and $D$, transects originated from an established adult orchid so that packets were at 0 metres, 0.25 metres, 0.5 metres and 1 metre from an adult plant. Site $A$ was in a location where there were no $M$. unifolia plants but $T$. longifolia was present. At Site $C$ and $D, M$. unifolia was present and there were no T. longifolia plants (Figure 3.3). Site B had no orchids present and was used as a control site. Seed packets in this site were spaced in the same way as in sites A, C, and D but originated from random locations within the site. All packets were buried so that their upper edge emerged from the soil and the flagging tape marker was visible. Seeds packets were recovered after 150 days and packets were searched for seeds which had developed to stage 1 or further. Seeds were placed on Oatmeal Agar in vitro, as negative controls, to establish whether seeds would progress in the absence of factors found in the field. 


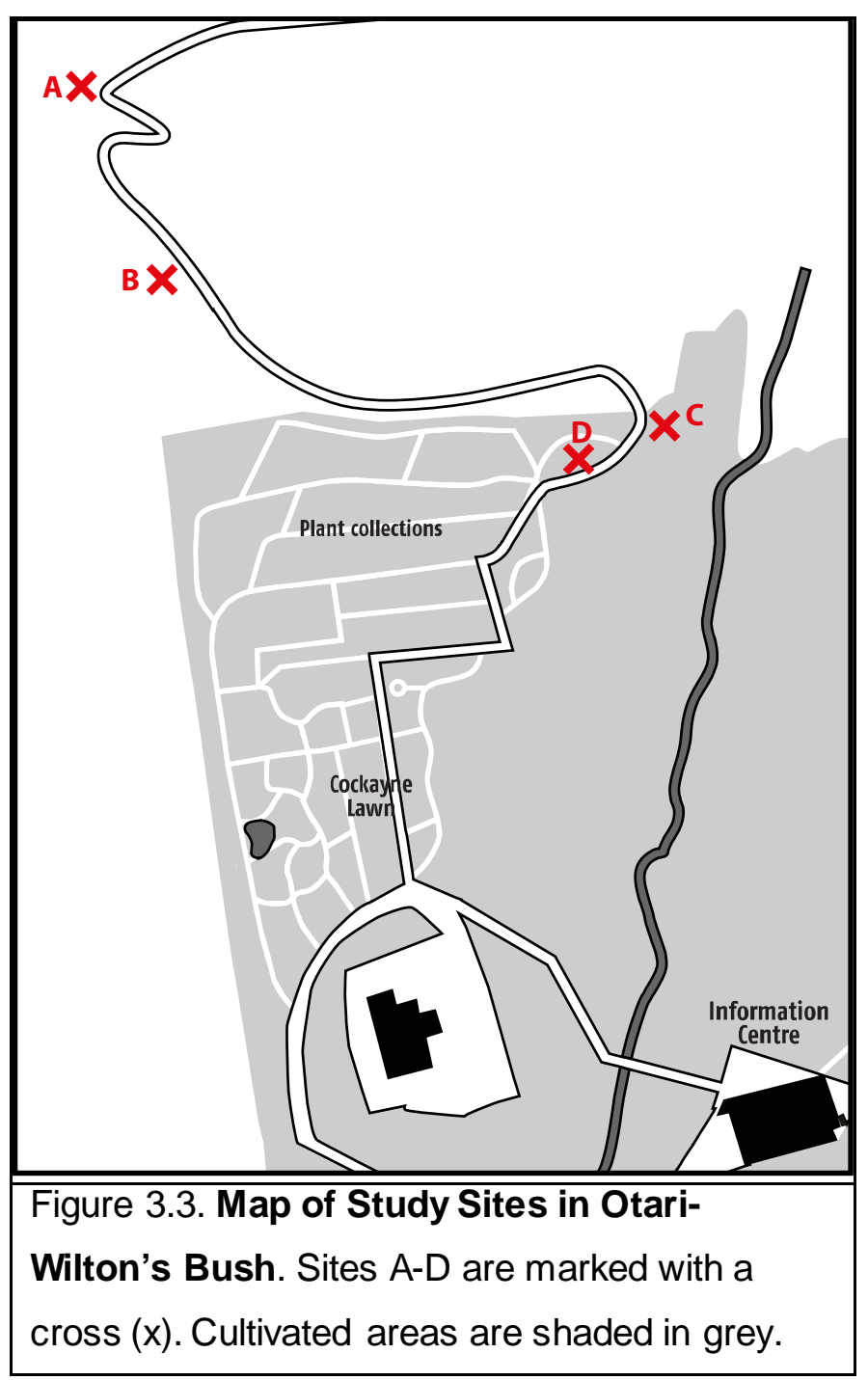

Table 3.1. Locations of In Situ Sites

\begin{tabular}{lllll}
\hline Site & $\begin{array}{l}\text { Orchid present at } \\
\text { site }\end{array}$ & $\begin{array}{l}\text { No. of } \\
\text { transects }\end{array}$ & Latitude & Longitude \\
\hline Site A & T. longifolia & 3 & -41.266766 & 174.755409 \\
Site B & None & 3 & -41.266997 & 174.756184 \\
Site C & M. unifolia & 2 & -41.267193 & 174.756889 \\
Site D & M. unifolia & 2 & -41.267339 & 174.756681 \\
\hline
\end{tabular}




\section{Sequencing and identification}

Two randomly selected protocorms of $M$. unifolia and two protocorms of $T$. longifolia were bisected and each half was placed directly into a $0.2 \mu$ tube, a method modified from Hynson et al. (2013). The primer pairs ITS1OF-ITS4OF were used to amplify for one half of the protocorm and ITS1a-ITS4-Tul to amplify with the other half of the protocorm (details for primers are in chapter 2). Each $20 \mu \mathrm{lPCR}$ also contained $1 \mathrm{M}$ betaine, $75 \mathrm{mM}$ Tris- $\mathrm{HCl}$ (pH8.8), $20 \mathrm{mM}$ ammonium sulphate, $2.5 \mathrm{mM} \mathrm{MgCl}, 0.5 \mu \mathrm{M}$ forward primer, $0.5 \mu \mathrm{M}$ reverse primer, $0.25 \mathrm{mM}$ of each deoxynucleotide (dATP, dCTP, dGTP and dTTP), $1 \cup(0.2 \mu l)$ Thermo Fisher Scientific Red Hot Taq DNA polymerase, and $0.01 \%(\mathrm{v} / \mathrm{v})$ Tween 20. In cases where PCR yields were low, $2 \mathrm{mg} / \mathrm{ml}$ BSA was added to preferentially bind to inhibiting factors (Farell \& Alexandre, 2012).

The ITS region was amplified by an initial denaturing stage of $95^{\circ} \mathrm{C}$ for 2 minutes followed by 35 cycles of $95{ }^{\circ} \mathrm{C}$ for 1 minute, $55^{\circ} \mathrm{C}$ for 1 min and $72{ }^{\circ} \mathrm{C}$ for 1 minute 30 seconds, culminating with an additional extension stage of $72{ }^{\circ} \mathrm{C}$ for 5 minutes. To clean up the resultant PCR products for DNA sequencing, Exonuclease I digested single stranded oligonucleotides and Shrimp Alkaline Phosphatase removed phosphate groups from excess dNTPs.

DNA sequencing reactions of $2.5 \mu \mathrm{M}$ forward or reverse primer and approximately $200 \mathrm{ng}$ of DNA were made up to a final volume of $10 \mu \mathrm{l}$ with $\mathrm{ddH}_{2} \mathrm{O}$ and run on the Applied Biosystems 3730xl DNA Analyzer by Macrogen Inc. (Seoul, South Korea).

The DNA sequences were edited with Geneious 4.8 and BLAST database queries of GenBank (Benson, Karsch-Mizrachi, Lipman, Ostell, \& Wheeler, 2005) identified closest formally identified match. Other voucher specimens and accessions representing closely related ( $\geq 89 \%$ identity) fungi isolated from other Microtis species were also included.

To determine the phylogenetic affinities among vouchered Tulasnella calospora and Tulasnella recovered from other Microtis species (as indicated in data fields of GenBank accessions), ITS accessions from GenBank and ITS DNA sequences generated in this study were aligned using the program MUSCLE. Model testing was carried out and a maximum likelihood phylogram was generated in MEGA6 using all sites and with 1000 bootstrap replicates. The outgroup used for the T. calospora phylogram was Multiclava mucida (GENBANK accession AF287875.1) after Suárez et al. (2006). 


\section{Results}

\section{Seed viability is much lower after 150 days in the soil}

The FDA assay (see example photo in Chapter 2) indicated that $52 \%$ of $M$. unifolia seed were viable prior to the field experiment and the mean seed viability across all sites after 150 days was $0.98 \%$. Similarly, $64 \%$ of $T$. longifolia seeds were viable prior planting, and viability dropped to $1.99 \%$ after 150 days. There were no viable $M$. unifolia seeds in site $B$ (control) after 150 days (Figure 3.4). These findings demonstrated that the seeds were viable and amenable prior to the field experiment.

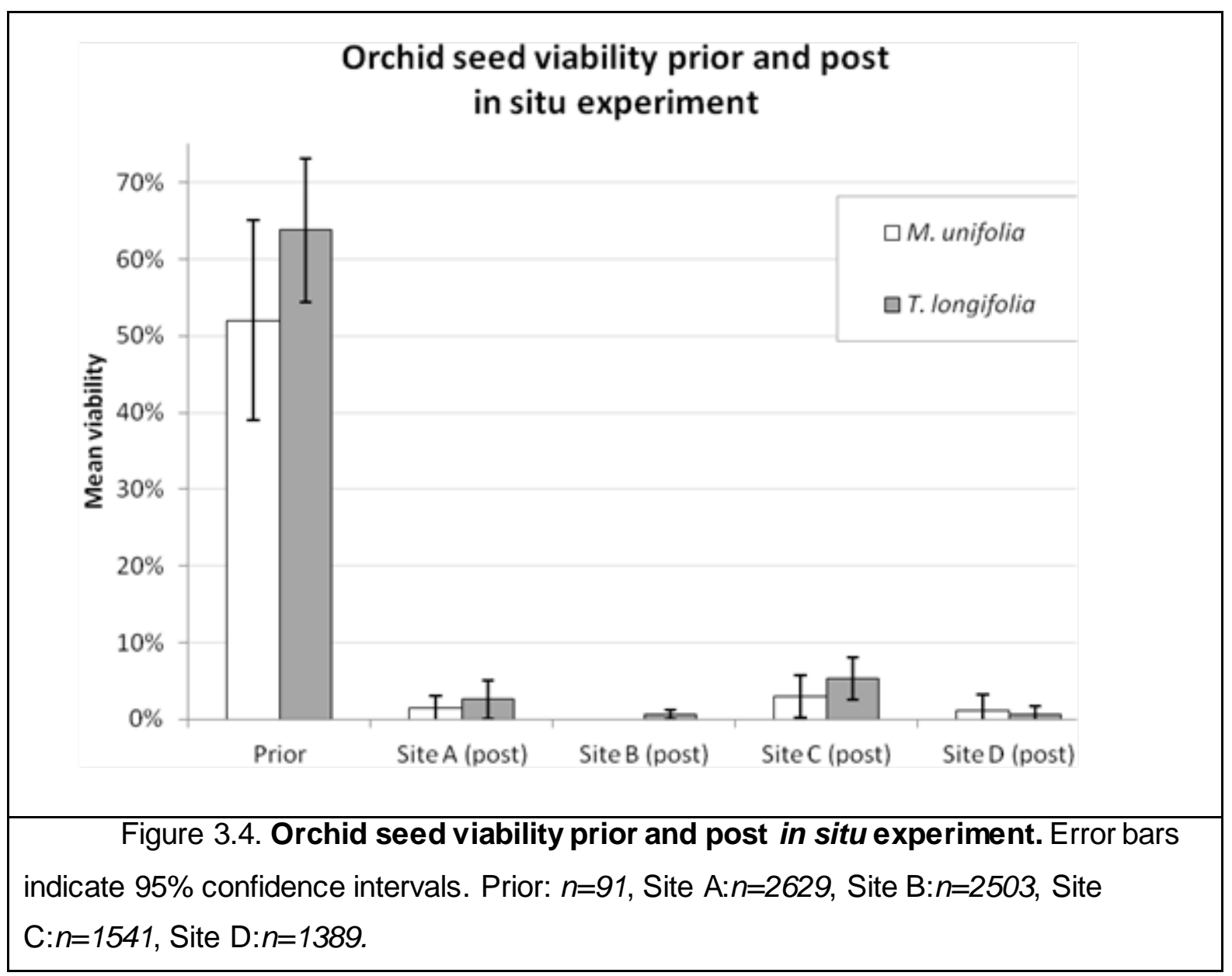

\section{Germination rates were low}

Seeds were considered to be germinated if they had progressed beyond stage 2 because the negative controls of $M$. unifolia and $T$. longifolia in the lab progressed to stage 2 but no further. After 150 days a total of $34(0.03 \%)$ M. unifolia and $30(0.02 \%) T$. longifolia seeds had progressed beyond stage 2 (for a description of the stages see Chapter 1). There were 22 germinated seeds of $M$. unifolia in Site A and 12 in the control 
Site B. No seeds of $M$. unifolia germinated at Site C or Site D. Only 10 seeds of $T$. longifolia germinated at Site A, Site B (control) and Site C, but none at Site D (Figure 3.5).

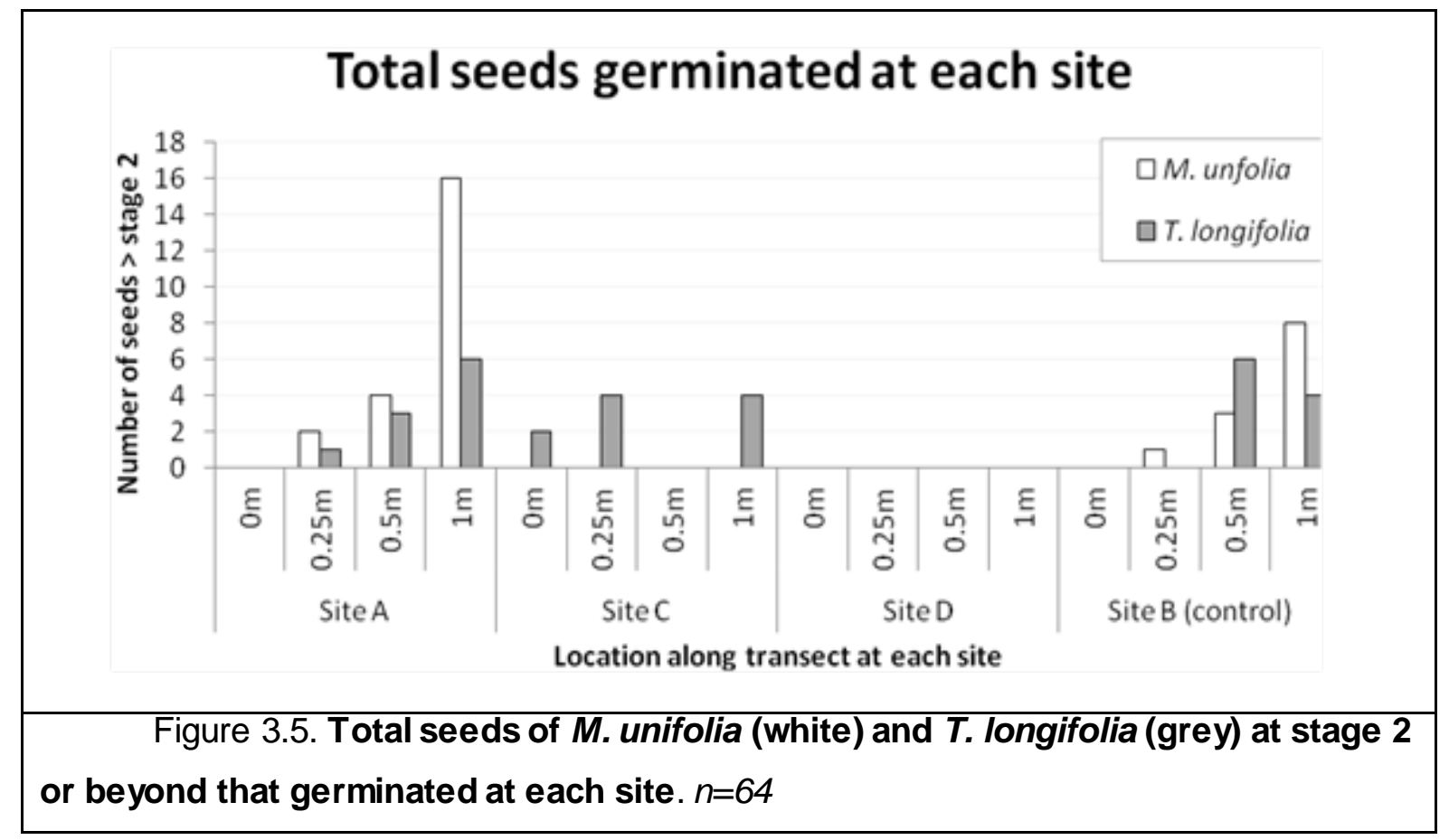

\section{Germination along transects was variable}

Transects at Site B (control) did not originate from an established adult orchid, and therefore were excluded from the following data pooled from all other sites. For M. unifolia there was no germination right next to an adult plant (0 metres) at all sites; two seeds germinated at 0.25 metres; four seeds germinated at 0.5 metres and; 16 seeds germinated at 1 metre. There was a strong positive correlation $(r=0.9640)$ between number of seeds germinated and distance from established orchid of $M$. unifolia (Figure 3.6, Left). For $T$. longifolia, two seeds germinated at 0 metres; five seeds germinated at 0.25 metres, three seeds germinated at 0.5 metres and; 10 seeds germinated at 1 metre. There was a moderately positive correlation $(r=0.8775)$ between number of seeds germinated and distance from established orchid of $T$. longifolia, (Figure 3.6, Right). 


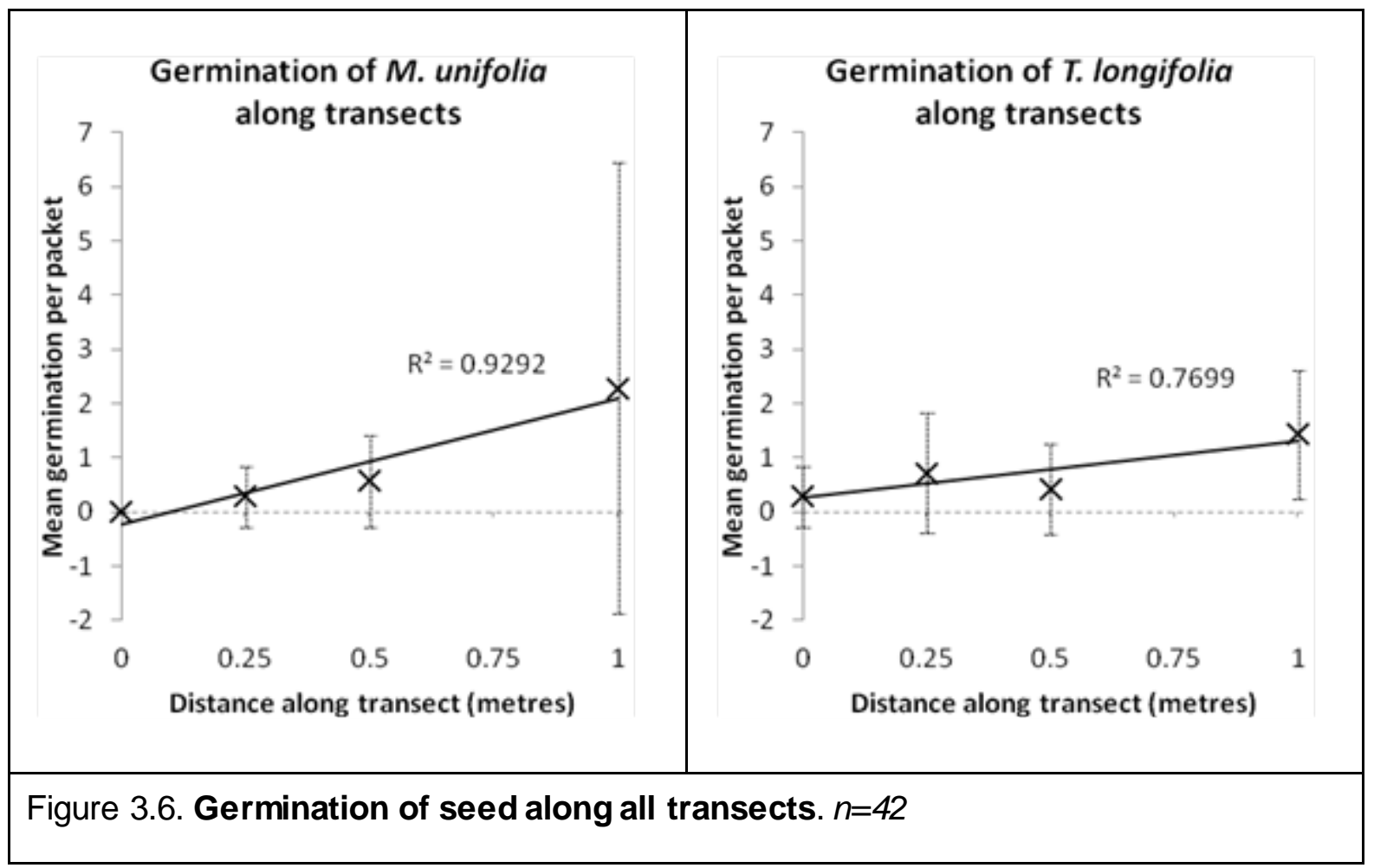

Most of the seed that had germinated, did not develop beyond stage 4, however, one packet recovered from a transect at Site B (control) contained six seedlings of M unifolia (Figure 3.7).

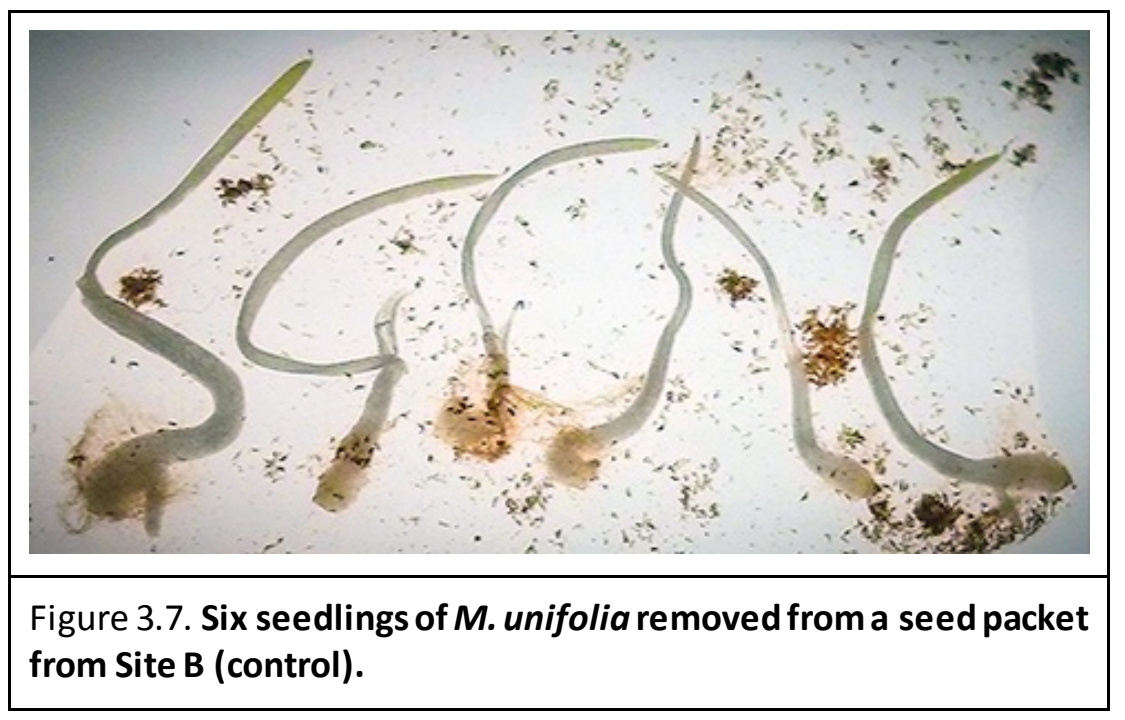




\section{Endomycorrhiza recovered from a $M$. unifolia protocorm}

To identify the fungi that contributed to seed germination in the field, two different primer pairs were used. Only one direct PCR of the bisected protocorm of $M$. unifolia using the primers ITS1a-ITS4-Tul successfully amplified a product, 563bp in length. The sequence was a 97\% match with a Tulasnella calospora (AY643804.3) isolated from Microtis parviflora in New South Wales, Australia (Bougoure, Bougoure, Cairney, \& Dearnaley, 2005) and a 96\% match with a vouchered specimen Tulasnella calospora (Boudier) Juel (DQ388044.1) isolated from an Australian Thelymitra antennifera (Lindl.) Hook.f (Warcup \& Talbot, 1967; Suárez et al., 2006).

The protocorm PCRs did not amplify a target fragment using the ITS1OF-ITS4OF primer pair, nor was there any amplification using ITS1a-ITS4-Tul with T. longifolia protocorms. It may have been that the cells did not heat up enough for the cell walls to be broken down sufficiently and to release the DNA. Boiling the protocorm at $100{ }^{\circ} \mathrm{C}$ rather than the $95{ }^{\circ} \mathrm{C}$ cycling temperature may have had a consistently better effect on releasing the template DNA (Hynson et al., 2013).

To demonstrate phylogenetic affinities among vouchered Tulasnella calospora and Tulasnella recovered from other Microtis species, a maximum likelihood tree was generated. The alignment of nine ITS sequences from T. calospora and Multiclavula mucida was 995 characters in length, of which 353 were conserved, 642 were variable but parsimony uninformative, and 58 were parsimony informative. The model testing procedure showed that the Kimura two-parameter model (Kimura, 1980) with a Gamma distribution to be the best, with a log likelihood of -2652.5439. A discrete Gamma distribution with five categories was used to model evolutionary rate differences among sites $(+G$, parameter $=0.9791)$ (Figure 3.8). The $T$. calospora sequence generated by this study is sister to the T. calospora isolated from M. parviflora (AY643804.3) with a bootstrap value of $93 \%$. Both of these $T$. calospora strains form a clade sister to the voucher accession for T. calospora (DQ88044.1). Both of the Tulasnellaceae isolated from $M$. capularis group together strongly (98\%), and form a highly supported clade with all the aforementioned sequences (89\%). A second divergent clade features two vouchered specimens of T. calospora (AY373298.1, EU218888.2), and nested within this clade is a Tulasnellaceae isolated from an undefined Microtis species. 


\begin{tabular}{|l|l|}
\hline & \\
\hline & \\
\hline
\end{tabular}




\section{Discussion}

This chapter reports on a set of experiments that investigated germination rates of M. unifolia and T. longifolia at four sites in Otari-Wilton's Bush and investigated the smallscale ( $\leq 1$ metre) distance-based pattern of suitable recruitment sites around established $M$. unifolia and $T$. Iongifolia. Seed viability of was assessed before and after the experiment. Additionally, this study identified which mycorrhiza facilitates germination $M$. unifolia but not $T$. longifolia within Otari-Wilton's Bush.

\section{The seeds are unlikely to remain in the seed bank}

For both $M$. unifolia and $T$. longifolia, the viability at the start of the field study was moderate-to-low, at $52 \%$ and $64 \%$ respectively. Data on the viability of seeds from NZ orchids is scarce and there are no published surveys of seed viability of NZ populations of M. unifolia or T. Iongifolia. In Eastbourne, Wellington, seeds from M. unifolia were $67 \%$ viable and seed from three sites of $T$. longifolia ranged from $64 \%$ to $93 \%$ viable (see Chapter 2). In comparison, an Australian study found that Thelymitra pauciflora seeds had $81.1 \%$ viability, and Microtis arenaria had $85.9 \%$ viability (Dowling \& Jusaitis, 2012). Seed viability may be linked to the length of time in storage. Prichard (1985) suggested that the length of time that orchid seeds are stored may be linked to the reductions in viability and this may explain the moderate viability scores obtained in the present study. However, Pritchard's study attempted to simulate the aging process by raising the seed storage temperature, but their finding was probably of limited use because adjusting the temperature is an unrealistic way of estimating the range of effects that might influence the rates of seed viability loss over time.

The range of suitable lengths of time for seed packets to remain in the soil will vary between species (Rasmussen \& Whigham, 1993) and the longevity of viable seeds in the field may also vary between species and between studies. For instance, in Australia an experiment with Drakaea orchid seeds, the baits remained in the soil for only 120 days before germination was assed (Phillips, Barrett, Dixon, \& Hopper, 2011) while there are reports of seed remaining viable beyond two years (Whigham, O'Neill, Rasmussen, Caldwell, \& McCormick, 2006). For many taxa, seeds should be buried in the beginning of the wet season and removed late in the growing season (Brundrett et al., 2003), which was the approach taken for this study.

The viability prior to the experiment is contrasted by the very low viability of seeds of M. unifolia (0.98\%) and T. longifolia (1.98\%) recovered from all sites after 150 days (Figure 3.4). This suggests that seed from $M$. unifolia and $T$. longifolia are not likely to persist in the seed bank for more than one year and that they form part of the transient 
seed bank (Thompson \& Grime, 1979). Therefore it is unlikely that lengthening the period that the seeds were buried would have significantly increased seed germination rates to higher than $1.01 \%$ for $M$. unifolia and $2 \%$ for $T$. longifolia. The mechanisms responsible for a significant loss of viability are still largely unknown.

Although the use of FDA for viability testing orchid seed viability is common (Dowling \& Jusaitis, 2012), it may underestimate viability in some species (Wood, Pritchard, \& Mugambi, 2003). Further studies with asymbiotic media may be useful to demonstrate whether viability assayed by FDA underestimated seed viability (Dowling \& Jusaitis, 2012).

\section{Overall germination}

It was surprising that germination of $M$. unifolia seeds was so low $(0.03 \%)$ across all sites, although some seeds had developed beyond the protocorm stages (Figure 3.7). Germination of $T$. longifolia was also low across all sites (0.02\%). Seeds of both species tended to clump together in the packets and were initially hydrophobic upon recovery. Though germination sometimes occurred in these clumps, it may have had a negative influence on germination and may also have contributed to seed mortality. The germination rates of packets were similar to a study of a terrestrial mycorrhizal-generalist, Habenaria repens, which found germination rates less than $0.05 \%$ in sites outside of its current range (Keel, Zettler, \& Kaplin, 2011). On the other hand, a study in a urban remnant park in Perth, Australia included a similarly ruderal species: Microtis media, and found that in situ germination rates exceeded $45 \%$ (Brundrett et al., 2003). In their experiment, seed was sprinkled evenly on filter paper and the paper inserted into the packet. There have been no previous studies that report germination for $M$. unifolia or $T$. longifolia in NZ. In future studies it would be useful to compare rates inside and outside of the species' current range (or natural versus urbanised habitat).

\section{Highest germination rates occurred at less disturbed sites}

Germination of $M$. unifolia seeds occurred at Site A and at Site B (control), at which no M. unifolia adults were present, but germination did not occur at Site $C$ and Site $D$, at which plants of $M$. unifolia were present. This confirms that suitable mycorrhizae are present in Site A and Site B (control), though a precise estimate of its abundance and distribution remains unknown. The lack of germination at Site $C$ and Site D does not mean there was an to the absence of suitable mycorrhizae. It may be that the distribution of the mycorrhizal fungi is patchy (Scade, Brundrett, Batty, Dixon, \& Sivasithamparam, 2006) and in this occasion did not make contact with seed, or that seeds had lost their viability prior to mycorrhizal contact. 
Although the presence of established $M$. unifolia plants at Site $C$ and Site D suggest these sites may be suitable for recruitment, it may be that recruitment of $M$. unifolia does not take place at all in these cultivated gardens and current plants could have been introduced with mulch or topsoil from other sites. Both $M$. unifolia and $T$. longifolia produce tubers and this may have enabled their persistence. Tillage may have also enabled them to spread beyond the range of suitable recruitment sites. Additionally, the effect of pesticide or herbicide residues on symbiotic mycorrhizae is unknown and these could have been applied in these garden bed sites. Positive and negative effects on growth vigour of Basidiomycota species have been found in the presence of herbicide (Roca et al., 2009). Future studies should investigate the effects of common horticultural chemicals on orchid mycorrhizae.

The germination results of $T$. longifolia among sites were similar to those of $M$ unifolia, except that germination did occur at Site C. This indicates that a suitable mycorrhiza was present at these sites and that the soil cultivation practices may not create barriers to the recruitment of this species. It is interesting to note that germination of $T$. longifolia did occur at the site at which $T$. longifolia adult plants were present but also at other sites where it was absent.

Site A and Site B (control) had the highest rates of germination for both species and these sites are both relatively undisturbed with decaying leaf and abundant plant material. These sites were difficult to access. In contrast, the other two sites (Site C and Site D) were easily accessible cultivated gardens, although they were not tended in the duration of this study. Both of these plots had a history of cultivation involving soil movement and weeding, and are adjacent to areas that are regularly sprayed with herbicide. Site $C$ had thin pebble mulch over the surface of the soil and Site D was highly exposed with bare soil. All these physical features of site $C$ and $D$ may have prevented seed germination and, furthermore, the complete lack of germination of both $M$. unifolia and $T$. longifolia in site $D$ may be due to the absence of coarse organic matter which is an important habitat for orchid mycorrhizae (Brundrett et al., 2003).

\section{Higher replicates are needed to confirm a small scale germination pattern}

The germination of $M$. unifolia was strongly correlated with the distance from adult plant $(r=0.9760)$, with germination increasing as distance from an adult plant increases. The pattern was similar, but only slightly weaker for $T$. longifolia $(r=0.8775)$. However, these results should be considered with caution due to the high variation among transects and the resulting 95\% confidence intervals (C.I.) for each distance point (Figure 3.6). The effect of the high variation is compounded by the low number of transects (seven 
transects) that were pooled for each species. A correlation of distance appears to be present at the control site (Site B, Figure 3.5). The absence of adult orchids at this site supports the hypothesis that correlations found in this dataset may be artefacts. For both species, more than 30 transects would need to be tested in order to provide 95\% C.I. germination values that do not fall below zero, using the mean and standard deviation values from the current samples. To confirm a distance-based pattern for M. unifolia, in which the 95\% C.I. do not overlap, using the current mean and standard deviation, data from more than 170 transects would need to be pooled. When investigating small-scale patterns of germination, the level of resolution is important to consider. Some have found greater recruitment in sites containing established orchids of the same species (Brundrett et al., 2003). Others, on a finer scale (<1 metre), have found no increased germination nearer to established plants of the same species (Masuhara \& Katsuya, 1994). Finally, because of the packet size, it is difficult to obtain meaningful information to a finer scale using this method in situ.

\section{Tulasnella calospora facilitates M. unifolia germination at Otari-Wilton's Bush}

The endophyte of $M$. unifolia was identified as Tulasnella calospora, and the analysis of DNA sequences suggested it is closely related (95\%) to the voucher specimen of $T$. calospora isolated from an Australian Thelymitra species (Figure 3.8). Tulasnella calospora is said to be a 'universal' orchid symbiont (Jiang, Yang, Zhang, \& Fu, 2011) because it has been found to induce germination in a range of orchids from in vitro experiments (Warcup, 1981). The present study confirms the presence of this mycorrhiza inside M. unifolia roots in NZ. The protocorm samples of $T$. longifolia failed to yield PCR products using the Basidiomycota- and Tulasnella-specific primer pairs, which suggests that the endophyte was either not present or was not a basidiomycete. However, it may be possible that secondary metabolites were present and caused interference with the PCR assay (Schori, Appel, Kitko, \& Showalter, 2013). Though this is unlikely because orchid seeds are largely parenchymatous (Arditti, 1967) and are not known to contain inhibitive compounds (Cafasso, Widmer, \& Cozzolino, 2005).

The recruitment of all plants is largely determined by two properties: availability of seed and ecological properties at microsites (Eriksson \& Ehrlén, 1992). The orchid's 'dust seed' (Eriksson \& Kainulainen, 2011) reproduction strategy means that seed availability is less likely to have been a factor limiting their distribution. It follows that microsite factors limit orchid recruitment. In this study germination did occur in some seed packets, indicating that factors other than the absence of suitable mycorrhizal partners are responsible for low germination rates in both species. Data from this study suggests that seed mortality, evidenced by the drop of viability before and after the experiment, may be 
the primary cause of low germination. Future studies should explore whether climatic, edaphic or biotic factors affect seed and protocorm mortality. Physiological factors such as soil particle size, water level are microsite features known to affect autotrophic plants (Keddy \& Constabel, 1986) and may have similar effects on orchids. Interestingly, the $M$. unifolia seed packet containing the six well-developed plants (Figure 3.7) was buried in a tiny depression which formed a puddle on the surface. This may have helped by preventing desiccation and overcoming the hydrophobic effects of the dry seed coat (Weston, Perkins, \& Entwisle, 2005). Biotic factors may also influence the seed germination by directly reducing seed viability, or indirectly by parasitizing the endosymbiont. Some Trichoderma fungi have been successfully used to control Rhizoctonia solani (Naeimi et al., 2010), a plant crop pathogen closely related to orchid mycorrhizae. It may be that other Rhizoctonia may be similarly affected by mycotrophic fungi. More studies on orchid seed pathogens and parasites may expose biotic factors causing seed mortality (see Chapter 2) which could explain the patchy distributions of terrestrial orchids.

The results presented in this chapter demonstrated that seed of $M$. unifolia and $T$. longifolia may not remain in the seed bank after one year at the study sites at OtariWilton's Bush. The low germination - and therefore low recruitment - may be offset by the annual persistence of adult orchids by its tuberous root system. It has also shown that a wide range of factors may contribute to the recruitment of orchids in the field. It was shown that there are increased germination rates for $M$. unifolia and $T$. longifolia at sites that are undisturbed with a high degree of organic matter on the soil surface.

In future field experiments consideration should be taken for each seed packet to be placed just under the surface of the soil, not below the layer of organic material. Additionally, seed packets may achieve higher germination rates with small amount of organic matter placed inside them to act as bait for the saprophytic mycorrhizal fungi. Future field trials should also gather additional information on soil properties, topology and environmental conditions. The monitoring of fluctuating factors such as moisture, light and heat will provide further insights into microsite properties and how these may affect seed germination. 


\section{References}

Alvey, A. a. (2006). Promoting and preserving biodiversity in the urban forest. Urban Forestry \& Urban Greening, 5(4), 195-201. doi:10.1016/j.ufug.2006.09.003

Arditti, J. (1967). Factors Affecting the Germination of Orchid Seeds. Botanical Review, 33(1), 197.

Benson, D. a, Karsch-Mizrachi, I., Lipman, D. J., Ostell, J., \& Wheeler, D. L. (2005). GenBank. Nucleic Acids Research, 33(Database issue), D34-8. doi:10.1093/nar/gki063

Bougoure, J. J., Bougoure, D. S., Cairney, J. W. G., \& Dearnaley, J. D. W. (2005). ITS-RFLP and sequence analysis of endophytes from Acianthus, Caladenia and Pterostylis (Orchidaceae) in southeastern Queensland. Mycological Research, 109(Pt 4), 452-60. Retrieved from http://www.ncbi.nlm.nih.gov/pubmed/15912933

Brundrett, M. C. (2007). Scientific approaches to Australian temperate terrestrial orchid conservation. Australian Journal of Botany, 55(3), 293. doi:10.1071/BT06131

Brundrett, M. C., Scade, A., Batty, A. L., Dixon, K. W., \& Sivasithamparam, K. (2003). Development of in situ and ex situ seed baiting techniques to detect mycorrhizal fungi from terrestrial orchid habitats. Mycological Research, 107(10), 1210-1220. doi:10.1017/S0953756203008463

Cafasso, D., Widmer, a, \& Cozzolino, S. (2005). Chloroplast DNA inheritance in the orchid Anacamptis palustris using single-seed polymerase chain reaction. The Journal of Heredity, 96(1), 66-70. doi:10.1093/jhered/esi002

Cooper, D. (1989). New Zealand native orchids. A field guide. (p. 103). Wellington: Wellington Orchid Society Inc.

Crowe, A. (2004). A Field Guide to the Native Edible Plants of New Zealand (4th ed., p. 192). Auckland: Penguin Group.

De Lange, P. J., Rolfe, J., St George, I., \& Sawyer, J. (2007). Wild orchids of the lower North Island. Wellington: New Zealand Department of Conservation.

De Long, J. R., Swarts, N. D., Dixon, K. W., \& Egerton-Warburton, L. M. (2013). Mycorrhizal preference promotes habitat invasion by a native Australian orchid: Microtis media. Annals of Botany, 111(3), 409-18. doi:10.1093/aob/mcs294

Dowling, N., \& Jusaitis, M. (2012). Asymbiotic in vitro germination and seed quality assessment of Australian terrestrial orchids. Australian Journal of Botany, 60(7), 592. doi:10.1071/BT12133

Eriksson, O., \& Kainulainen, K. (2011). The evolutionary ecology of dust seeds. Perspectives in Plant Ecology, Evolution and Systematics, 13(2), 73-87. doi:10.1016/j.ppees.2011.02.002

Farell, E. M., \& Alexandre, G. (2012). Bovine serum albumin further enhances the effects of organic solvents on increased yield of polymerase chain reaction of GC-rich templates. BMC Research Notes, 5(1), 257. doi:10.1186/1756-0500-5-257 
Hynson, N. a, Weiß, M., Preiss, K., Gebauer, G., \& Treseder, K. K. (2013). Fungal host specificity is not a bottleneck for the germination of Pyroleae species (Ericaceae) in a Bavarian forest. MolecularEcology, 22(5), 1473-81. doi:10.1111/mec.12180

Jiang, W., Yang, G., Zhang, C., \& Fu, C. (2011). Species composition and molecular analysis of symbiotic fungi in roots of Changnienia amoena (Orchidaceae). African Journal of Microbiology Research, 5(3), 222-228. doi:10.5897/AJMR10.479

Keddy, P. A., \& Constabel, P. (1986). Germination of Ten Shoreline Plants in Relation to Seed Size, Soil Particle Size and Water Level: An Experimental Study. Journal of Ecology, 74(1), 133141.

Keel, B. G., Zettler, L. W., \& Kaplin, B. A. (2011). Seed Germination of Habenaria repens (Orchidaceae) in situ Beyond its Range, and its Potential for Assisted Migration Imposed by Climate Change Seed Germination of Habenaria repens (Orchidaceae) in situ Beyond its Range, and its Potential for Assist, 76(1), 43-54.

Kimura, M. (1980). A simple method for estimating evolutionary rates of base substitutions through comparative studies of nucleotide sequences. Journal of Molecular Evolution, 16(2), 111-120. doi:10.1007/BF01731581

Marjot, Y. T. (1992). Sixty years of change in a forest reserve : Otari Plant Museum, Wilton, Wellington. Victoria University of Wellington.

Naeimi, S., Okhovvat, S. M., Javan-Nikkhah, M., Vágvölgyi, C., Khosravi, V., \& Kredics, L. (2010). Biological Control of Rhizoctonia solani AG1-1A, the Causal Agent of Rice Sheath Blight with Trichoderma Strains. Phytopathologia Mediterranea, 49, 287-300.

Phillips, R. D., Barrett, M. D., Dixon, K. W., \& Hopper, S. D. (2011). Do mycorrhizal symbioses cause rarity in orchids? Journal of Ecology, 99(3), 858-869. doi:10.1111/j.1365-2745.2011.01797.x

Pritchard, H. W. (1985). Determination of orchid seed viability using fluorescein diacetate. Plant, Cell and Environment, 8(9), 727-730. doi:10.1111/1365-3040.ep11611849

Rasmussen, H. N. (1995). Terrestrial orchids from seed to mycotrophic plant. Melbourne: Cambridge University Press.

Rasmussen, H. N., \& Whigham, D. F. (1993). Seed Ecology of Dust Seeds in Situ: A New Study Technique and Its Application in Terrestrial Orchids. American Journal of Botany, 80(12), 1374-1378.

Reid, J. S. (1935). A Preliminary Study of the Vegetation of Otari Plant Museum. Victoria University College.

Roca, E., D’Errico, E., Izzo, A., Strumia, S., Esposito, A., \& Fiorentino, A. (2009). In vitro saprotrophic basidiomycetes tolerance to pendimethalin. International Biodeterioration \& Biodegradation, 63(2), 182-186. doi:10.1016/j.ibiod.2008.08.004

Scade, A., Brundrett, M. C., Batty, A. L., Dixon, K. W., \& Sivasithamparam, K. (2006). Survival of transplanted terrestrial orchid seedlings in urban bushland habitats with high or low weed cover. Australian Journal of Botany, 54(4), 383-389. doi:10.1071/BT04025 
Scanlen, E., \& St George, I. (2011). Colour field guide to the native Orchids of New Zealand (3rd Ed., p. 83). Wellington: New Zealand Native Orchid Group.

Schori, M., Appel, M., Kitko, A., \& Showalter, A. M. (2013). Engineered DNA Polymerase Improves PCR Results for Plastid DNA. Applications in Plant Sciences, 1(2), 1200519. doi:10.3732/apps.1200519

Soga, M., Yamaura, Y., Koike, S., \& Gaston, K. J. (2014). Woodland remnants as an urban wildlife refuge: a cross-taxonomic assessment. Biodiversity and Conservation, 23(3), 649-659. doi:10.1007/s10531-014-0622-9

Suárez, J. P., Weiss, M., Abele, A., Garnica, S., Oberwinkler, F., \& Kottke, I. (2006). Diverse tulasnelloid fungi form mycorrhizas with epiphytic orchids in an Andean cloud forest. Mycological Research, 110(Pt 11), 1257-70. doi:10.1016/j.mycres.2006.08.004

Swarts, N. D., \& Dixon, K. W. (2009). Terrestrial orchid conservation in the age of extinction. Annals of Botany, 104(3), 543-56. doi:10.1093/aob/mcp025

Thompson, K., \& Grime, J. P. (1979). Seasonal Variation in the Seed Banks of Herbaceous Species in Ten Contrasting Habitats. The Journal of Ecology, 67(3), 893. doi:10.2307/2259220

Warcup, J. H. (1973). Symbiotic germination of some Australian terrestrial orchids. New Phytologist, 72(2), 387-392. doi:10.1111/j.1469-8137.1973.tb02046.x

Warcup, J. H. (1975). Factors affecting symbiotic germinations of orchid seed. In F. E. Sanders, B. Mosse, \& P. B. Tinker (Eds.), Endomycorrhizas (pp. 89-104). London: Academic Press.

Warcup, J. H. (1981). The mycorrhizal relationships of Australian orchids. New Phytologist, 87(2), 371-381. doi:10.1111/j.1469-8137.1981.tb03208.x

Warcup, J. H., \& Talbot, P. H. B. (1967). Perfect States of Rhizoctonias Associated With Orchids. New Phytologist, 66(4), 631-641. doi:10.1111/j.1469-8137.1967.tb05434.x

Weston, P. H., Perkins, A. J., \& Entwisle, T. J. (2005). More than symbioses: orchid ecology, with examples from the Sydney Region. Cunninghamia , 9(1), 1-15. Retrieved from https://www.rbgsyd.nsw.gov.au/_data/assets/pdf_file/0020/72524/Cun9Wes001.pdf

Whigham, D. F., O'Neill, J. P., Rasmussen, H. N., Caldwell, B. a., \& McCormick, M. K. (2006). Seed longevity in terrestrial orchids - Potential for persistent in situ seed banks. Biological Conservation, 129(1), 24-30. doi:10.1016/j.biocon.2005.10.029

White, J. A., Tallaksen, J., \& Charvat, I. (2008). The effects of arbuscular mycorrhizal fungal inoculation at a roadside prairie restoration site. Mycologia, 100(1), 6-11. Retrieved from http://www.ncbi.nlm.nih.gov/pubmed/18488348

Wood, C., Pritchard, H., \& Mugambi, G. (2003). Fluorescein diacetate and orchid seed viability in UK and Kenyan species. In Seed Conservation: Turning Science into Practice (pp. 493-506).

Young, T. P. (2000). Restoration ecology and conservation biology. Biological Conservation, 92(1), 73-83. doi:10.1016/S0006-3207(99)00057-9 


\section{Chapter 4: Phylogenetic affinities and symbiotic germination of Spiranthes novae-zelandiae Hook.f., a nationally vulnerable wetland orchid}

\section{Introduction}

The genus Spiranthes Rich. has a worldwide distribution (Dueck \& Cameron, 2007) and includes approximately 50 species (Tsukaya, 2005). The majority of these orchids are terrestrial with basal leaf formation (Rasmussen, 1995) of white, yellow or pink flowers in dense spirals on terminal spikes (Sheviak \& Brown, 2002). Their roots are fleshy and slender to tuberous (Rasmussen, 1995). Ongoing work by Dueck and Cameron (2007) aims to re-evaluate the phylogeny of the entire Spiranthes genus. Though the use of molecular markers in 27 North American species has been greatly informative, an understanding of the diversity of Eurasian species is lacking, with only three species from this large area presented in Dueck and Cameron's (2007) work.

Spiranthes sinensis (Pers.) Ames is one of the most widespread species and it is found in Russia, India, Japan, China, Southeast Asia, and the East of Australia (Tanaka, Kondo, \& Sato, 1997). This species was first described by Christiaan Persoon (1805) as Neottia sinensis in 1805, from voucher material collected China. It was later transferred to Spiranthes by Oakes Ames (1908). There are a number of other species morphologically similar to S. sinensis such as S. australis (R. Brown) Lindl and Spiranthes novaezelandiae sensu stricto Hook.f., which is endemic to New Zealand (NZ). Spiranthes australis was described Robert Brown as Neottia australis in 1810 using material collected at Port Jackson, Australia (Brown, 1810) and assigned to Spiranthes in 1824 by John Lindley (Edwards \& Ridgway, 1924). Spiranthes novae-zelandiae differs from S. australis by the narrow labellum and it was described by Joseph Hooker in 1853 using a specimen from the North Island collected by William Colenso (Fitch \& Hooker, 1853). The extent of similarity between these three species has created great confusion and currently the nomenclature of the Asian-Pacific members of this genus is in need of revision due to species-level and variety-level names being used almost interchangeably. For instance, $S$. novae-zelandiae has been sometimes erroneously identified as S. australis and $S$. sinensis in NZ (New Zealand Plant Conservation Network, 2014).

In the north of the North Island, populations of a variant of S. novae-zelandiae have been recorded in a number of sites (Matthews, 2009). Currently this entity is known 
as Spiranthes aff. novae-zelandiae or Spiranthes 'Motutangi' (De Lange et al., 2009). This variety differs from $S$. novae-zelandiae by its white labellum with folded edge that unfurls as it matures (Scanlen \& St George, 2011). Understanding this data deficient taxon is a high priority (Townsend et al., 2008) so that its conservation status may be decided. There is a third form present in the area, but with more flared labella and larger flowers, and it's believed this entity may actually be $S$. australis (New Zealand Plant Conservation Network, 2014).

Karyotypic studies show that S. sinensis, S. australis, and S. novae-zelandiae typically have chromosome counts of $2 n=30$ (Dawson, Molloy, \& Beuzenberg, 2007), although some studies report $S$. australis and $S$. sinensis to be $n=12$ or $n=16$ (Dawson, 2000). A number of species such as S. hongkongensis and the North American S. parksii are reported to be tetraploid (Dawson et al., 2007; Dueck \& Cameron, 2007). Though chromosome counts may not elucidate differences between S. sinensis, S. australis and S. novae-zelandiae, there is morphological variation of chromosomes during prometaphase. Further investigation is needed to assess their diagnostic value (Dawson et al., 2007).

Spiranthes novae-zelandiae is perennial and produces a dense, helically arranged inflorescence of pink or white flowers with fringed white labella. The flowering stems may grow up to 1 metre tall (New Zealand Plant Conservation Network, 2014). Flowers are produced from January to April and fruit from April to July (De Lange, Rolfe, St George, \& Sawyer, 2007). Flowers of S. novae-zelandiae are thought to be pollinated by thrips or self-pollinated (Scanlen \& St George, 2011). In Japan, fruit set is always higher than pollen removal rate for $S$. sinensis (Iwata, Nagasaki, Ishii, \& Ushimaru, 2012), and it may be that the pattern is the same for $S$. novae-zelandiae. This orchid has been recorded in wetlands or waterways from mountain locations to coastal areas of the North Island, South Island and Chatham Islands. Decline of many populations have been reported mainly due to the destruction of wetlands (De Lange et al., 2007). In fact, damage to wetlands has also been substantial and over $90 \%$ of the wetlands occurring in NZ prehuman settlement have been destroyed (Hunt, 2007). Currently, Spiranthes novaezelandiae is considered nationally vulnerable, occupying a total area of less than $10 \mathrm{~km}^{2}$ and a predicted decline of 30-70\% (Lange et al., 2012). One population in the Wellington region, for example, is on a commercial property and may be entirely lost if site developments occur. Some individuals from this population have been relocated to a protected area but the population is aging and there is no evidence of recruitment occurring at the new location (C. Lehnebach, personal communication, April 7, 2014) 
Symbiotic germination for conservation of endangered orchids has long been occurring in Europe (Clements, Muir, \& Cribb, 1986), North America (Zettler, 1996) and Australia (Dixon, 1994). Symbiotic germination of Spiranthes seeds is possible and several species of Spiranthes have been successfully germinated overseas using a range of Rhizoctonia and Rhizoctonia-like Basidiomycota fungi (Masuhara \& Katsuya, 1994; Shan, Liew, Weatherhead, \& Hodgkiss, 2002). These techniques could help with maintaining S. novae-zelandiae and other threatened orchids in NZ but no such research has yet been implemented here (Watkins, 2012).

The aim of this study was to determine the phylogenetic affinities of the NZ Spiranthes: S. novae-zelandiae and S. novae-zelandiae var. 'Motutangi' using nuclear and plastid genetic markers and compare them with other Asian-Pacific Spiranthes species. A second aim of this study was to isolate, culture and identify the mycorrhizae that promote germination of $S$. novae-zelandiae. 


\section{Methods}

\section{Collection of roots and seeds}

Plant and seed material of S. novae-zelandiae s.s. of four individuals was collected from a single site in January 2013 from a protected area in the lower North Island, NZ (Ward, 2012) (A, Figure 4.). Leaf material of three individuals of S. novae-zelandiae was collected from private land in the Nelson region (B, Figure 4.) and leaf material of four individuals of S. novae-zelandiae var. 'Motutangi' was collected in March 2013 from private land in, Northland, NZ (C, Figure 4.). Precise locations are withheld to protect populations. Leaf material of four individuals of $S$. sinensis was sent from Hiroshima and voucher specimens are currently lodged in the WELT Herbarium at the Museum of New Zealand (WELT SP102377, WELT SP102378, WELT SP102380).

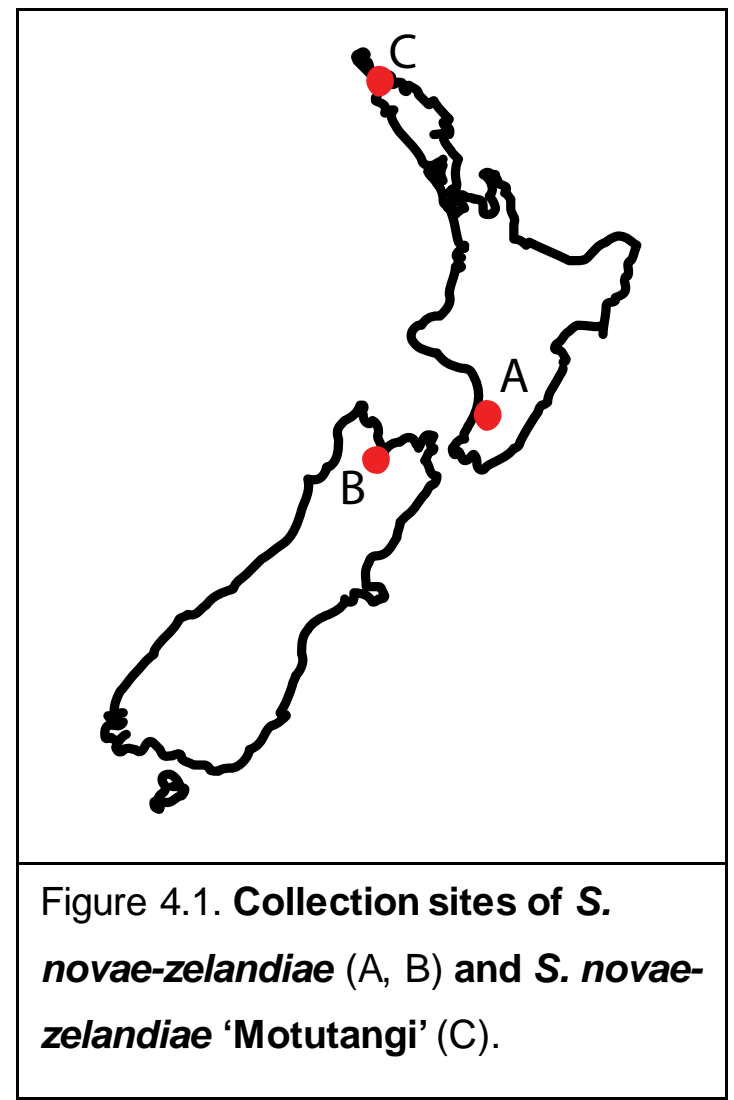

\section{Plant DNA extraction}

DNA was extracted from the leaves using CTAB extraction method modified from Doyle and Doyle (1987). Leaves were macerated in liquid nitrogen in a $1.7 \mathrm{ml}$ microcentrifuge tubes and then $450 \mu \mathrm{l}$ of CTAB buffer was added to each tube/sample. The tubes were shaken vigorously and incubated at $65{ }^{\circ} \mathrm{C}$ for 30 minutes. A $450 \mu$ l aliquot of chloroform was added to each sample, shaken rigorously, and then rested for 15 
minutes to allow precipitation. The tubes were spun in a centrifuge at 4,000 rpm for 5 minutes. The supernatant from each tube was removed by large bore pipette tips into new $1.7 \mathrm{ml}$ microcentrifuge tubes and $450 \mu$ of isopropanol was added. The tubes were gently inverted three times then placed into a $-20{ }^{\circ} \mathrm{C}$ freezer for 15 minutes. The cloudy precipitate was gently removed from each tube and placed into new $1.7 \mathrm{ml}$ microcentrifuge tubes with a large bore pipette tip. A $450 \mu$ aliquot of $80 \%$ ethanol was added and the tubes were inverted gently three times. The supernatant was removed and discarded leave the pellet at the bottom of the tube undisturbed. The $80 \%$ ethanol wash was repeated two more times for each tube. The ethanol was allowed to evaporate before re-suspending the pellet in $20 \mu \mathrm{T}$ TE pH8.0. The purified DNA sample was stored at $-80{ }^{\circ} \mathrm{C}$.

\section{Fungal isolation and culturing}

A fungal isolation media (FIM) was prepared, modified from Clements and Ellyard (1979), as a low nutrient, antibacterial media so that initial colonies develop slower and bacterial contamination is minimised. First, $0.143 \mathrm{~g}$ of streptomycin sulphate was combined with $10 \mathrm{ml}$ of sterile double distilled water $\left(\mathrm{ddH}_{2} \mathrm{O}\right)$ and shaken till well dissolved. This solution was filter-sterilised in a $2 \mu \mathrm{m}$ sterilising filter and put to one side. A volume of $990 \mathrm{ml}$ of $\mathrm{dd}_{2} \mathrm{O}$ was placed on a stirring platform to which the following reagents were added: $0.3 \mathrm{~g}$ of sodium nitrate, $0.2 \mathrm{~g}$ of potassium dihydrogen orthophosphate, $0.1 \mathrm{~g}$ magnesium sulphate, $0.1 \mathrm{~g}$ potassium chloride, $0.1 \mathrm{~g}$ yeast extract and $2.5 \mathrm{~g}$ of Sucrose. The solution was then brought to pH6.8 (Batty, Brundrett, \& Ramsay, 2001) before adding $8 \mathrm{~g}$ of agar. The solution was then autoclaved for 20 minutes at $120^{\circ} \mathrm{C}$ and returned to the stirring platform to cool to approximately $60^{\circ} \mathrm{C}$ before adding the streptomycin sulphate solution. The media was then poured into $60 \mathrm{~mm}$ Petri dishes under a laminar flow and allowed to cool and set. Plates were stored in the dark at $4{ }^{\circ} \mathrm{C}$ and used within 5 days. The antibacterial properties of the streptomycin sulphate solution are reduced after 10 days or prolonged light exposure.

Fresh lateral root was serially washed in sterile double-distilled water $\left(\mathrm{ddH}_{2} \mathrm{O}\right)$. Epidermis cells were scraped and removed. Pelotons were manually removed from cortical cells and serially washed in sterile $\mathrm{dd}_{2} \mathrm{O}$ before placing on to Petri dishes containing FIM. Growing tips of resulting fungal colonies were sub-cultured onto FIM plates to obtain pure strains.

A nutrient-rich media was used to grow thick hyphal mats for DNA extraction and as inoculants for orchid seed germination experiments. A $1 \mathrm{~L}$ volume of $\mathrm{ddH}_{2} \mathrm{O}$ was placed on a stirring platform and $24 \mathrm{~g}$ of PDA powder was dissolved into it. The solution 
was brought to pH6.8 (Janes, 2009) before adding $8 \mathrm{~g}$ of Agar. The solution was then autoclaved at $120^{\circ} \mathrm{C}$ for 20 minutes. The media was then poured into $60 \mathrm{~mm}$ petri dishes under a laminar flow and allowed to cool and set. Plates were stored at $4{ }^{\circ} \mathrm{C}$ until they were used.

\section{Fungal DNA extraction}

Genomic DNA was extracted using a modification of a previously described protocol (Beach, Piper, \& Nurse, 1982). Each isolate culture was scraped from the PDA plates to obtain between $0.1 \mathrm{~g}$ and $0.5 \mathrm{~g}$ of hyphal material that was placed with $300 \mu \mathrm{l}$ of glass beads into $1.7 \mathrm{ml}$ microcentrifuge tubes. A $300 \mu \mathrm{l}$ aliquot of $5 \%$ SDS was added to each tube and the mixtures were macerated with sterile pestles. A $300 \mu$ aliquot of 25:24:1 phenol-chloroform-isoamyl alcohol was added to each tube and they were vortexed for 6 minutes. The tubes were centrifuged at $14,000 \mathrm{rpm}$ for 5 minutes before the upper, aqueous phase of each was placed into new $1.7 \mathrm{ml}$ microcentrifuge tubes containing $1 \mathrm{ml}$ of $90 \%$ ethanol. Tubes were inverted gently five times and centrifuged at $14,000 \mathrm{rpm}$ for 5 minutes. The supernatant was poured off from each tube and the pellets were allowed to dry before being re-suspended in TE pH8. The samples were electrophoresised in a $1 \%$ agarose gel, stained with ethidium bromide, and the concentration and size of the extracted DNA was estimated while visualising the gel using UV light.

\section{Amplification and sequencing of DNA}

For investigating phylogenetic affinities among Asian-Pacific Spiranthes, the primer pairs ITS1a-ITS4 and trnL-trnF were used to amplify ITS1-5.8-ITS2 nuclear regions and trnL-trnF plastid regions (Table 1). For fungal identification, the internal transcribed spacer (ITS) region was selected for its ability to identify fungi to the species level (Nilsson, Kristiansson, Ryberg, Hallenberg, \& Larsson, 2008). The primer pair, ITS1aITS4-Tul, was used to amplify and sequence the endosymbiont ITS region (Table 4.1) because generic fungal primers may exclude Tulasnellaceae (Taylor et al., 2002) .

Table 4.1. Primers used to amplify ITS1-5.8-ITS2 nrDNA and trnL-trnF cpDNA.

\begin{tabular}{lll}
\hline Primer & Sequence (5'-3') & Source \\
\hline ITS1a & CCTTTGTACACACCGCCCGT & (Sharpe, Harbach, \& Butlin, 2000) \\
ITS4 & TCCTCCGCTTATTGATATGC & (White, Bruns, Lee, \& Taylor, 1990) \\
ITS4-Tul & CCGCCAGATTCACACATTGA & (Taylor \& McCormick, 2008) \\
trnL (tabC) & CGAAATCGGTAGACGCTACG & (Taberlet, Gielly, Pautou, \& Bouvet, 1991) \\
trnF (tabF) & ATTTGAACTGGTGACACGAG & (Taylor \& McCormick, 2008) \\
\hline
\end{tabular}


For use in PCR, the DNA samples were diluted 1:100. Each $20 \mu \mathrm{lPCR}$ contained $1 \mathrm{M}$ betaine, $75 \mathrm{mM}$ Tris- $\mathrm{HCl}$ (pH8.8), $20 \mathrm{mM}$ ammonium sulphate, $2.5 \mathrm{mM} \mathrm{MgCl}$, 0.5 $\mu \mathrm{M}$ forward primer, $0.5 \mu \mathrm{M}$ reverse primer, $0.25 \mathrm{mM}$ of each deoxynucleotide (dATP, dCTP, dGTP and dTTP), $1 \cup(0.2 \mu l)$ Thermo Fisher Scientific Red Hot Taq DNA polymerase, $0.01 \%(\mathrm{v} / \mathrm{v})$ Tween 20 , and $1 \mu$ of template DNA. In cases where PCR yields were low, $2 \mathrm{mg} / \mathrm{mlBSA}$ was added to preferentially bind to inhibiting factors (Farell \& Alexandre, 2012).

Loci were amplified using an initial denaturing stage of $95{ }^{\circ} \mathrm{C}$ for 2 minutes followed by 35 cycles of $95{ }^{\circ} \mathrm{C}$ for 1 minute, $55^{\circ} \mathrm{C}$ for 1 min and $72{ }^{\circ} \mathrm{C}$ for 1 minute 30 seconds, culminating with an additional extension stage of $72{ }^{\circ} \mathrm{C}$ for 5 minutes. To clean up PCR products for sequencing, Exonuclease I digested single stranded oligonucleotides and Shrimp Alkaline Phosphatase removed phosphate groups from excess dNTPs.

DNA sequencing reactions of $2.5 \mu \mathrm{M}$ forward or reverse primer and approximately $200 \mathrm{ng}$ of DNA were made up to a final volume of $10 \mu \mathrm{l}$ with $\mathrm{ddH}_{2} \mathrm{O}$ and run on the Applied Biosystems 3730xI DNA Analyzer by Macrogen Inc. (Seoul, South Korea).

\section{Phylogenetic analyses of plant and fungi sequences}

The DNA sequences were edited and consensus sequences were generated using Geneious 4.8. BLAST database queries of GenBank (Benson, Karsch-Mizrachi, Lipman, Ostell, \& Wheeler, 2005) were used to identify the organism by the closest matches with sequence similarity $>97 \%$. ). Additional sequences of $S$. sinensis were obtained from Yibo Luo at the Chinese Academy of Sciences, and included in the following analyses.

To provide an overview of global Spiranthes distribution, All Spiranthes ITS accessions on GenBank were included in an alignment with ITS sequences generated by this study. Sequences were aligned with MUSCLE (Edgar, 2004). The best-fit DNA substitution model and a maximum likelihood tree were determined using MEGA6 (Tamura, Stecher, Peterson, Filipski, \& Kumar, 2013). All DNA sites were included and 1000 bootstrap replicate test was performed. Nodes with bootstrap support of $<50 \%$ were collapsed. Broad-scale distribution ranges were mapped on to major clades. The outgroup was Scoila lanceolata var. lanceolata (Dueck \& Cameron, 2007).

To investigate phylogenetic affinities within the Asian-Pacific Spiranthes, ITS accessions from GenBank and ITS sequences generated in this study were aligned with MUSCLE. Model testing was carried out and a maximum likelihood analysis was generated in MEGA6 using all sites and with 1000 bootstrap replicates. The outgroup 
used for the Asian-Pacific phylograms was Spiranthes glabarencens (syn. Cyclopogon glabarencens). The same process was followed for the construction of the Spiranthes trnL-trnF phylogram.

The nuclear (ITS) and plastid (trnL-trnF) markers for the Asian-Pacific Spiranthes species were concatenated and those with coverage of both markers were included and aligned with MUSCLE. Model testing was carried out and a maximum likelihood phylogram was generated in MEGA6 using all sites and with 1000 bootstrap replicates. The outgroup used for the Asian-Pacific phylograms was S. glabarencens.

To investigate endosymbiont phylogenetic affinities, the ITS sequence generated in this study was aligned with ITS sequences from GenBank from formally identified Tulasnella calospora vouchers. ITS accessions of $T$. calospora isolated from other Spiranthes species were included and aligned with MUSCLE. Model testing was carried out and a maximum likelihood phylogram was generated in MEGA6 using all sites and with 1000 bootstrap replicates.

\section{In vitro germination of $S$. novae-zelandiae seeds}

Seeds were stored in dark and dry conditions at room temperature for four months. Seeds were then surface-sterilised in a $2 \%$ calcium hypochlorite solution with $2 \mathrm{ml}$ of tween80 on a stirring platform for 10 minutes. Seeds were then washed three times in sterile $\mathrm{ddH}_{2} \mathrm{O}$.

An oatmeal agar (OMA) media was prepared with $2.5 \mathrm{~g}$ finely cut oats in $1 \mathrm{~L}$ $\mathrm{ddH}_{2} \mathrm{O}$. The solution was brought to $\mathrm{pH} 5.5$ and $8 \mathrm{~g}$ of Agar was added. The media was autoclaved for 20 minutes at $120^{\circ} \mathrm{C}$, before placing on a stirring platform to combine. The solution was poured into $60 \mathrm{~mm}$ Petri dishes and allowed to set in the laminar flow. Surface-sterile seeds were spread on the OMA plates and stored for four days to ensure no contamination was present. Contaminated plates were discarded.

A small square of agar containing T. calospora isolated from S. novae-zelandiae roots was placed on each OMA-seed plate. Inoculated plates were sealed with plastic paraffin film and placed in a dark incubator set to $17^{\circ} \mathrm{C}$. Progress was monitored regularly, and seeds that proceeded into stage four of germination were moved to an incubator at 20 ${ }^{\circ} \mathrm{C}$ and a diurnal cycle of 12 hours light and 12 hours dark. After 146 days protocorms were transplanted on to autoclaved wetland soil and moved to $19{ }^{\circ} \mathrm{C}$ diurnal cycle of 14 hours light and 10 hours dark. For the light phase of the diurnal cycles, 35 Watt fluorescent tubes were used. 


\section{Results}

\section{Spiranthes phylogenetic analysis}

To establish a phylogenetic framework to study symbiotic germination of S. novaezelandiae, 20 novel Asian-Pacific Spiranthes sequences were generated. Of these, eight were ITS sequences and 12 were trnL-trnF sequences.

The eight novel Spiranthes ITS sequences were aligned with 67 GenBank accessions to illustrate the broad biogeographic distributions of major clades. The alignment of 75 ITS sequences was 526 characters in length, of which 381 were conserved, 55 were variable but parsimony uninformative, and 90 were parsimony informative. Model testing revealed the HKY model (Hasegawa, Kishino, \& Yano, 1985) with a Gamma distribution to be the best with a log likelihood of -1812.3592. A discrete Gamma distribution with five categories was used to model evolutionary rate differences among sites $(+G$, parameter $=0.3085)$. The phylogenetic tree showed four main clades which have distinct geographic ranges (Figure 4.2). The taxa in the North American clade were extensively sampled and weakly supported (54\%). A number of polytomies occurred and some accessions of the same species grouped separately. The Asian-Pacific clade was strongly supported (95\%) and contains members of S. sinensis, S. australis, and S. novae-zelandiae. The African-European clade was also highly supported (97\%). Notably, one accession for $S$. sinensis and one accession for $S$. australis occurred in this clade rather than the Asian-Pacific clade. The North American-British Isles clade was strongly supported (97\%), but only contained one species. Spiranthes glabrescens is the only known species from South America and there is some doubt whether it should be included in the genus Spiranthes or another genus (Salazar \& Jost, 2012). 


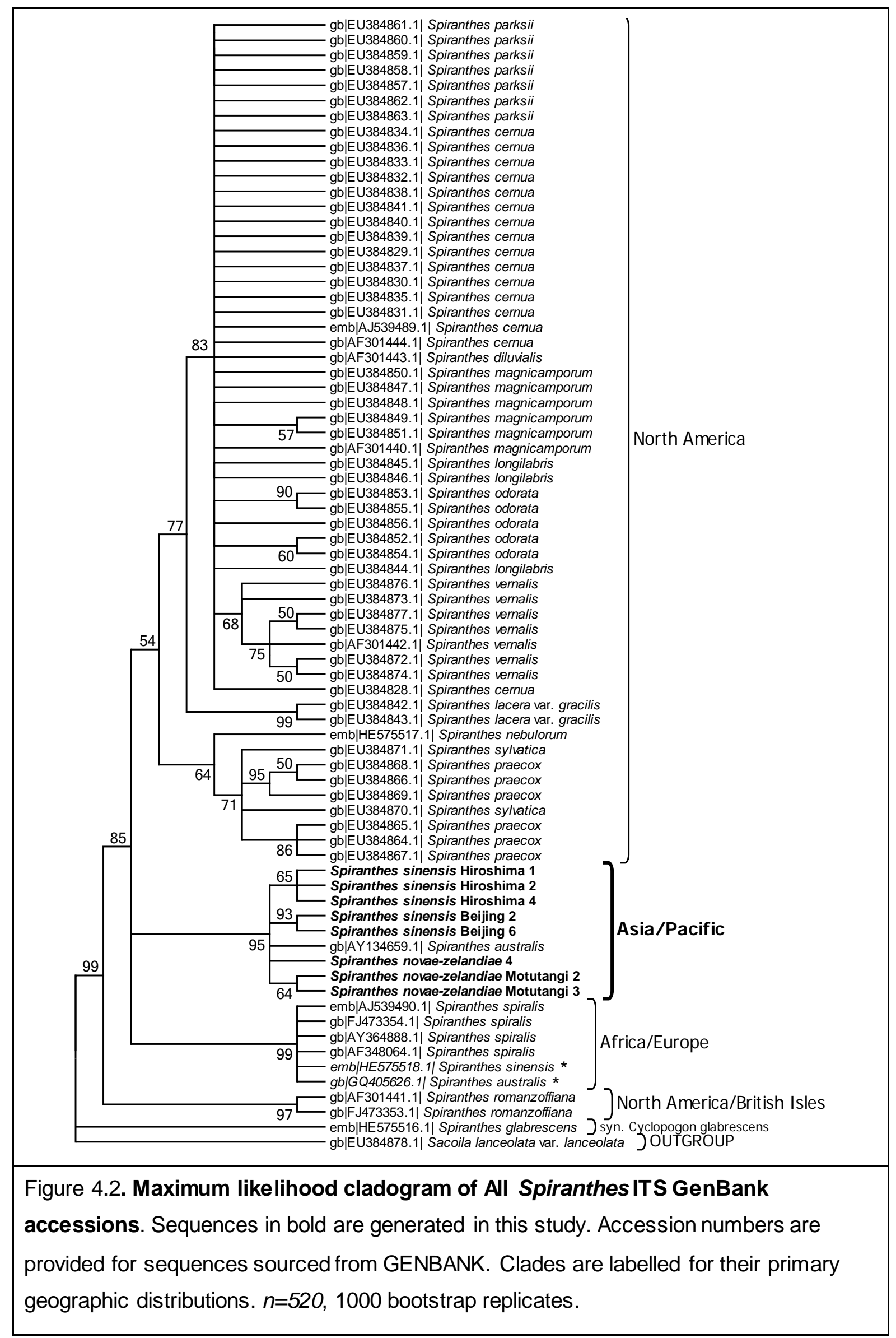


The alignment of 12 Asian-Pacific Spiranthes ITS sequences was 520 characters in length, of which 448 were conserved, 50 were variable but parsimony uninformative, and 22 were parsimony informative. Model testing revealed the Kimura two-parameter model (Kimura, 1980) to be the best with a log likelihood of -1068.48. (Figure 4.3). The maximum pairwise p-distance between members of the ingroup in the ITS1-5.8s-ITS2 alignment was 0.14 . The phylogram (Figure 4.3) suggested that $S$. australis shared a common ancestor with the clade that contained S. sinensis, S. novae-zelandiae and S. novae-zelandiae 'Motutangi'. The figure also suggested that $S$. sinensis may be paraphyletic, forming two separate clades that matched location. NZ Spiranthes is nested within S. sinensis. The low bootstrap values, such as those for the clade including $S$. sinensis from Beijing and S. novae-zelandiae (13\%), reduced the inferential weight of this figure.

\begin{tabular}{|l|l|l|l|l|}
\hline Spiranthes sinensis Beijing 6 \\
Spiranthes novae-zelandiae 4
\end{tabular}

The alignment of 21 Asian-Pacific Spiranthes trnL-trnF sequences was 1269 characters in length, of which 1179 were conserved, 70 were variable but parsimony uninformative, and 20 were parsimony informative. Model testing revealed the Tamura three-parameter model (Tamura, 1992) with a Gamma distribution to be the best with a log likelihood of -2156.4427 . A discrete Gamma distribution with five categories was used to model evolutionary rate differences among sites $(+G$, parameter $=0.3906)$ (Figure 4.4). The maximum pairwise $p$-distance between members of the ingroup in the trnL-trnF 
alignment was 0.03 . The analysis suggested that $S$. sinensis is paraphyletic, with $S$. novae-zelandiae nested within it. All of the GenBank accessions for S. sinensis forms and varieties were from material sourced in Japan except for emb|HE575528.1, which was from "eastern Asia" (Salazar \& Jost, 2012). The sequences from Beijing formed a strongly supported clade (83\%) distinct from the largely NZ and Japanese clade with only $36 \%$ bootstrap support. Spiranthes sinensis var. amoena appeared to be a paraphyletic variety, and grouped strongly with S. sinensis from Hiroshima and S. sinensis f. gracili. Additionally, it formed its own moderately supported clade (62\%). The chloroplast evidence suggested that S. novae-zelandiae and S. novae-zelandiae 'Motutangi' are sister taxa, though the bootstrap support values were weak (27\%).

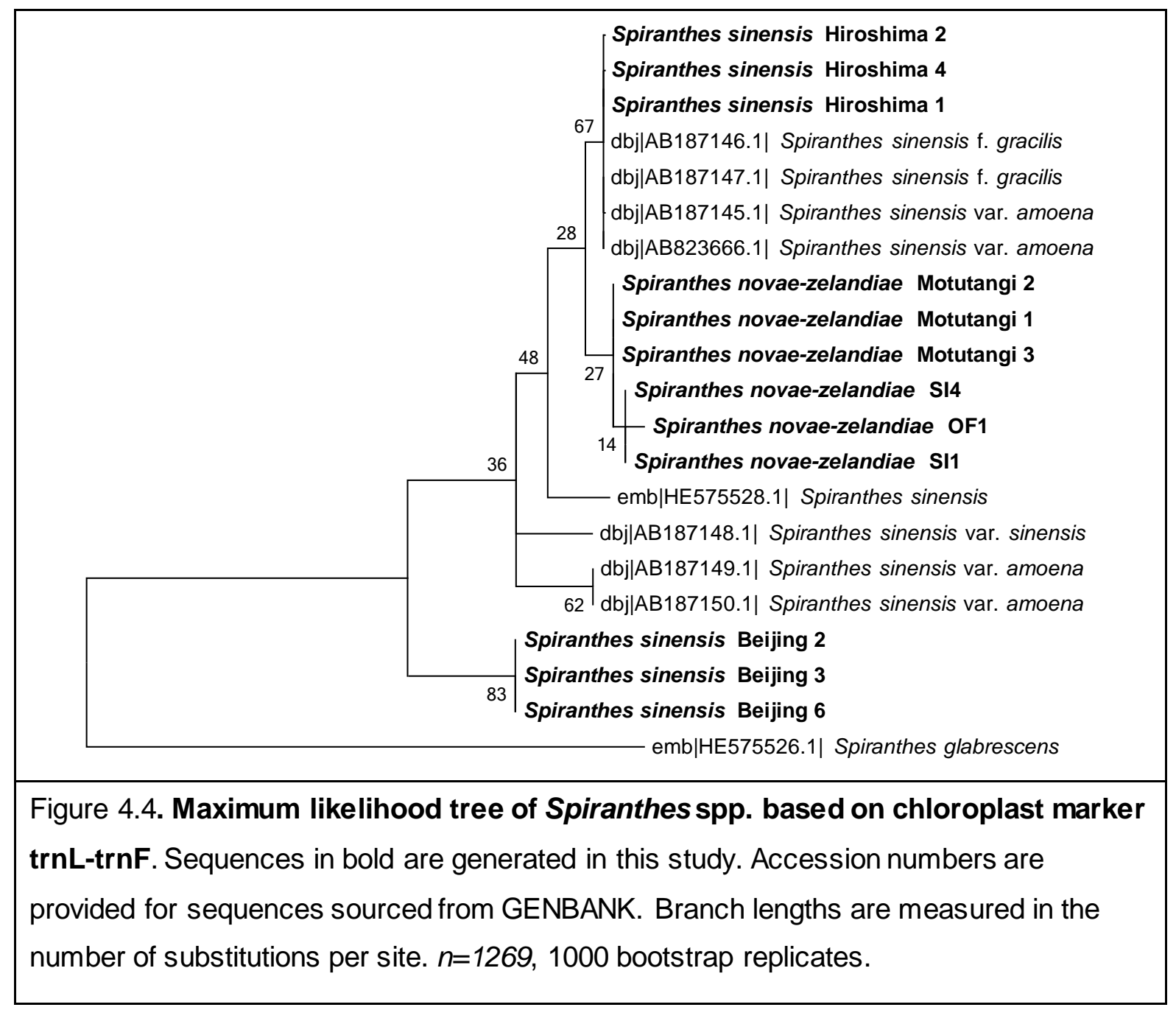

The alignment of 10 Asian-Pacific Spiranthes concatenated ITS and trnL-trnF sequences was 1737 characters in length, of which 1473 were conserved, 244 were variable but parsimony uninformative, and 20 were parsimony informative. Model testing revealed the Tamura three-parameter model (Tamura, 1992) with a Gamma distribution to 
be the best with a log likelihood of -3151.9506 . A discrete Gamma distribution with five categories was used to model evolutionary rate differences among sites $(+G$, parameter = 0.3906) (Figure 4.4). The maximum pairwise $p$-distance between members of the ingroup in the concatenated ITS1-6.8sITS2 and trnL-trnF alignment was 0.10. The phylogram was marked by high bootstrap values ( $\geq 80 \%$ ), and S. sinensis from Beijing formed a strongly supported clade (100\%), distinct from the clade of sequences from Japan, NZ, and eastern Asia (80\% bootstrap support). The figure also suggested that both Spiranthes taxa from NZ are sister to S. sinensis from Hiroshima with 93\% bootstrap support. Finally, S. novae-zelandiae appeared as a sister group to S. novae-zelandiae 'Motutangi' with $87 \%$ bootstrap support.

The p-distance between S. novae-zelandiae and the 'Motutangi' variant was 0.002 . The p-distance between $S$. novae-zelandiae and the $S$. sinensis voucher was 0.016 . The p-distance between S. sinensis from Hiroshima and the S. sinensis voucher was 0.019 . The p-distance between S. sinensis from Beijing and the S. sinensis voucher was 0.032 . The p-distance between S. sinensis from Beijing and S. sinensis from Hiroshima was 0.013. The p-distance between S. sinensis from Beijing and S. novae-zelandiae was 0.016. The p-distance between S. sinensis from Hiroshima and S. novae-zelandiae was 0.004 .

\begin{tabular}{|c|c|}
\hline & $\begin{array}{l}\text { Spiranthes sinensis Hiroshima } 1 \\
\text { Spiranthes sinensis Hiroshima } 4 \\
\text { Spiranthes sinensis Hiroshima } 2\end{array}$ \\
\hline $\begin{array}{l}\text { Figure 4.5. Maximum Likelihood tree of Spiran } \\
\text { trnF markers. Sequences in bold are generated } \\
\text { provided for sequences sourced from GENBANK. } \\
\text { number of substitutions per site. } n=1737.1000 \text { bc }\end{array}$ & $\begin{array}{l}\text { thes using concatenated ITS and trnL- } \\
\text { in this study. Accession numbers are } \\
\text { Branch lengths are measured in the } \\
\text { ootstrap replicates. }\end{array}$ \\
\hline
\end{tabular}




\section{Mycorrhizal phylogenetic analysis}

For identification of the mycorrhizal partner that facilitates germination and to assess its phylogenetic affinities, the ITS region was used to generate two novel $T$. calospora sequences that were aligned with six GenBank accessions. The final alignment of eight ITS sequences was 976 characters in length, of which 673 were conserved, 240 were variable but parsimony uninformative, and 63 were parsimony informative. Model testing revealed the Kimura two-parameter model (Kimura, 1980) with a Gamma distribution to be the best with a log likelihood of -2506.5202. A discrete Gamma distribution with five categories was used to model evolutionary rate differences among sites $(+G$, parameter $=0.7781)($ Figure 4.6). The accession AB369939 was for $T$. calospora isolated from S. sinensis from Japan (Shimura et al., 2009), and formed a sister group to $T$. calospora isolated from $S$. novae-zelandiae with $88 \%$ bootstrap support. The four other $T$. calospora accessions were formally identified and vouchered specimens, and formed a sister group to T. calospora isolated from Spiranthes species.

The p-distance between T. calospora from S. sinensis and T. calospora from S. novae-zelandiae was 0.025 . The $p$-distance between $T$. calospora vouchers and $T$. calospora from S. novae-zelandiae was 0.091 . The p-distance between T. calospora vouchers and T. calospora from S. sinensis was 0.079 .

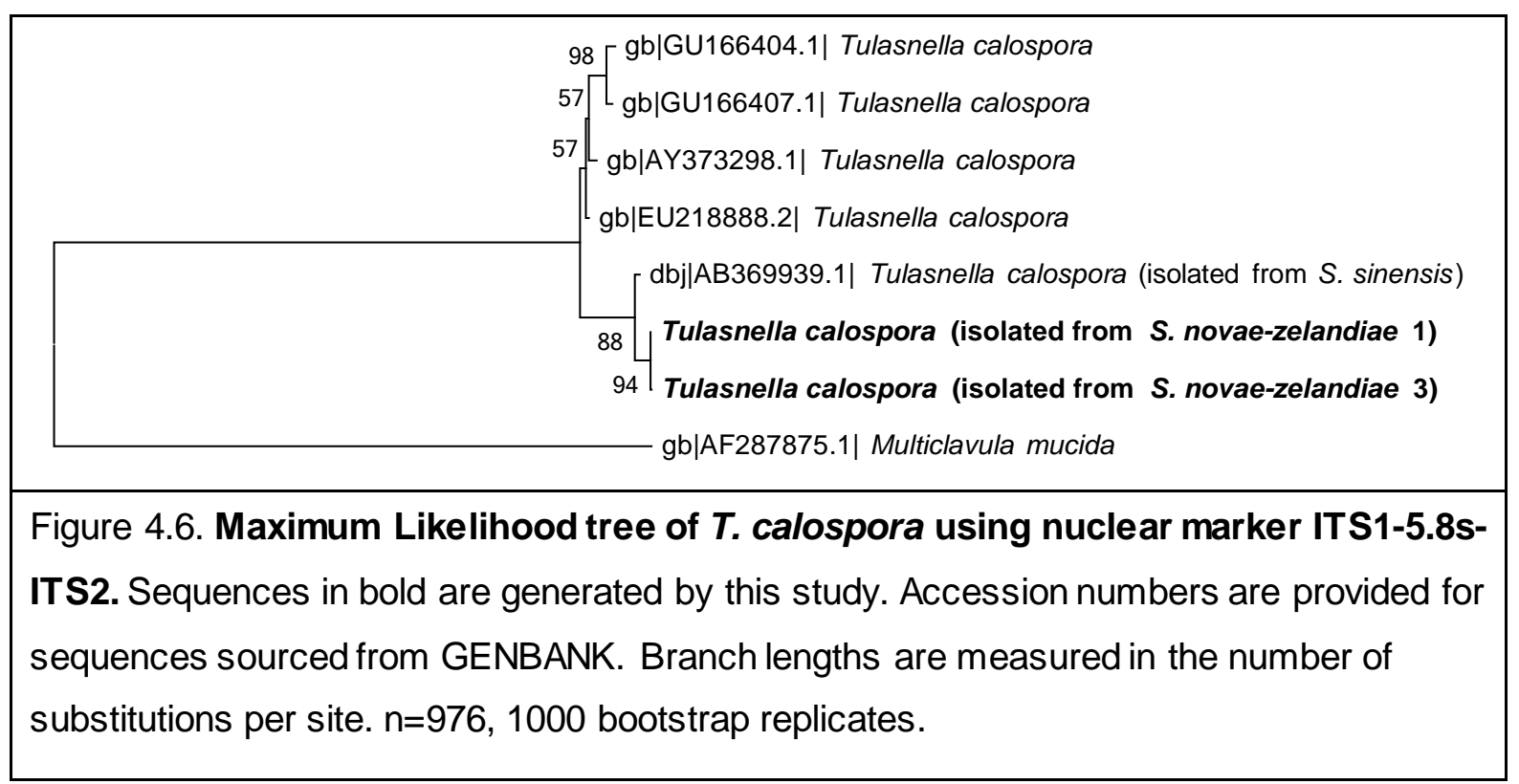




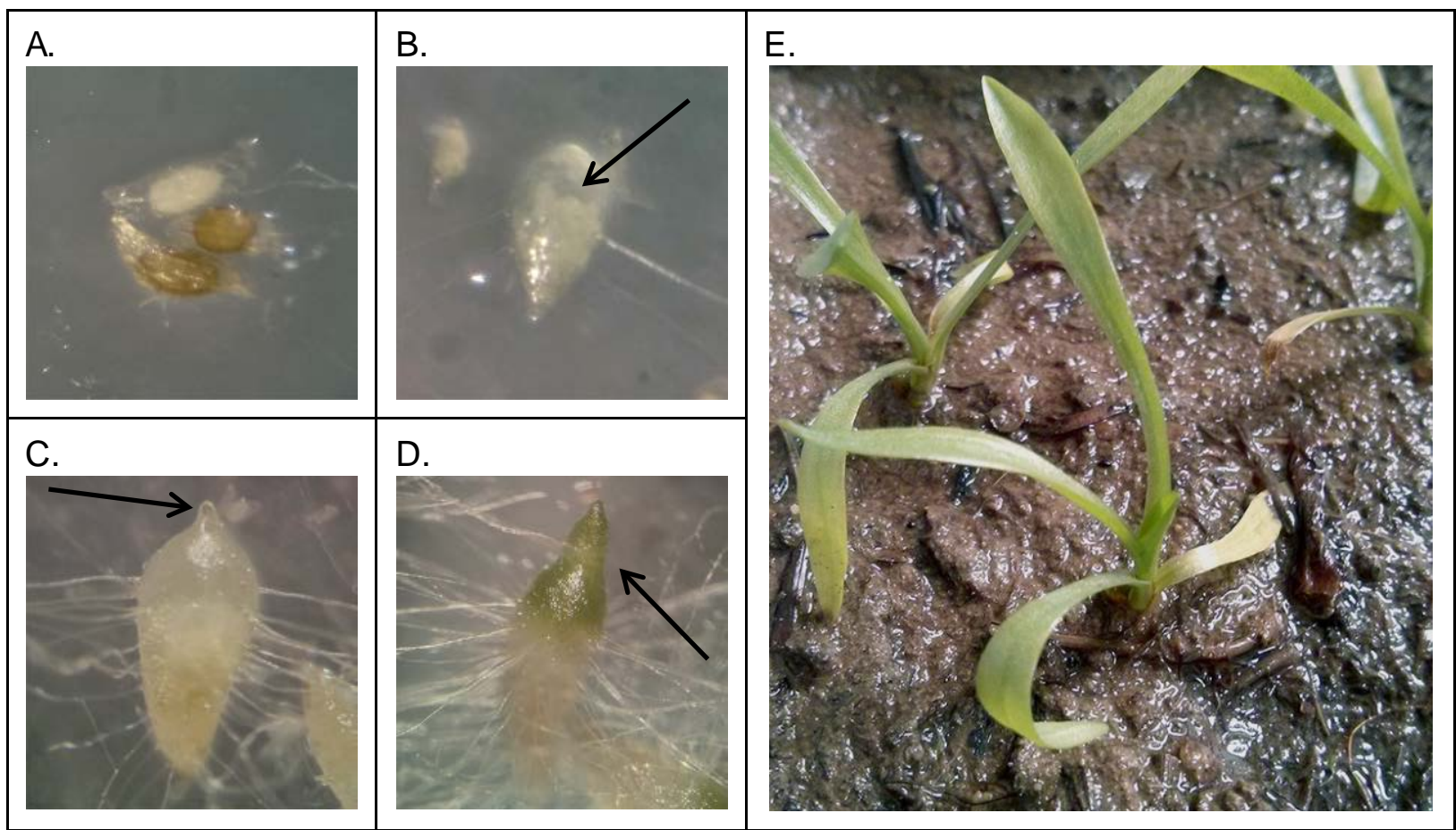

Figure 4.7. Stages of development of $\mathbf{S}$. novae-zelandiae. A) Stage 1, Day26, embryos swollen, production of rhizoids. B) Stage 2-3, day 33, Rupture of testa, further rhizoid formation, pelotons visible (indicated by arrow), symbiosis established. C) Stage 4, Day 67, emergence of leaf shoot (indicated by arrow). D) Stage 5, day 81, elongation of leaf, green chlorophyllous tissues develop (indicated by arrow). E. Seedling, Day 227. Stages follow Stewart \& Zettler (2002).

\section{In vitro germination}

Protocorms developed rapidly 26 days after inoculation many seeds reached stage two of germination. Protocorms began to progress to stage three after 33 days. The first protocorms reached stage four after 46 days and pelotons became visible inside the protocorms (Figure 4.7, B). At day 68, the majority of seeds on a plate developed to stage four and were moved to an incubator with a diurnal light cycle. After four days in the incubator, green, chlorophyllous colouration developed in the apical leaf primordium and tissues of the protocorms (Figure 4.7, D), and seeds began to develop into stage five. Secondary leaves began to appear at day 90. Development seemed to stop at 145 days but resumed after seedlings were transplanted onto sterile soil. 


\section{Discussion}

This chapter had two aims. The first was to assess the phylogenetic affinities of the NZ endemic S. novae-zelandiae with overseas species that are morphologically similar, and the second was to attempt to symbiotically propagate the species from seed.

The ITS sequences were grouped very strongly by global geographic distribution and supported the previously reported close relationships of S. sinensis, S. australis and S. novae-zelandiae (Figure 4.2). However, the two exceptions: S. sinensis (HE575518.1) and S. australis (GQ405626.1) which grouped very strongly with S. spiralis in the clade of African-European samples (Figure 4.2). Spiranthes spiralis is widely distributed in Africa, southern Europe and the Mediterranean (Machon et al., 2003) but its north western distribution limit is in the United Kingdom and the Netherlands (Jacquemyn, Brys, Hermy, \& Willems, 2007). Recently specimens of S. spiralis have been found in Nepal (Acharya, Wood, Berwian, \& Sharma, 2010) and it may be that their range is greater than previously thought. These two sequences grouped together in the ITS phylogram of the Asian-Pacific Spiranthes but forming a different clade to the rest of the S. sinensis and S. australis samples (Figure 4.3). Further investigation of the vouchers for these anomalous accessions is necessary to confirm their identity.

It is apparent from the number of North American GenBank accession entries on the phylogenetic tree of the entire genus Spiranthes that ITS sequence sampling has been extensive in North America compared to the other regions of the world. However, the ITS marker alone was not able to segregate taxa in line with current systematics. Even after concatenating four markers (ITS, NAD7, trnL, and trnS-fM), the phylogeny generated by Dueck and Cameron (2007) was not able to clearly resolve all North American Spiranthes species.

The Asian-Pacific ITS phylogram presents a moderately supported paraphyly of $S$. sinensis and S. novae-zelandiae (Figure 4.3). However, the analysis suffers from a lack of taxon sampling. Additional sampling of $S$. sinensis from other regions may give an indication of the variation of the ITS region within this species.

When compared with the phylogram generated from the trnL-trnF marker, the topology of the ITS tree is more resolved and supported by higher bootstrap values. The maximum p-distance values of the ITS alignment are higher (0.14) than the trnL-trnF alignment (0.03), indicating that the ITS sequences (which is mostly non-coding) are more divergent from each other. Indeed, the chloroplast trnL-trnF region of the Asian-Pacific Spiranthes may not be variable enough to delineate to the species or variety level with 
acceptable certainty. The phylogram is marked by low bootstrap support and a polytomy and sequences of $S$. sinensis var. amoena being grouped with a number of other taxa (Figure 1). The latter phenomenon may be the result of hybridisation or even erroneous identification. However, the phylogram suggests that the $S$. sinensis from Beijing is strongly divergent from the other S. sinensis and S. novae-zelandiae. Interestingly, all of the varieties of $S$. sinensis that appear in the phylogram are also from Japanese sources. This suggests regional variation in the chloroplast and that NZ Spiranthes share some of this variation. Further sampling from other Asian and Pacific locations is needed to investigate this pattern further.

Despite the limitations of the trnL-trnF marker for phylogeny reconstruction, specific variation at loci in the marker can be paralleled to flowering phenology in Japanese $S$. sinensis varieties (Tsukaya, 2005). Though the variation is not functionally linked, it may be that similar parallels may be found in between markers of $S$. novaezelandiae s.s. and the 'Motutangi' variant. The flowering period of S. novae-zelandiae s.S is from January to April, while the S. novae-zelandiae 'Motutangi' variant flowers from December to February (Scanlen \& St George, 2011). No such phenotypic patterns were paralleled to the variation of the ITS marker (Tsukaya, 2005).

The concatenated nuclear and chloroplast tree (Figure 4.5) forms the most resolved phylogram and it has been suggested that phylogenies using concatenated sequence data are generally more robust than those based on single marker data because they contain more data and therefore better resolution (Devulder, Pérouse de Montclos, \& Flandrois, 2005). However, the phylogram includes only a few taxa and $S$. australis sequences for both markers are lacking - which means that a plenary phylogeny of the Asian-Pacific Spiranthes remains to be completed. The phylogram suggests that the Japanese $S$. sinensis is a sister species to $S$. novae-zelandiae. Both of these entities form a clade that shares a common ancestor with the formally identified and vouchered $S$. sinensis specimen (voucher K:M.W. Chase 10450, Eastern Asia). The Chinese S. sinensis markers appear distinct and independent, forming and early diverging clade. The concatenated phylogram also provides molecular evidence that the S. novae-zelandiae 'Motutangi' variant is a distinct group within S. novae-zelandiae s.s. This is not seen in the phylograms of the chloroplast marker (Figure 4.4) nor the nuclear marker (Figure 4.3) separately. When compared with Dueck and Cameron's (2007) North American Spiranthes study, there appears to be better support in data set present in this study for $S$. novae-zelandiae 'Motutangi' to be given species designation than for some of the currently accepted North American Spiranthes. For example, S. cernua and S. parksii were poorly resolved even when using four concatenated markers (Dueck \& Cameron, 
2007). Further investigation may support the classification of S. novae-zelandiae 'Motutangi' as a distinct species. This may affect its conservation status, elevating it to 'Nationally Endangered' or 'Nationally Critical' from its current 'Data Deficient' label (Lange et al., 2012). It is clear that the taxonomy of the Asian-Pacific Spiranthes needs to be revised to resolve apparent paraphyly and to better understand conservation risks. It may also help in the prioritisation of immediate and long-term conservation and management efforts.

This is probably the first study to document in vitro symbiotic germination of any NZ endemic orchid. It is the first to report of symbiotic germination of a Nationally Vulnerable NZ endemic orchid. Germination of S. novae-zelandiae was achieved using a strain of $T$. calospora that was isolated from S. novae-zelandiae. Tulasnella calospora is the asexual stage (anamorph) of Rhizoctonia repens which is a well-known endosymbiont of a range of Australian orchids (Warcup, 1981). Germination progressed beyond the five protocorm stages (see Chapter 1). Similarly to reports of other Spiranthes species, development proceeded quickly, with germination beginning within one month (Rasmussen, 1995) (Stewart \& Zettler, 2002). Some protocorms achieved stage 4 within 46 days. Development seemed to slow down on OMA after developing to stage 5, even with diurnal light cycles. Development resumed again when the protocorms were transferred to sterile wetland soil. This phenomenon also occurs in some North American terrestrial orchids (Stewart \& Zettler, 2002).

The phylogram of the T. calospora ITS marker (Figure 4.6) reveals that the inoculant isolated from $S$. novae-zelandiae genetically very similar to a $T$. calospora strain isolated from S. sinensis (AB369939.1) from Aichi, Honshu, Japan (Shimura et al., 2009). It is interesting to note that the sample of $T$. calospora isolated from $S$. sinensis was collected from less than $500 \mathrm{~km}$ from the sample of $S$. sinensis that forms a sister clade to S. novae-zelandiae in the concatenated phylogram (Figure 4.5). This suggests that phylogenetic affinity of the mycorrhizae shows congruence in the phylogenetic affinity of the orchid host. Similar patterns have been found in Pterosylidinae orchids, which are specific to locally-adapted mycorrhizal clades and suggests co-diversification (Otero, Thrall, Clements, Burdon, \& Miller, 2011). Further research into understanding geographic patterns of mycorrhizal specificity among Asian-Pacific Spiranthes is required to detect codiversification.

Symbiotic germination of $S$. sinensis is non-specific within rhizoctonias in vitro, but more specific to $R$. repens in situ (Masuhara \& Katsuya, 1994). A range of $R$. solani and other rhizoctonias, including members of 26 anastomosis groups, were able to induce 
germination in S. sinensis (Masuhara, Katsuya, \& Yamaguchi, 1993). The same researchers earlier found that $S$. sinensis var. amoena mostly associated the $R$. repens in the field but occasionally $R$. solani (Masuhara \& Katsuya, 1992). It may follow that germination of $S$. novae-zelandiae is also non- specific for symbiotic mycorrhizae in vitro (see Chapter 2). If the pattern found in S. sinensis holds for S. novae-zelandiae, then it follows that $S$. novae-zelandiae may also be more specific for $R$. repens in the field.

Though the decline of S. novae-zelandiae is attributed to the habitat loss (De Lange et al., 2007) the specific mechanisms limiting its current distribution are still unknown. As yet there is no direct evidence for orchids to be limited in their distribution by mycorrhizal specificity (Phillips, Barrett, Dixon, \& Hopper, 2011) (McCormick \& Jacquemyn, 2014). The propagation method used in this study will enable population reinforcement for declining populations and the conservation of regional genetic diversity. A program aiming to determine the best way to manage $S$. novae-zelandiae populations by monitoring the quantity, distribution and flowering pattern of one of two S. novaezelandiae sites in the northern half of the South Island is currently being carried out and this information will be compared with grazing regimes and water table information (Stein, 2012). Recruitment rates of $S$. novae-zelandiae are still unknown and this may need to be investigated to determine if recruitment is low or whether it is occurring at all. If recruitment does not occur, it is likely these remnant populations are "senile populations". Rasmussen (1995), suggested that senile populations may persist for many years by reproducing vegetatively developing from tuberous roots. Discovering the biotic or abiotic causes of low recruitment may facilitate orchid conservation.

As mentioned previously, orchids that are able to associate with a range of fungi in vitro tend to be more specific in their associations in situ (Otero, Ackerman, \& Bayman, 2004). The non-uniform distribution of fungi coupled with competition with possible mycotrophic fungi (see Chapter 2) and pathogens during sensitive stages of protocorm development may present barriers to efficient in situ propagation programs. If adult plants persist in habitats that are no longer suitable for the mycorrhizal fungi, then recruitment desists. Young orchids germinated in situ are also more sensitive to climatic conditions (Batty et al., 2006). In vitro propagation of orchids allow for the advancement of protocorms unhindered by biotic and climatic factors, enabling higher numbers of surviving orchid seedlings. An advantage of germinating S. novae-zelandiae using fungal isolates native to the local population, is the ability to re-introduce the plants to the habitat without the risks associated with introducing non-native fungi (Schwartz et al., 2006). Furthermore, isolating fungi from orchids in declining habitats, and inoculating orchid seed in vitro, enables the ex situ conservation of endemic fungal strains. 
Developing methods to propagate NZ's endangered native wetland orchids to support restoration of populations is important and urgently needed. For extant populations there is still the ability to discover mycorrhizal partners use in vitro methods to propagate them despite their declining habitats. The continued development of the $S$. novae-zelandiae plants germinated from this study will be monitored. Their adaption to natural environmental conditions is critical to understanding the viability of their possible long-term establishment in wild populations. 


\section{References}

Acharya, K. P., Wood, J. J., Berwian, R., \& Sharma, A. (2010). Spiranthes spiralis (Orchidaceae), A New Record for the Nepal Himalaya. Harvard Papers in Botany, 15(1), 71-72. doi:10.3100/025.015.0121

Ames, O. (1908). Orchidaceae: Illustrations and studies of the family Orchidaceae. Fascicle II. Boston: Houghton, Mifflin and Company. Retrieved from https://archive.org/details/orchidaceaeillus02ames

Batty, A. L., Brundrett, M. C., Dixon, K. W., \& Sivasithamparam, K. (2006). In situ symbioticseed germination and propagation of terrestrial orchid seedlings for establishment at field sites. Australian Journal of Botany, 54(4), 375. doi:10.1071/BT04024

Batty, A. L., Brundrett, M., \& Ramsay, M. (2001). Orchid Conservation Techniques Manual (Workshop V.). Perth: Botanic Gardens and Parks Authority.

Beach, D., Piper, M., \& Nurse, P. (1982). Construction of a Schizosaccharomyces pombe gene bank in a yeast bacterial shuttle vector and its use to isolate genes by complementation. MGG Molecular \& General Genetics, 187(2), 326-329. doi:10.1007/BF00331138

Benson, D. a, Karsch-Mizrachi, I., Lipman, D. J., Ostell, J., \& Wheeler, D. L. (2005). GenBank. Nucleic Acids Research, 33(Database issue), D34-8. doi:10.1093/nar/gki063

Brown, R. (1810). Prodromus florae Novae Hollandiae et insulae Van-Diemen, exhibens characteres plantarum quas annis 1802-1805. Londini: typis R. Taylor et socii,. doi:10.5962/bhl.title.3678

Clements, M. A., \& Ellyard, R. K. (1979). The symbiotic germination of Australian terrestrial orchids. American Orchid Society Bulletin, 48, 810-816.

Clements, M. A., Muir, H., \& Cribb, P. J. (1986). A Preliminary Report on the Symbiotic Germination of European Terrestrial Orchids. Kew Bulletin, 41(2), 437. doi:10.2307/4102957

Dawson, M. I. (2000). Index of chromosome numbers of indigenous New Zealand spermatophytes. New Zealand Journal of Botany, 38(1), 47-150.

doi:10.1080/0028825X.2000.9512673

Dawson, M. I., Molloy, B. P. J., \& Beuzenberg, E. J. (2007). Contributions to a chromosome atlas of the New Zealand flora-39. Orchidaceae. New Zealand Journal of Botany, 45(4), 611-684. doi:10.1080/00288250709509743

De Lange, P. J., Norton, D. A., Courtney, S. P., Heenan, P. B., Barkla, J. W., Cameron, E. K., ... Townsend, A. J. (2009). Threatened and uncommon plants of New Zealand (2008 revision). New Zealand Journal of Botany, 47(1), 61-96. doi:10.1080/00288250909509794

De Lange, P. J., Rolfe, J., St George, I., \& Sawyer, J. (2007). Wild orchids of the lower North Island. Wellington: New Zealand Department of Conservation. 
Devulder, G., Pérouse de Montclos, M., \& Flandrois, J. P. (2005). A multigene approach to phylogenetic analysis using the genus Mycobacterium as a model. International Journal of Systematic and Evolutionary Microbiology, 55(Pt 1), 293-302. doi:10.1099/ijs.0.63222-0

Dixon, K. W. (1994). Towards integrated conservation of Australian endangered plants - the Western Australian model. Biodiversity and Conservation, 3(2), 148-159. doi:10.1007/BF02291885

Doyle, J. J., \& Doyle, J. L. (1987). A rapid DNA isolation procedure for small quantities of fresh leaf tissue. Phytochemical Bulletin, 19, 11-15.

Dueck, L. A., \& Cameron, K. M. (2007). Sequencing re-defines Spiranthes relationships, with implications for rare and endangered taxa. Lankesteriana International Journalon Orchidology, 7(1-2), 190-195.

Edgar, R. C. (2004). MUSCLE: multiple sequence alignment with high accuracy and high throughput. Nucleic Acids Research, 32(5), 1792-7. doi:10.1093/nar/gkh340

Edwards, S., \& Ridgway, J. (1924). The Botanical register: consisting of coloured figures of exotic plants, cultivated in British gardens; with their history and mode of treatment. VolumeX ( $p$. 265). London: Printed for James Ridgway.

Ercole, E., Rodda, M., Molinatti, M., Voyron, S., Perotto, S., \& Girlanda, M. (2013). Cryopreservation of orchid mycorrhizal fungi: a tool for the conservation of endangered species. Journal of Microbiological Methods, 93(2), 134-7. doi:10.1016/j.mimet.2013.03.003

Farell, E. M., \& Alexandre, G. (2012). Bovine serum albumin further enhances the effects of organic solvents on increased yield of polymerase chain reaction of GC-rich templates. $B M C$ Research Notes, 5(1), 257. doi:10.1186/1756-0500-5-257

Fitch, W. H., \& Hooker, J. D. (1853). The botany of the Antarctic voyage of H.M. discovery ships Erebus and Terror in the Years 1839-184: under the command of Captain Sir James Clark Ross /by Joseph Dalton Hooker. London: Reeve Brothers. doi:10.5962/bhl.title.16029

Forester, L., \& Townsend, A. (2004). Threatened plants of Northland Conservancy Threatened plants of Northland Conservancy (p. 80). Wel: Department of Conservation, Te Papa Atawhai. Retrieved from http://www.doc.govt.nz/Documents/science-andtechnical/ThrplantsNorthland01.pdf

García, V. G., Onco, M. A. P., \& Susan, V. R. (2006). Review. Biology and Systematics of the form genus Rhizoctonia. Spanish Journal of Agricultural Research, 4(1), 55-79. Retrieved from http://revistas.inia.es/index.php/sjar/article/download/178/175

Hasegawa, M., Kishino, H., \& Yano, T. (1985). Dating of the human-ape splitting by a molecular clock of mitochondrial DNA. Journal of Molecular Evolution, 22(2), 160-74.

Hunt, J. (2007). Wetlands of New Zealand: A Bitter-Sweet Story (p. 256). Auckland: Random House. 
Iwata, T., Nagasaki, O., Ishii, H. S., \& Ushimaru, A. (2012). Inflorescence architecture affects pollinator behaviour and mating success in Spiranthes sinensis (Orchidaceae). The New Phytologist, 193(1), 196-203. doi:10.1111/j.1469-8137.2011.03892.x

Jacquemyn, H., Brys, R., Hermy, M., \& Willems, J. (2007). Long-term dynamics and population viability in one of the last populations of the endangered Spiranthes spiralis (Orchidaceae) in the Netherlands. Biological Conservation, 134(1), 14-21. doi:10.1016/j.biocon.2006.07.016

Janes, J. K. (2009). Techniques for Tasmanian native orchid germination. Nature Conservation Report 09/1. Hobart: Department of Primary Industries and Water.

Kimura, M. (1980). A simple method for estimating evolutionary rates of base substitutions through comparative studies of nucleotide sequences. Journal of Molecular Evolution, 16(2), 111-120. doi:10.1007/BF01731581

Lange, P. J. De, Rolfe, J. R., Champion, P. D., Courtney, S. P., Heenan, P. B., Barkla, J. W., ... Hitchmough, R. A. (2012). Conservation status of New Zealand indigenous vascular plants, 2012 (p. 70). Wellington: Department of Conservation, Te Papa Atawhai. Retrieved from http://www.nzpcn.org.nz/publications/NZTCS-Vascular Plants - 2013.pdf

Machon, N., Bardin, P., Mazer, S. J., Moret, J., Godelle, B., \& Austerlitz, F. (2003). Relationship between geneticstructure and seed and pollen dispersal in the endangered orchid Spiranthes spiralis. New Phytologist, 157(3), 677-687. doi:10.1046/j.14698137.2003.00694.x

Masuhara, G., \& Katsuya, K. (1992). Mycorrhizal differences between genuine roots and tuberous roots of adult plants of Spiranthes sinensis var. amoena (Orchidaceae). The Botanical Magazine Tokyo, 105(3), 453-460. doi:10.1007/BF02497660

Masuhara, G., \& Katsuya, K. (1994). In situ and in vitro specificity between Rhizoctonia spp. and Spiranthes sinensis (Persoon) Ames, var. amoena (M. Bieberstein) Hara (Orchidaceae). New Phytologist, 127(4), 711-718. doi:10.1111/j.1469-8137.1994.tb02974.x

Masuhara, G., Katsuya, K., \& Yamaguchi, K. (1993). Potential for symbiosis of Rhizoctonia solani and binucleate Rhizoctonia with seeds of Spiranthes sinensis var. amoena in vitro. Mycological Research, 97(6), 746-752. doi:10.1016/S0953-7562(09)80156-1

Matthews, K. (2009). Far North Spiranthes. New Zealand Native Orchid Group Journal, 112, 16. Retrieved from http://www.nativeorchids.co.nz/Journals/112/page16.html

McCormick, M. K., \& Jacquemyn, H. (2014). What constrains the distribution of orchid populations? New Phytologist, 202(2), 392-400. doi:10.1111/nph.12639

New Zealand Plant Conservation Network. (2014). Spiranthes novae-zelandiae. www.nzpcn.org.nz. Retrieved March 17, 2014, from http://www.nzpcn.org.nz/flora_details.aspx?ID=1305

Nilsson, R. H., Kristiansson, E., Ryberg, M., Hallenberg, N., \& Larsson, K.-H. (2008). Intraspecific ITS Variability in the Kingdom Fungi as Expressed in the International Sequence Databases and Its Implications for Molecular Species Identification. Evolutionary Bioinformatics Online, 4(3), 193-201. 
Otero, J. T., Ackerman, J. D., \& Bayman, P. (2004). Differences in mycorrhizal preferences between two tropical orchids. MolecularEcology, 13(8), 2393-404. doi:10.1111/j.1365294X.2004.02223.x

Otero, J. T., Thrall, P. H., Clements, M., Burdon, J. J., \& Miller, J. T. (2011). Codiversification of orchids (Pterostylidinae) and their associated mycorrhizal fungi. Australian Journal of Botany, 59(5), 480. doi:10.1071/BT11053

Persoon, C. H. (1805). Synopsis plantarum, seu Enchiridium botanicum, complectens enumerationem systematicamspecierum hucusque cognitarum/curante C.H. Persoon. Parisiis Lutetiorum: C.F. Cramerum. doi:10.5962/bhl.title.638

Phillips, R. D., Barrett, M. D., Dixon, K. W., \& Hopper, S. D. (2011). Do mycorrhizal symbioses cause rarity in orchids? Journal of Ecology, 99(3), 858-869. doi:10.1111/j.1365-2745.2011.01797.x

Rasmussen, H. N. (1995). Terrestrial orchids from seed to mycotrophic plant. Melbourne: Cambridge University Press.

Salazar, G. a., \& Jost, L. (2012). Quechua, a New Monotypic Genus of Andean Spiranthinae (Orchidaceae). Systematic Botany, 37(1), 78-86. doi:10.1600/036364412X616657

Scanlen, E., \& St George, I. (2011). Colour field guide to the native Orchids of New Zealand (3rd Editio., p. 83). Wellington: New Zealand Native Orchid Group.

Schwartz, M. W., Hoeksema, J. D., Gehring, C. a, Johnson, N. C., Klironomos, J. N., Abbott, L. K., \& Pringle, A. (2006). The promise and the potential consequences of the global transport of mycorrhizal fungal inoculum. Ecology Letters, 9(5), 501-15. doi:10.1111/j.14610248.2006.00910.x

Shan, X. C., Liew, E. C. Y., Weatherhead, M. a, \& Hodgkiss, I. J. (2002). Characterization and taxonomic placement of Rhizoctonia-like endophytes from orchid roots. Mycologia, 94(2), 230-9. Retrieved from http://www.ncbi.nlm.nih.gov/pubmed/21156492

Sharpe, R. G., Harbach, R. E., \& Butlin, R. K. (2000). Molecularvariation and phylogeny of members of the Minimus Group of Anopheles subgenus Cellia (Diptera: Culicidae). Systematic Entomology, 25(2), 263-272. doi:10.1046/j.1365-3113.2000.00118.x

Sheviak, C. J., \& Brown, P. M. (2002). Orchidaceae. In Flora of North America Editorial Committee (Ed.), Flora of North America: north of Mexico. Volume 26. Magnoliophyta: Liliidae: Liliales and Orchidales. (p. 752). New York: Oxford University Press.

Shimura, H., Sadamoto, M., Matsuura, M., Kawahara, T., Naito, S., \& Koda, Y. (2009).

Characterization of mycorrhizal fungi isolated from the threatened Cypripedium macranthos in a northern island of Japan: two phylogenetically distinct fungi associated with the orchid. Mycorrhiza, 19(8), 525-34. doi:10.1007/s00572-009-0251-4

Stein, T. (2012). Marsh orchid study. Open Space, (82), 14.

Stewart, S. L., \& Zettler, L. W. (2002). Symbioticgermination of three semi-aquatic rein orchids (Habenaria repens, H. quinquiseta, H. macroceratitis) from Florida. Aquatic Botany, 72(1), 25-35. doi:10.1016/S0304-3770(01)00214-5 
Swarts, N. D., \& Dixon, K. W. (2009). Terrestrial orchid conservation in the age of extinction. Annals of Botany, 104(3), 543-56. doi:10.1093/aob/mcp025

Taberlet, P., Gielly, L., Pautou, G., \& Bouvet, J. (1991). Universal primers for amplification of three non-coding regions of chloroplast DNA. Plant Molecular Biology, 17(5), 1105-1109. doi:10.1007/BF00037152

Tamura, K. (1992). Estimation of the Number of Nucleotide Substitutions When There Are Strong Transition-Transversion and G+C-Content Biases. Molecular Biology and Evolution, 9(4), 678687.

Tamura, K., Stecher, G., Peterson, D., Filipski, A., \& Kumar, S. (2013). MEGA6: Molecular Evolutionary Genetics Analysis version 6.0. Molecular Biology and Evolution, 30(12), 2725-9. doi:10.1093/molbev/mst197

Tanaka, R., Kondo, K., \& Sato, K. (1997). Micropropagation of Spiranthes sinensis (Pers.) Ames (Orchidaceae). In Y. P. Bajaj (Ed.), High-Tech and Micropropagation VI (p. 397). Berlin Heidelberg: Springer. doi:10.1007/978-3-662-03354-8_21

Taylor, D. L., T. D. Bruns, J. R. Leake, and D. J. Read. (2002). Mycorrhizal specificity and function in myco-heterotrophic plants. In M. G. A. van der Heijden and I. R. Sanders (Eds.), The Ecology of Mycorrhizas (pp. 375-414). Springer-Verlag, Berlin.

Taylor, D. L., \& McCormick, M. K. (2008). Internal transcribed spacer primers and sequences for improved characterization of basidiomycetous orchid mycorrhizas. The New Phytologist, 177(4), 1020-33. doi:10.1111/j.1469-8137.2007.02320.x

Townsend, A. J., Lange, P. J. De, Duffy, C. A. J., Miskelly, C. M., Molloy, J., \& Norton, D. A. (2008). New Zealand Threat Classification System manual (p. 35). Wellington: Department of Conservation, Te Papa Atawhai.

Tsukaya, H. (2005). Molecular variation of Spiranthes sinensis (Orchidaceae) in Japan, with special reference to systematic treatment of seasonally differentiated groups and a dwarf form, $f$. gracilis, from Yakushima Island. Journal of Plant Research, 118(1), 13-8. doi:10.1007/s10265004-0186-y

Warcup, J. H. (1981). The mycorrhizal relationships of Australian orchids. New Phytologist, 87(2), 371-381. doi:10.1111/j.1469-8137.1981.tb03208.x

Ward, M. (2012). New colony of threatened orchid spotted. Trilepidea, (101), 8-9.

Watkins, R. L. S. (2012). The biogeography, ecology and endophyte mycorrhiza of the New Zealand Corybas alliance (Orchidaceae) : specifically, Nematoceras iridescens (Irwin et Molloy) Molloy, D.L.Jones \& M.A.Clem. (species). Massey University.

White, T. J., Bruns, T., Lee, S., \& Taylor, J. (1990). Amplification and Direct Sequencing of Fungal Ribosomal RNA Genes for Phylogenetics. In M. A. Innis, D. H. Gelfand, J. J. Sninsky, \& T. J. White (Eds.), PCR Protocols A guide to methods and applications (pp. 315-322). San Diego: Academic Press.

Zettler, L. W. (1996). Symbiotic Seed Germination of Terrestrial Orchids in North America During the Last Decade - A Progress Report (p. 11). Jacksonville. 


\section{Chapter 5: General discussion and recommendations}

This thesis represents an important step forward for the progress of orchid research in New Zealand. It is the first report of endophyte effects on seed germination (Chapter 2), the first formal assessment of seed viability (Chapter 2), and the first documented symbiotic germination of an endangered NZ orchid (Chapter 4). Moreover, it establishes a starting point for future studies of orchid diversity, surveys of mycorrhizae at sites, and most importantly, it has documented a set of methodological steps for the propagation of NZ orchids for conservation purposes. This chapter provides an overview of the main findings of the thesis research and a general discussion about the benefits and outcomes of the work. It is concluded with several recommendations for future research.

\section{Endophyte diversity}

Fungi from three phyla were represented in endophyte diversity: Ascomycota, Basidiomycota and Zygomycota. The levels of diversity of fungal endophytes of NZ orchids were found to be variable, though there appeared to be no obvious pattern of diversity that could be linked to orchid species, distribution, abundance, range or habitat. It was also found that diversity was under-sampled. The response of fungi to sampling and culturing techniques, and phyla-specific growth factors may account for the unexpectedly low number of Basidiomycota recovered. The methods of determining operational taxonomic units (OTUs) were more sensitive than the $97 \%$ threshold recommended by a number of studies, and the findings suggested that orchid seed responded differentially to OTUs that were more than $97 \%$ similar to each other.

\section{Germination}

The seed of nearly all of the species included in this study were able to progress to stage 2 of germination without an inoculant, with the exception of Spiranthes novaezelandiae. Four isolates were found to have a significant positive effect on germination. These were able to facilitate development into stages which are considered to be symbiotic (stage 3 or greater). The inoculants 'Epacrid' (A24) and Beauveria (A35) showed a significant effect on germination rates for S. novae-zelandiae, 'Epacrid' (A24) and Tulasnella (B03) showed a significant positive effect on germination rates for Microtis unifolia, and finally, Mortierella (Z14) showed a significant positive effect on germination rates for Thelymitra longifolia from one site. These particular inoculants should be 
investigated further to confirm the effects reported in this research, because among these, only Tulasnella (B03) is known to form symbiotic associations with any of these orchids.

The effect of each inoculant was observed on seed germination, but these fungi may behave differently in adult plants than in seeds. Some inoculants that are not known to be pathogenic to plants appear to have negative effects on seed development.

Negative effects on orchid seed germination were consistently seen by three isolates, each from different phyla: Hypocrea (A01), Rhizoctonia (B02) and Mortierella (Z07). Future studies should investigate how endophytes affect orchid seeds that have already formed symbiotic associations. Though many of the inoculants had no effect on seed germination, they may influence fungi that do. For instance, a mycotrophic fungus may parasitize an endosymbiont, disrupting the symbiosis and halting seed development.

The effects of solitary fungi on orchid seed development should be considered as the first step for investigating the net effects of the endophyte community. Experiments demonstrating the effects of members of fungal communities on each other are scarce, perhaps because the complexity of such experiments increases exponentially with each additional endosymbiont. A study testing the effects of fungicides on orchid endophytes found that in some cases mortality and recruitment were affected differently due to sensitivity variations between co-occurring endophytes (Bayman, González, Fumero, \& Tremblay, 2002). Studies that focus on fungal communities will not only identify conditions that are optimal for the establishment of orchids, but also fungal community factors that present risks to germinating orchid seed.

The isolation and culture methods used in this study have been developed and optimised for the isolation of specific fungal groups that are culturable, therefore excluding many fungal taxa for which culture conditions are unknown (Stark, Babik, \& Durka, 2009). To uncover greater diversity, massively parallel DNA sequencing techniques such as the Ion Torrent or Illumina platforms should be used to determine the DNA sequence composition of sample. For example, a 'deep sequencing' approach might enable rare or low frequency fungi to be detected and identified. One such study recovered more than 1000 OTUs (as determined by $97 \%$ similarity threshold) from six different forest soils and found that Basidiomycota accounted for $43.7 \%$ of OTUs (Buée et al., 2009). With this approach diversity can be compared within an orchid and in the soils around it. This approach can also begin to form a more complete picture of fungal assemblages and their diversity (Orgiazzi et al., 2013). 
Though a phylogenetic approach may elucidate the diversity present in endophyte communities it does little to describe the interactions therein. To achieve this goal a 'functional diversity' approach will be needed that considers genotypic and phenotypic diversity, with spatial and temporal dimensions to assess the function of the community (McGuire et al., 2010). Fungal succession research may also provide explanations about the variation in endophyte diversity (Milligan \& Williams, 1988) and reveal patterns of species recruitment and attrition.

\section{Seed baiting}

The in situ experiment demonstrated how orchid seeds probably form part of the transient seed bank in Otari-Wilton's Bush by not persisting beyond one growing season. However, seed packets might have been a poor simulation of natural germination conditions and abiotic factors in the experiment design negatively affected their mortality. Overall, low germination rates were found at all sites in Otari-Wilton's Bush, and germination was more likely at undisturbed sites. Often invasive and fast-growing taxa are the first to colonise disturbed sites. One possible explanation is that these fast-growing fungi competitively exclude slower-growing symbiotic fungi on newly-available substrate. Conversely, undisturbed sites may have more stable fungal communities that could buffer the effect pathogens or exclude them altogether.

Germination of $M$. unifolia was facilitated by Tulasnella calospora at one of these undisturbed sites. The in situ experiment demonstrated that fungi that enabled germination of either M. unifolia or T. longifolia were present at most sites. No pattern of germination could be confirmed in distances less than one metre, with the number of replicates used in this study. While overall site conditions may contribute to germination, perhaps factors on a smaller scale also influence germination.

The in situ seed baiting method may be useful for understanding recruitment range limits of orchids but the degree of disturbance to the site was relatively high. Future studies that involve continually monitoring if additional environmental data such as temperature and moisture may increase habitat disturbances and could put additional pressure on at-risk populations, negatively affecting recruitment similarly to what was observed at the disturbed sites in this study.

The methods used in this study may be used for locating sites for translocation of at-risk orchid populations with minor alterations, such as fewer seed distributed evenly throughout the packet with additional organic matter to serve as substrate for saprophytic fungi (Swarts, Sinclair, Francis, \& Dixon, 2010). The seed baiting technique may also function as a way to source compatible mycorrhizal fungi in a target relocation site before 
using it to germinate the subject orchid species. Using these types of supporting methods, survival and recruitment of the orchids at the new location might be promoted.

\section{Ex situ orchid propagation}

The ex situ propagation of orchids reduces the threat of competition and pathogens, and risks associated with environmental or climatic stochasticity (Kasso \& Balakrishnan, 2013). The ex situ germination of S. novae-zelandiae was facilitated by a Tulasnella calospora (B03) strain that was isolated from the wild population at Tararua Forest Park. Though the inoculant was successful in germinating the seed, it was demonstrated in Chapter 2 (Table 2.2) that the proportion germinating (achieving stage 3 or greater) was below the $5 \%$ significance of the TukeyHSD. Despite this, plants progressed beyond protocorms stages into the partially myco-heterotrophic plants. The low proportion of germination may be due to the inoculant being the result of multiple subculturing events, which could reduce its effectiveness in establishing the symbiosis (Hollick, 2004).

The example of S. novae-zelandiae demonstrates a propagation methodology that could be applied to other NZ orchid species. Sourcing symbiotic fungi from the same population as the seed has been collected, enables the conservation of both the host and its symbionts. This may be particularly important for species which are endangered primarily by decline in habitat suitability or habitat loss. It is of some urgency that the methodologies for propagating a number of critically endangered orchids are properly developed and applied.

\section{Conservation considerations}

The Asian-Pacific Spiranthes are in need of taxonomic review and DNA markers showed that there is genetic support for Spiranthes novae-zelandiae 'Motutangi' to be assigned a level of taxonomic distinction, and the official conservation status that such designation warrants. Morphological studies should consider this evidence when deciding whether it should be considered as a separate species or a variety of S. novae-zelandiae. There is more molecular support for the species-level designation of this entity in the ITS marker alone, than for some of the North American Spiranthes species (Figure 4.2).

Nearly $40 \%$ of NZ orchids are of conservation concern and, to date, very little has been done to secure their survival. Studies like the one reported here - and suggested above would increase the likelihood of survival of these important members of New Zealand's rich biodiversity heritage. 


\section{References}

Bayman, P., González, E. J., Fumero, J. J., \& Tremblay, R. L. (2002). Are fungi necessary ? How fungicides affect growth and survival of the orchid Lepanthes rupestris in the field, 10021008.

Buée, M., Reich, M., Murat, C., Morin, E., Nilsson, R. H., Uroz, S., \& Martin, F. (2009). 454 Pyrosequencing analyses of forest soils reveal an unexpectedly high fungal diversity. The New Phytologist, 184(2), 449-56. doi:10.1111/j.1469-8137.2009.03003.x

Hollick, P. S. (2004). Mycorrhizal specificity in endemic Western Australian terrestrialorchids (tribe Diurideae): Implications for conservation. Retrieved from http://researchrepository.murdoch.edu.au/103/

IUCN Species Survival Commission. (2012). IUCN Red List Categories and Criteria (2nd Ed., p. 32). Gland, Switzerland: International Union for Conservation of Nature.

Kasso, M., \& Balakrishnan, M. (2013). Ex Situ Conservation of Biodiversity with Particular Emphasis to Ethiopia. ISRN Biodiversity, 2013, 1-11. doi:10.1155/2013/985037

McGuire, K. L., Bent, E., Borneman, J., Majumder, A., Allison, S. D., \& Treseder, K. K. (2010). Functional diversity in resource use by fungi. Ecology, 91(8), 2324-2332. doi:10.1890/090654.1

Milligan, M. J., \& Williams, P. G. (1988). The Mycorrhizal Relationship of Multinucleate Rhizoctonias from Non-Orchids with Microtis (Orchidaceae). New Phytologist, 108(2), 205209.

Orgiazzi, A., Bianciotto, V., Bonfante, P., Daghino, S., Ghignone, S., Lazzari, A., ... Girlanda, M. (2013). 454 Pyrosequencing Analysis of Fungal Assemblages from Geographically Distant, Disparate Soils Reveals Spatial Patterning and a Core Mycobiome. Diversity, 5(1), 73-98. doi:10.3390/d5010073

Stark, C., Babik, W., \& Durka, W. (2009). Fungi from the roots of the common terrestrial orchid Gymnadenia conopsea. Mycological Research, 113(Pt 9), 952-9. doi:10.1016/j.mycres.2009.05.002

Swarts, N. D., Sinclair, E. a, Francis, A., \& Dixon, K. W. (2010). Ecological specialization in mycorrhizal symbiosis leads to rarity in an endangered orchid. Molecular Ecology, 19(15), 3226-42. doi:10.1111/j.1365-294X.2010.04736.x 